\title{
EFFECT OF NITROUS OXIDE EXPOSURE DURING SURGERY ON THE HOMOCYSTEINE CONCENTRATIONS OF CHILDREN
}

by

Dubraiicka Pichardo

A thesis submitted in conformity with the requirements for the degree of M.Sc.

Graduate Department of Nutritional Sciences University of Toronto

(C) Copyright by Dubraiicka Pichardo 2010 


\title{
EFFECT OF NITROUS OXIDE EXPOSURE DURING SURGERY ON THE HOMOCYSTEINE CONCENTRATIONS OF CHILDREN
}

\author{
Master of Science, 2010 \\ Dubraiicka Pichardo \\ Graduate Department of Nutritional Sciences \\ University of Toronto
}

\begin{abstract}
In this study we determined the effect of nitrous oxide $\left(\mathrm{N}_{2} \mathrm{O}\right)$ on homocysteine concentrations in children and whether blood levels of folate, vitamin B12, B6, methylmalonic acid (MMA) and methylenetetrahydrofolate reductase C6777T genotype affected this relationship. Homocysteine was measured before and after $\mathrm{N}_{2} \mathrm{O}$. Vitamin levels, MMA and genotype were determined preoperatively. Median age of the 32 participants was 11 months (3126 months). All children had folate and B6 levels above deficiency values $(7.4,20 \mathrm{nmol} / \mathrm{L}$ respectively). Five children had MMA levels indicating deficiency ( $\geq 0.21 \mu \mathrm{mol} / \mathrm{L})$. Postexposure homocysteine concentrations increased by 25\% $(P=<0.001)$. Duration of exposure and initial homocysteine concentrations were predictors of the increase $\left(r^{2}=0.821, P=<0.001\right)$. Vitamin B12 and initial homocysteine concentrations were inversely associated $\left(\mathrm{r}^{2}=0.277, P=\right.$ 0.004). Folate, vitamin B6 and genotype showed no effect. In conclusion, $\mathrm{N}_{2} \mathrm{O}$ exposure leads to increased homocysteine in children. Studies investigating benefit of pre-surgical vitamin B12 supplementation may prove worthwhile.
\end{abstract}




\section{ACKNOWLEDGMENTS}

Thank you is not enough I am deeply grateful and feel blessed for these two years and the many learnings, experiences and friends acquired. The work before your eyes is the merit of Dr. Debbie L. O’Connor whose intelligence, strong scientific understanding, expertise and upmost kindness guided me through my Masters’ journey. Thank you Debbie for believing in me, for pushing me beyond my mind barriers and for teaching me the importance of laughing at myself.

I would like to thank all the children and families for participating and believing in research. To Dr. Christopher Forrest, the surgeons and nurses of the Plastic Surgery Division at the Hospital for Sick Children thank you for facilitating recruitment and your support of this study. To my thesis committee members Dr. Igor Luginbuehl thank you for your enthusiasm, for opening and holding open the door to the OR. Your many efforts made this work possible. Dr. Paul Wales, I greatly appreciate your advice it has proven worthwhile to make all those analyses. But mostly thank you for the time you dedicated to this work regardless of your busy schedule. Dr. Ahmed El-Sohemy it has been a pleasure to work with you. This thesis benefited greatly from your detail oriented approach and has improved the quality of my work.

To Aneta Plaga and Puneet Bath thank you fondly for being there and making sure I stayed alive. To Aneta Plaga, Susanne Aufreiter, Alanna Lakoff, Brenda Hartman and Yaseer Shakur thank you for your friendship, for your merriness and for rescuing me from my clumsy self. I feel we will always be connected as a big O’Connor-extended family.

To my dearest siblings thank you for being a part of who I am and for listening to my woes and little triumphs in this journey. Gracias mamá por tu amor, apoyo y por enseñarme a ser valiente, todo lo que soy te lo debo a tí. Finally, thank you Orestes for being the reason I try to be a better person. Your love and support in everything I am and do make my life a happy one.

To all of you who generously contributed to the achievement of this work in numerous different ways, I promise to retain and apply all these learnings in my life. 


\section{TABLE OF CONTENTS}

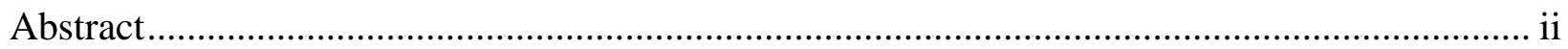

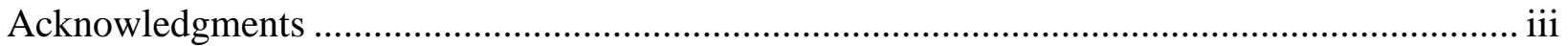

Table of contents .............................................................................................................. iv

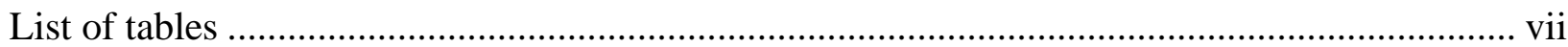

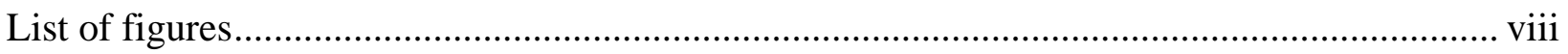

List of abreviations .................................................................................................... ix

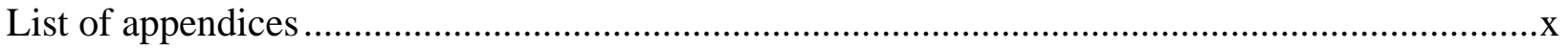

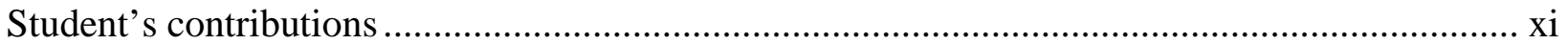

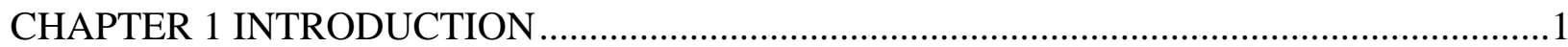

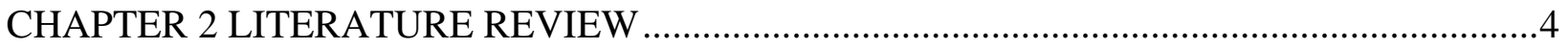

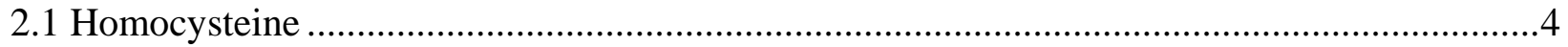

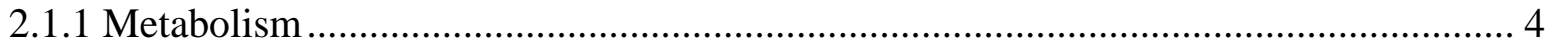

2.1.1.1 Metabolic pathways ............................................................................................ 4

2.1.1.2 Enzymatic regulation .................................................................................... 6

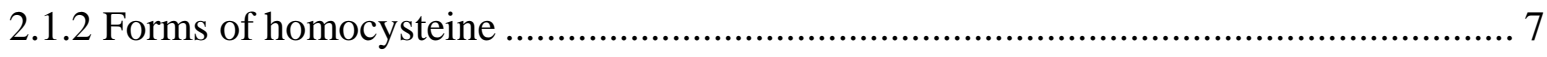

2.1.3 Determinants of homocysteine concentrations.............................................................. 9

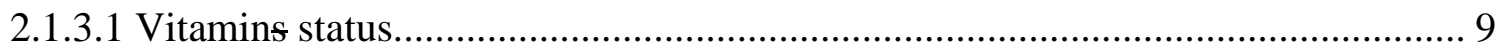

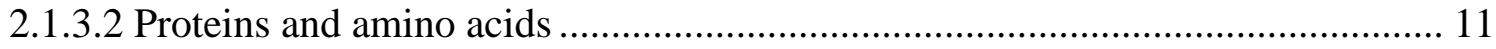

2.1.3.3 Genetic determinants ......................................................................................... 13

2.1.3.4 Hepatic and renal function............................................................................ 14

2.1.3.5 Age and sex.............................................................................................. 16

2.1.3.6 Effect of recent food intake on circulating tHcy concentrations ......................... 16 


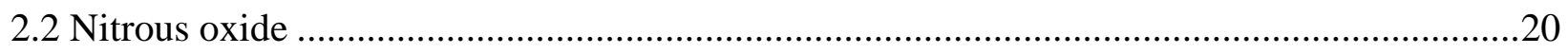

2.2.1 Nitrous oxide anesthesia.................................................................................. 20

2.2.2 Metabolic effects of nitrous oxide ..................................................................... 21

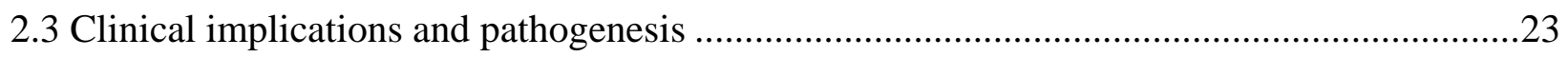

2.3.1 Clinical implications of acute hyperhomocysteinemia.............................................. 23

2.3.2 Chronic hyperhomocysteinemia and risk of ischemic heart disease and stroke..... 26

2.3.3 Pathogenesis of vascular disease due to hyperhomocysteinemia ............................. 28

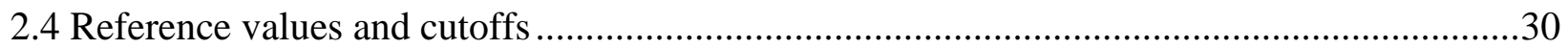

2.4.1 Homocysteine concentrations ................................................................................ 30

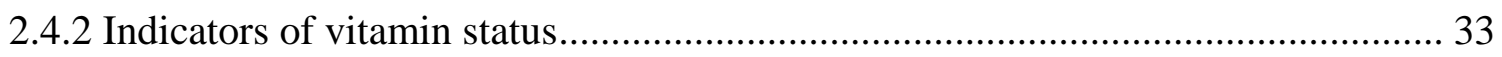

2.4.3 Reference values: folate, vitamin B12 and vitamin B6 .......................................... 34

2.4.4 Cutoffs: folate, vitamin B12 and vitamin B6..................................................... 36

CHAPTER 3 THE EFFECT OF NITROUS OXIDE EXPOSURE DURING SURGERY ON THE HOMOCYSTEINE CONCENTRATIONS OF CHILDREN .................................................38

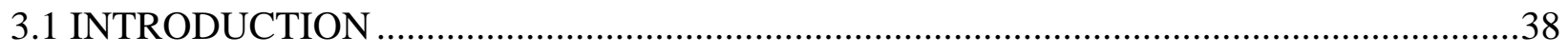

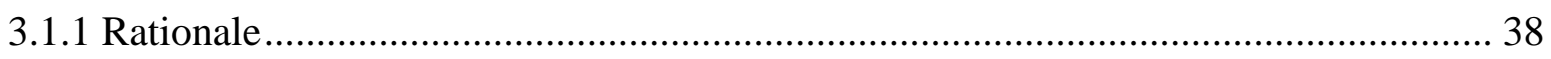

3.1.2 Research questions .............................................................................................. 39

3.1.3 Objectives .............................................................................................................. 40

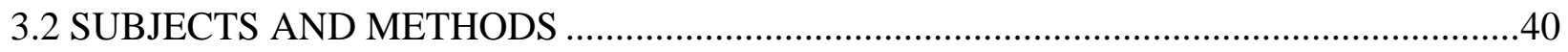

3.2.1 Subjects......................................................................................................... 40

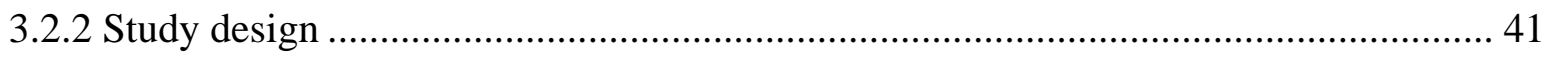

3.2.3. Collection and analyses ............................................................................................ 42

3.2.3.1 Sample collection and laboratory analyses.......................................................... 42

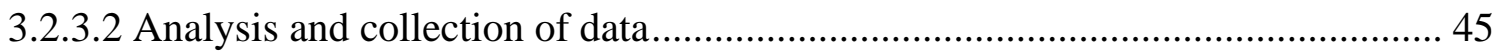




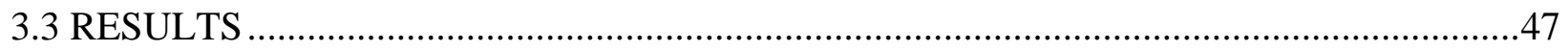

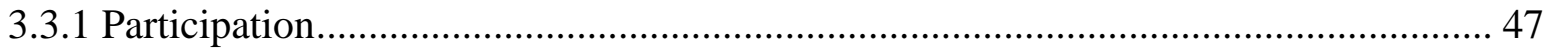

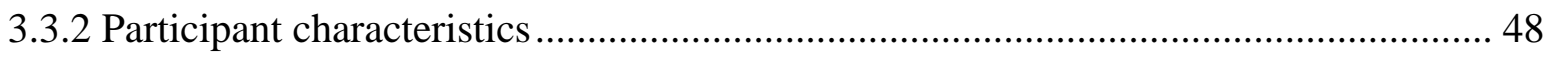

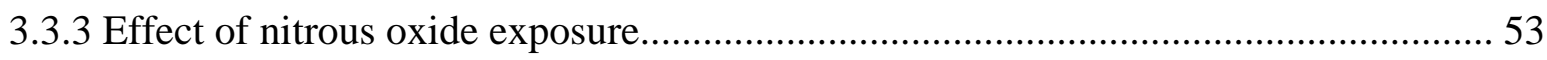

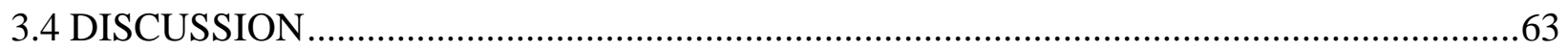

CHAPTER 4 CONCLUSIONS AND FUTURE DIRECTIONS ................................................

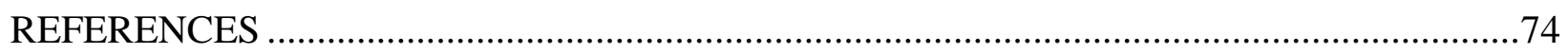

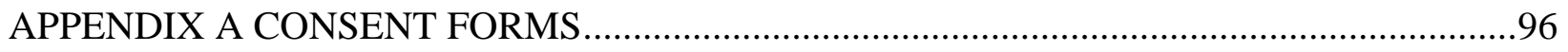

APPENDIX B PREDICTED VALUES .......................................................................107 


\section{LIST OF TABLES}

Table 2.0 Effect of recent food intake on circulating homocysteine concentrations.....

Table 2.1 Homocysteine concentrations of children in health and disease.....

Table 2.2 Reference values: RBC and total folate, vitamin B12 and vitamin B6 for children $>1$ year age

Table 2.3 Reference values for serum folate, RBC folate, serum vitamin B12, plasma methylmalonic acid and vitamin B6 levels in children 0 to 6 months old...

Table 3.3.1 Subjects characteristics and intraoperative data.

Table 3.3.2 Pre-exposure biomarkers values.

Table 3.3.3 Energy and nutrient composition of food consumed prior to collection of postoperative sample

Table 3.3.4 Results from univariate linear regression analyses comparing (A) preoperative tHcy concentration and (B) the change in post-exposure tHcy concentrations versus various predictors

Table 3.3.5 Multivariate model data: change in postoperative tHcy concentrations adjusted for duration of $\mathrm{N}_{2} \mathrm{O}$ exposure and preoperative tHcy concentration

Table 3.3.6 Univariate model data: association between preoperative tHcy concentrations and vitamin B12 level. 


\section{LIST OF FIGURES}

Figure 2.1 Homocysteine metabolism....................................... 5

Figure 2.2 Forms of homocysteine in human plasma............................ 8

Figure 3.3 .1 Participation flow chart........................................ 48

Figure 3.3.2 Comparison between pre and post-exposure total homocysteine (tHcy) concentrations...................................................... 53

Figure 3.3.3 Correlation between pre-to-post difference in total homocysteine concentrations and duration of exposure to nitrous oxide anesthesia.

Figure 3.3.4 Correlation between pre-to-post difference in total homocysteine concentrations and pre-exposure tHcy concentrations................... 55

Figure 3.3.5 Correlation between pre-to-post difference in total homocysteine concentrations and preoperative vitamin B12 levels. 


\section{LIST OF ABREVIATIONS}

$\begin{array}{ll}\mathrm{N}_{2} \mathrm{O} & \text { Nitrous oxide } \\ \text { MMA } & \text { Methylmalonic acid } \\ \text { Hcy } & \text { Homocysteine } \\ \text { tHcy } & \text { Total homocysteine concentration } \\ \text { SAM } & \text { S-adenosylmethionine } \\ \text { SAH } & \text { S-adenosylhomocysteine } \\ \text { CBS } & \text { Cystathionine } \beta \text {-synthase } \\ \text { MTHFR } & \text { Methylenetetrahydrofolate reductase } \\ \text { ENIGMA } & \text { Effectiveness of Nitrous oxide in the Gas Mixture for Anesthesia Trial } \\ & \\ \text { NHANES } & \text { National Health and Nutrition Examination Survey } \\ & \end{array}$




\section{LIST OF APPENDICES}

Appendix A Research Consents.......................................... 97

Appendix B $\quad$ Predicted values............................................... 108 


\section{STUDENT'S CONTRIBUTIONS}

- Elaborated annotated bibliography for principal investigators and explored feasibility of research study

- Designed research study, prepared a detailed research proposal and data collection forms

- Submitted study to Research Ethics Committee at the Hospital for Sick Children

- Established contact and material transfer agreements for the analyses of blood samples for methylmalonic acid, vitamin B12 and vitamin B6

- Obtained approval for recruitment in designated clinical areas at the Hospital for Sick Children

- $\quad$ Recruited study participants

- Collected blood samples and relevant data

- Processed blood samples and performed laboratory determinations of plasma total homocysteine and folate concentrations. In addition completed DNA extractions and MTHFR C677T genotyping

- Performed most statistical analyses

- Wrote thesis

- Wrote and submitted an abstract for presentation at Experimental Biology 2010 


\section{CHAPTER 1 INTRODUCTION}

\subsection{Introduction}

At the onset of this study, no one had evaluated the effect of exposure to nitrous oxide during surgery on the homocysteine concentrations of children. A growing body of evidence indicates that homocysteine acutely rises as a side effect of exposure to nitrous oxide during surgery in adults (1-9). Homocysteine is an intermediary metabolite in metabolism of the sulfurcontaining amino acids. It is produced by de-methylation of methionine and is a substrate for synthesis of cystathionine and then cysteine (10). Under normal conditions, homocysteine is remethylated back to methionine by the enzyme methionine synthase which requires the reduced form of vitamin B12 as a coenzyme and 5-methyltetrahydrofolate as the methyl donor (11). Nitrous oxide oxidizes vitamin B12 thereby inactivating methionine synthase which results in acute accumulation of homocysteine in the blood (12).

Whether this acute effect translates into clinical outcomes of relevance has been the research objective of two recent prospective randomized control trials in adults $(4,6)$. In these trials, nitrous oxide-induced acute hyperhomocysteinemia $(\geq 13.4 \mu \mathrm{mol} / \mathrm{L})$ was associated with increased risk of myocardial ischemia (6), and other major post-surgical complications (4). Adverse side effects of exposure to nitrous oxide may differ in adults versus in growing children (13). Nitrous oxide is widely used for pediatric anesthetic procedures at the Hospital for Sick Children, and the use of nitrous oxide is common pediatric anesthetic practice around the world (14).

The purpose, of the present study was to answer the following research questions: 1) What is the effect of a prolonged exposure to nitrous oxide during surgery on the total homocysteine concentration in pediatric patients? 2) Do the vitamin levels of folate, vitamin B12 
and vitamin B6 prior to nitrous oxide anesthesia impact the postsurgical homocysteine levels in children? and 3) Does genotype for the methylenetetrahydrofolate reductase polymorphisms (MTHFR) C677T impact post-surgical homocysteine concentrations?.

In the literature review that follows, the metabolism of homocysteine is discussed and the factors regulating its concentration in blood are described. These factors include vitamin status (folate, vitamin B12 and B6), genetic determinants, hepatic and renal function, age and sex (15). Dietary protein intake may also influence homocysteine concentrations (16-18).

In the second section of the literature review, an explanation of how nitrous oxide acts as an anesthetic and analgesic agent is provided, as well as the mechanisms by which it elevates homocysteine concentrations. The clinical implications of nitrous oxide-induced elevation in homocysteine and the pathogenesis of hyperhomocysteinemia are reviewed in the third section of this comprehensive review.

The fourth and last section of the literature review summarizes current Canadian and international data on population values and cutoffs for plasma and serum concentrations in children of homocysteine, folate, vitamin B6, vitamin B12 and methylmalonic acid (MMA) (a long-term indicator of vitamin B12 status). The information contained in the fourth section was used as reference values and significant cutoffs for the purpose of interpreting results of the present study.

Chapter three of this thesis consists of the report of my research project. To address the aforementioned research questions, I conducted a prospective cohort design. Participants of the study were pediatric patients $<11$ years of age, scheduled for surgery with use of nitrous oxide (50-70\% concentration), expected to last $\geq 2$ hours. A blood sample was obtained immediately prior to surgery and a second specimen was collected 12 to 24 hours thereafter. We compared 
initial homocysteine concentrations to concentrations in the postoperative period and explored whether the pre-surgical status of folate, vitamin B12 and vitamin B6 affected the post-exposure outcome in homocysteine. In addition, subjects' MTHFR C677T genotype was determined. The relationship of genotype with initial and post-exposure homocysteine concentrations and with vitamin status was explored.

Determination of total homocysteine in plasma was conducted by Liquid Chromatograpy-Electrospray Tandem Mass Spectrometry as described by Rafii and Elango et.al., (19). Total plasma folate concentration was determined by a microbiological assay as described by Molloy et.al., (20). Serum levels of vitamin B12 were measured by solid phase competitive chemiluminescent enzyme immunoassay using a commercial kit and analyzer equipment. Concentrations of MMA in plasma were measured by chemical ionization gas chromatography mass spectrometry according to the method described by Yazdanpanah and collaborators (21). Vitamin B6 (pyridoxal-5-phosphate) levels in plasma were measured by high performance liquid chromatography with on-line derivatization and fluorescence detection. DNA was extracted from whole blood lyses using a commercially prepared kit and genotype was determined by allele-specific Real Time Polymerase Chain Reaction as described by Eny and Wolever et. al. (22). 


\section{CHAPTER 2 LITERATURE REVIEW}

\subsection{Homocysteine}

\subsubsection{Metabolism}

\subsubsection{Metabolic pathways}

Homocysteine is a metabolite involved in the metabolism of the sulfur-containing amino acids methionine and cysteine, in pathways commonly known as the methionine cycle and transsulfuration pathway (Figure 2.1) (11). Methionine is the precursor of S-adenosylmethionine (SAM), the primary methyl donor for various reactions in the body including synthesis of myelin, production of neurotransmitters (serotonin, norepinephrine, and dopamine) synthesis and methylation of DNA $(23,24)$. S-adenosylhomocysteine (SAH) is generated by demethylation of SAM, which is subsequently hydrolyzed to homocysteine (Figure 2.1) (25).

In the methionine cycle, homocysteine can be remethylated back to methionine by the combined action of the cobalamin (vitamin B12) dependent enzymes methionine synthase and methionine synthase reductase $(10,26)$. Remethylation of homocysteine requires methylcobalamin. To form methylcobalamin needed to remethylate homocysteine, cobalamin (I), bound to methionine synthase, picks up the methyl group from 5-methyltetrahydrofolate and transfers it to homocysteine, thereby producing methionine and free tetrahydrofolate (Figure 2.1) (27). Activity of methionine synthase to form methionine depends on the presence of methionine synthase reductase which maintains methylcobalamin in its fully reduced, active state (26). The enzyme methylenetetrahydrofolate reductase (MTHFR) is responsible for the conversion of 
5,10-methylene tetrahydrofolate to 5-methyl tetrahydrofolate. Methionine synthase and MTHFR are present in all mammalian tissues (28).

\section{Figure 2.1 Homocysteine metabolism}

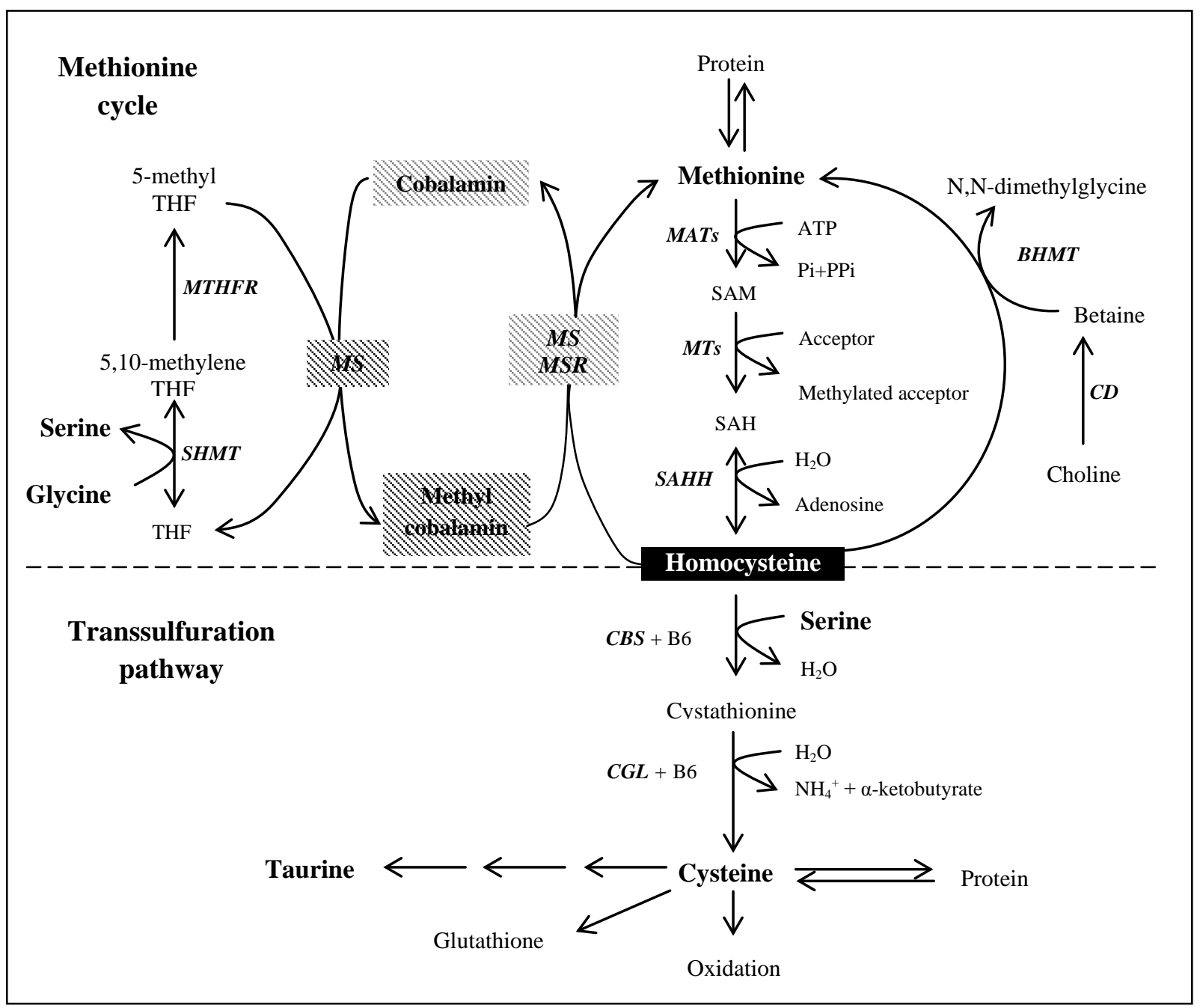

Hatched boxes denote locations where nitrous oxide oxidizes cobalamin (I) and inhibits MS. Abbreviations: THF tetrahydrofolate; MTHFR methylene tetrahydrofolate reductase; SHMT serine hydroxymethyltranferase; MS methionine synthase; MSR methionine synthase reductase; MATs methionine adenosyltransferases; MTs methyltransferases; SAM S-Adenosylmethionine; SAH S-adenosylhomocysteine; SAHH S-adenosylhomocysteine hydrolase; BHMT betaine-homocysteine methyltransferase; CD choline hydrolase; CBS cystathionine $\beta$-synthase; CGL cystathionine $\gamma$-lyase. 
An alternative salvage pathway for regeneration of homocysteine to methionine involves the enzyme betaine-homocysteine methyltransferase and betaine (29, 30). Betaine-homocysteine methyltransferase may occur only in the liver of mammalians and in the kidneys of primates and hogs (25, 31-33).

In the transsulfuration pathway, homocysteine is condensed with serine to form cystathionine, which is then cleaved to form cysteine and $\alpha$-ketobutyrate (see Figure 2.1). The vitamin B6 (pyridoxine) dependent enzyme cystathionine $\beta$-synthase (CBS) is responsible for cystathionine synthesis, whereas the next step in cysteine formation is catalyzed by cystathionine

$\gamma$-lyase. The latter is also vitamin B6 dependent. Conversion of homocysteine to cystathionine is an irreversible process (34), therefore the transsulfuration pathway results in catabolism of homocysteine clearing it from the metabolism. However, unlike the enzymes operating in the methionine cycle, those required to direct homocysteine toward cysteine synthesis have a tissue distribution limited to liver, kidney, brain, small intestine and pancreas $(11,25,35)$.

\subsubsection{Enzymatic regulation}

The metabolic response to a low methionine diet is to conserve available methionine for synthesis of SAM. In contrast, with a high methionine diet the metabolic response is to dispose of excess SAH. Whether methionine is preferably conserved or disposed is regulated by allosteric inhibitors/activators of the methionine cycle and tissue distribution of the various components of the methionine cycle and transsulfuration pathway. Elevated SAM inhibits MTHFR (36) while up regulating CBS activity $(37,38)$ and stabilizing it against proteolitic degradation (39). Expression of the betaine-homocysteine methyltransferase gene is also 
inhibited by high SAM levels (40). By inhibiting MTHFR, elevated SAM blocks the formation of 5-methyltetrahydrofolate. This, in turn, inhibits the transsulfuration specific enzyme glycine N-methyltransferase (41). Given the reversibility of the S-adenosylhomocysteine hydrolase reaction (SAH to homocysteine and vice versa) when remethylation of homocysteine is blocked by a lack of 5-methyltetrahydrofolate this results in enhanced synthesis of SAH (25). Elevated SAH concentrations inhibit the SAM-dependent inhibition of MTHFR (25). SAH also inhibits its own synthesis and virtually all methyltransferases activity (responsible for removal of the adenosyl group from SAM) including glycine $\mathrm{N}$-methyltransferase $(11,42)$. In addition, high methionine and SAH concentrations inhibit methionine synthase and betaine-homocysteine methyltransferase (37). Elevated SAM up-regulates CBS activity $(37,38)$ and stabilizes it against proteolitic degradation (39). Increased SAM levels also up-regulate the high potency transsulfuration specific enzyme methionine adenosyltransferase III and the glycine Nmethyltransferase reaction (25). The net effect is clearance of homocysteine by activation of the transsulfuration pathway in excess of methionine.

The second factor in regulating the conservation or disposal of methionine is tissue distribution. While the methionine adenosyltransferases I and II, along with methionine synthase, S-adenosylhomocysteine hydrolase and MTHFR are present in all mammalian cells; the essential nature of methionine provides an explanation for the limited tissue distribution of the enzymes in the transsulfuration pathway present only in liver, kidney, pancreas and brain $(11,25,34)$.

\subsubsection{Forms of homocysteine}

Homocysteine in human plasma is present in multiple species, for simplicity these have been grouped as protein-bound and non-protein-bound homocysteine (Figure 2.2). Protein- 
bound homocysteine refers to the portion of this metabolite that is bound to albumin as proteinhomocysteine mixed disulfide; this is the predominant form and its concentration in plasma accounts for $\sim 80 \%$ of total homocysteine. Homocysteine-cysteine mixed disulfide, homocystine and homocysteine are the non-protein-bound forms present in plasma and are commonly known as free homocysteine. Total homocysteine (tHcy) comprises all of the homocysteine forms found in human plasma (43).

Figure 2.2 Forms of homocysteine in human plasma

\begin{tabular}{|c|c|}
\hline $\begin{array}{c}\mathrm{H} \\
\text { I } \\
\mathrm{HS}-\mathrm{CH}_{2}-\mathrm{CH}_{2}-\mathrm{C}-\mathrm{COOH} \\
\mathrm{I} \\
\mathrm{NH}_{2}\end{array}$ & 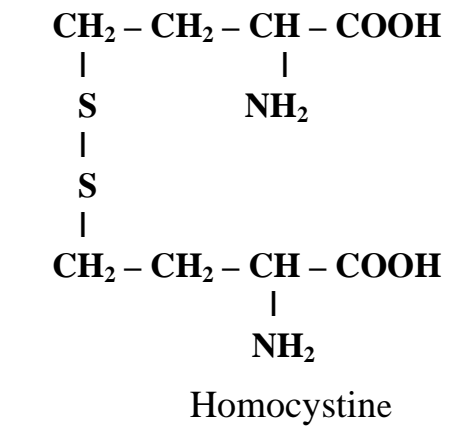 \\
\hline 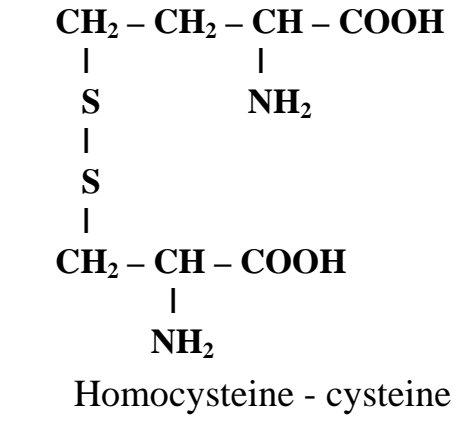 & $\begin{array}{cc}\underset{\mathrm{CH}}{\mathrm{CH}_{2}}-\mathrm{CH}_{2} & -\mathrm{CH}-\mathrm{COOH} \\
\mathrm{I} & \mathrm{I} \\
\mathrm{S} & \mathrm{NH}_{2} \\
\mathrm{I} & \\
\mathrm{S} & \\
\mathrm{I} & \\
\text { Albumin } & \end{array}$ \\
\hline
\end{tabular}




\subsubsection{Determinants of homocysteine concentrations}

Sex, age, pregnancy, organ function, diet, use of certain drugs and presence of specific genetic mutations are known determinants of total homocysteine concentrations in plasma (15, 16). Smoking may also influence total homocysteine concentrations to a certain degree $(15,16)$.

\subsubsection{Vitamins status}

Folate, vitamin B12 and vitamin B6 are implicated in the metabolism of homocysteine (see Figure 2.1), therefore, inadequate versus optimal status of folate, vitamins B12 and B6 mediate tHcy concentrations in blood (44-46). Large epidemiologic interventional and observational studies demonstrate an inverse relationship between homocysteine concentrations and folate, vitamins B12 and B6 intakes from natural dietary sources (47-52), fortified foods (5356), or supplements (57-59).

Before fortification of the food supply in North America, folic acid supplementation was shown to be the most efficient way in lowering homocysteine concentrations compared to vitamins B12 and B6 $(60,61)$. Folate is the generic name for a group of compounds which are involved in the transfer of single-carbon atom groups (62). Leaf vegetables, orange juice and cereals fortified with folic acid are good dietary sources of folates (63). The active folate coenzymes in human metabolism are: 5-formyltetrahydrofolate, 10-formyltetrahydrofolate, 5formiminotetrahydrofolate, 5,10-methenyltetrahydrofolate, 5,10-methylenetetrahydrofolate and 5-methyltetrahydrofolate (23). The folate coenzymes are involved in (1) thymidylate synthesis used for synthesis of DNA (5,10-methylenetetrahydrofolate) (2) purine formation (10formyltetrahydrofolate), (3) synthesis of serine and glycine (5,10-methylenetetrahydrofolate), (4) 
catabolism of histidine (5-formimiotetrahydrofolate), (5) remethylation of homocysteine to methionine (5-methyltetrahydrofolate) (23).

Sub-optimal vitamin B12 status is a common cause of elevated homocysteine concentrations in the general population (64). Susceptible groups are vegetarian (65), the elderly (46), women (66), exclusively breast fed infants (67-69) and individuals who either by circumstance or choice have limited access to foods of animal origin $(70,71)$. Vitamin B12 deficiency and concurrent elevated homocysteine concentrations in infants and children are associated with impaired cognitive development and function $(72,73)$ and in the elderly with Alzheimer disease and dementia (60, 74). In fact, high homocysteine and MMA concentrations ( $>15.0$ and $\geq 0.26 \mu \mathrm{mol} / \mathrm{L}$, respectively) are indicative of vitamin B12 deficiency in adults (15). In populations consuming grains and flours fortified with folic acid, cobalamin deficiency has become the predominant vitamin-related cause of high homocysteine concentrations $(75,76)$. Vitamin B12 is the generic term that refers to cobalamins which are cobalt containing compounds (63). Dietary sources of cobalamins for humans are limited to foods of animal origin especially liver and meat (62). The cobalamins active in human metabolism are 5'deoxyadenosylcobalamin (adenosylcobalamin) and methylcobalamin (23). Vitamin B12 serves as (1) coenzyme for methionine synthase in the remethylation of homocysteine (methylcobalamin), (2) cofactor in nucleic acid metabolism via conversion of 5methyltetrahydrofolate to tetrahydrofolate (methylcobalamin), (3) degradation of some amino acids and odd-chain fatty acids by acting as coenzyme for conversion of L-methylmalonylcoenzyme A to succinyl-coenzyme A (adenosylcobalamin) (62).

Vitamin B6 supplementation showed a less dramatic effect on homocysteine concentrations in meta-analyses and clinical trials when compared to folic acid and cobalamin 
supplementation (77-79), however CBS deficient subjects respond to pyridoxine treatment with a marked decrease in total homocysteine concentrations (80). The two active forms of vitamin B6 are the phosphates pyridoxal-5' -phosphate or pyridoxamine-5'-phosphate (62). Vitamin B6 is well distributed in foods and good sources are fish, poultry, yeast and bran (62). Vitamin B6 functions as a coenzyme in over 100 enzymes, it is necessary in the metabolism of (1) amino acids, (2) glycogen and (3) may diminish the action of steroids thereby influencing energy metabolism (23).

\subsubsection{Proteins and amino acids}

Whether or not an individual's protein intake influences homocysteine concentrations is still a matter of debate. While results from some human $(81)$ and rodent $(82,83)$ studies suggest a decreased effect on homocysteine with moderate to high protein diets, other authors report a significantly positive correlation between protein intake and plasma homocysteine concentration in humans (65). In rats, higher homocysteine concentrations are exhibited in animals consuming a high versus animals fed a standard casein diet (84). Nevertheless, a number of observational studies in humans have shown no correlation between protein intake and plasma homocysteine concentration (85-88).

For instance obese adults consuming a high protein, low protein or control diet over a 3 or 6 months period showed no significant difference in homocysteine concentration $(89,90)$. Prior to folic acid fortification of food supply in 1998, a large observational study in humans by Shimakawa et. al., found that plasma homocysteine concentrations were inversely associated 
with intakes of folate, cobalamin, and pyridoxine but not with intakes of methionine and protein (85). Furthermore, over a 24 hours period there was no significant difference in fasted homocysteine concentrations regardless of high protein or low protein intake $(17,91)$.

A number of studies have investigated the individual role of amino acids in the regulation of methionine by administration of free crystal amino acid doses to humans and to animal models. However, free crystal amino acids are not part of a normal diet. In addition, in dietary proteins; methionine and cysteine are frequently found together and in similar-ratio quantities along with other amino acids (92).

Free methionine is a potent hyperhomocysteinemic agent (93). Free serine, glycine and cysteine supplements lowered homocysteine concentrations in rodents fed either a low-protein or a high-protein diet (94-96). The lowering effect of cysteine is associated with increased plasma cysteine concentrations in rodents (97). In apparently healthy humans, concurrent intake of free cysteine and serine can attenuate the rise on postprandial homocysteine concentrations as a result of free methionine (17). The latter effect is due to utilization of homocysteine for synthesis of glutathione (91). In fact, adult men showed a significantly higher ratio of newly formed homocysteine molecules diverted towards transsulfuration when fed an amino acid crystals diet deprived of cysteine (98). Conversely, when the diet was low in methionine and high in cysteine, homocysteine was used for remethylation/transmethylation reactions (98). Concomitant ingestion of vitamin B12 in protein rich foods may represent a confounding factor in the homocysteine response to dietary proteins. 


\subsubsection{Genetic determinants}

The identified genetic determinants of homocysteine concentrations are polymorphisms of enzymes MTHFR and CBS. The human MTHFR gene is located on chromosomal region 1p36.3 (99). Normal MTHFR activity maintains the pool of 5-methyltetrahydrofolate (major circulating form of folate), thus providing substrate for the methionine cycle and prevent an elevation on homocysteine concentrations. More than 16 polymorphisms in the MTHFR gene have been identified (100). Mutations causing $>80 \%$ reduction in enzymatic activity are rare, mostly diagnosed in infancy and may produce severe clinical symptoms (100).

A common mutation in the MTHFR gene occurs at the 677 position. This polymorphism, known as MTHFR C677T, converts an alanine codon to valine (101) thereby producing a thermolabile variant (101-103). The net effect of this abnormality is a $35-50 \%$ reduction in enzymatic function $(101,104)$. When folate and riboflavin status are low, homozygous (TT) and some heterozygous (CT) individuals have homocysteine concentrations approximately 2.5 $\mu \mathrm{mol} / \mathrm{L}$ above levels normally found in people without this mutation ([CC] homozygous) (105). Studies comparing potential genetic determinants have shown that the MTHFR C677T polymorphism is the most common genetic determinant of homocysteine concentrations (106108). The allele frequency of MTHFR C677T polymorphism in the general population is 35\% in North America (101, 109). The genotype prevalence found in Caucasians is approximately 10 to $15 \%$ for the homozygous (TT) mutation, $\sim 40 \%$ for the heterozygous mutation (CT) and $~ 50$ for the (CC) homozygous (110-113). The population distribution varies by ethnic group and geographical location (114). For instance, the polymorphisms distribution of C677T allele in the French-Canadian population is approximately 37\% CC homozygous, 50\% heterozygous and 14.5\% TT homozygous (115). 
Conversely it has been shown that neither the homozygous nor the heterozygous state of the second most common polymorphism, MTHFR A1298C, leads to an elevation in plasma homocysteine or decreased plasma folate concentration, which is evident for the TT homozygous state for C677T (116). However, compound heterozygosity for both the C677T and the A1298C is associated with reduced enzyme activity (117).

More than 130 disease-associated mutations in the CBS gene have been identified (118). CBS deficiency leads to exceedingly high concentrations of homocysteine in urine and blood and elevated methionine concentrations in blood (119). Clinical signs and symptoms are present early on in life; and include mental retardation, psychiatric disorders, ectopia lentis, and skeletal abnormalities, in addition to a greatly increased risk of thromboembolic events (120).

Data from newborn screening shows that the worldwide birth prevalence of CBS deficiency is $\sim 1$ in 300,000 live births (120). The A2756G polymorphism of the methionine synthase enzyme has been suggested to influence homocysteine concentrations. The mutant $G$ allele is associated with lower homocysteine concentrations than wild types and may have a protective effect against thromboembolic events and ischemic stroke $(106,121)$.

\subsubsection{Hepatic and renal function}

Liver and kidney function are major determinants of homocysteine concentrations. Since most cells lack transsulfuration enzymes, excess SAH and homocysteine produced as a consequence of normal methylation processes are transported to liver and kidneys for catabolism (122). Circulating homocysteine concentrations reflect the efficacy of catabolism in the liver and kidneys (123-125). Patients with a chronic liver disease may present with homocysteine 
concentrations 3.4 to $6.2 \mu \mathrm{mol} / \mathrm{L}$ higher than healthy controls (126). The level of hyperhomocysteinemia corresponds to the level of hepatic damage (126, 127). Loss of hepatic function is associated with impairment of the transsulfuration pathway and decreased methionine adenosyltransferase III activity (128). The healthy liver is well adapted for catabolism of excess homocysteine (24). The hepatic transsulfuration enzymes CBS, cystathionine $\gamma$-lyase and methionine adenosyltransferase III have a high kinetic potency for sulfur-containing substrates (25). Synthesis of these enzymes and of glycine N-methyltransferase is up-regulated by increased methionine levels (see enzymatic regulation above) (25). In addition, hepatic cells synthesize betaine-homocysteine methyltransferase allowing for homocysteine removal via transmethylation $(32,33)$. In turn, hyperhomocysteinemia aggravates liver injury by inducing oxidative stress and fibrosis (129).

Hyperhomocysteinemia is a well known side effect of nephropathies (130-132). In fact, homocysteine concentrations are inversely associated with the glomerular filtration rate (133). The kidney is the major site of SAH disposal (122), and renal tubules avidly reabsorb homocysteine (134). Hence, normal kidney function comprises handling most of the homocysteine produced in the body. In renal failure SAM, SAH, cystathionine, cysteine and sulfate accumulate in the blood (131). This suggests that the principal culprit for hyperhomocysteinemia in renal failure is a decrease in the enzymatic clearance of homocysteine (130). Although the precise mechanisms are yet to be elucidated, two pieces of evidence direct attention towards the transsulfuration pathway: folic acid supplements only partially reduce hyperhomocysteinemia and there is a decrease in metabolic total homocysteine clearance through transsulfuration in renal patients (131). 


\subsubsection{Age and sex}

Higher homocysteine concentrations in boys than in girls have been found in some (135139), but not all (140-143) published studies. Data from the National Health and Nutrition Examination Survey (NHANES) ${ }^{1}$ in the U.S., showed that sex differences in homocysteine concentrations in children begin at around 10 years of age $(138,139)$. Boys presented with $~ 8 \%$ higher plasma tHcy concentrations than girls with variability by ethnic group $(138,139)$. Endogenous estrogens during the pubertal period in girls have been suggested as an explanation for age-sex related differences. Observations that total homocysteine concentrations are higher postmenopausally and during pregnancy are consistent with this hypothesis $(144,145)$. Androgens such as testosterone as well as increased muscle mass during adolescence in boys could also play a role in age-sex differences $(105,139)$.

\subsubsection{Effect of recent food intake on circulating tHcy concentrations}

Summarized in Table $\mathbf{2 . 0}$ are the results of studies comparing samples collected prior to and after food intake. These studies report findings in healthy volunteers as well as in patients with cardiac, vascular or metabolic disorders $(18,146-152)$. There appears to be a diurnal variation in tHcy concentrations independent of food intake. An analysis done on the data presented in Table $2.0(18,146-152)$, found that during the morning and early afternoon hours ( $\sim 0800$ to $1500 \mathrm{~h}$ ), tHcy concentrations do not differ between the fasted and postprandial state

\footnotetext{
${ }^{1}$ The National Health and Nutrition Examination Survey (NHANES) are national surveys designed to obtain representative information on the health and nutritional status of the civilian, noninstitutionalized U.S. population through interviews and direct physical examinations
} 
(10.3 \pm 1.7 vs. $10.2 \pm 2.0 \mu \mathrm{mol} / \mathrm{L}$, respectively $P=0.842)$. Most studies observed that tHcy concentrations rise between late afternoon and through the night ( 1600 to 2200h) $(18,148,149$, 152). The maximum level of increase (at $2200 \mathrm{~h}$ ) reported in the literature is $\sim 20 \%$ above the morning values (149).

The methionine content of dietary protein can enhance the transsulfuration pathway by increasing SAM concentrations which in turn activate stabilizing CBS against degradation (25). Given the irreversibility of the reaction catalyzed by CBS the transsulfuration pathway can result in clearance of homocysteine form tissues. In fact larger differences in pre-to-post-prandial tHcy concentrations may occur following a protein-rich meal. In a study by Verhoef et al, tHcy concentrations increased steadily shortly after breakfast reaching a peak of $11.4 \mu \mathrm{mol} / \mathrm{L}$ three hours after lunch and returning to pre-prandial concentrations $(9.3 \pm 2.1 \mu \mathrm{mol} / \mathrm{L})$ the next morning. Individuals in this study consumed a diet containing 257 grams of protein (21.2\% of total energy intake) including 4.3 methionine grams (18). 
Table 2.0 Effect of recent food intake on circulating homocysteine concentrations

\begin{tabular}{|c|c|c|c|c|c|c|c|c|c|c|c|}
\hline \multirow{3}{*}{$\begin{array}{c}\text { Study } \\
\text { (reference) }\end{array}$} & \multirow{3}{*}{$\mathrm{n}$} & \multirow{3}{*}{$\mathrm{M}: \mathrm{F}$} & \multirow{3}{*}{ Age } & \multirow{3}{*}{$\begin{array}{l}\text { Health } \\
\text { status }\end{array}$} & \multirow{3}{*}{$\begin{array}{c}\text { Meal } \\
\text { description }\end{array}$} & \multicolumn{6}{|c|}{ Homocysteine $(\mu \mathrm{mol} / \mathrm{L})$ mean \pm SD or $95 \% \mathrm{CI}$} \\
\hline & & & & & & \multirow{2}{*}{$\begin{array}{l}\text { Time } \\
\text { fasted } \\
\text { to fed }\end{array}$} & \multirow{2}{*}{$\begin{array}{l}\text { Fasted } \\
\geq 10 \mathrm{hr}\end{array}$} & \multirow{2}{*}{$\begin{array}{c}\text { Post- } \\
\text { prandial }\end{array}$} & \multicolumn{3}{|c|}{ Fasted to fed change } \\
\hline & & & & & & & & & Mean & Min & Max \\
\hline $\begin{array}{l}\text { Hodgson } \\
2007 \text { (146) }\end{array}$ & 20 & $17: 3$ & 62.1 & CAD & $\begin{array}{l}\mathrm{B}=812.6 \mathrm{kcal} ; \\
33 \mathrm{~g} \text { protein }\end{array}$ & $\begin{array}{l}\text { 3.5h after } \\
\text { BF }\end{array}$ & $\begin{array}{l}10.4 \\
(9.4-11.4)\end{array}$ & $\begin{array}{l}9.9 \\
(8.9-10.9)\end{array}$ & $\begin{array}{l}0.4 \downarrow \\
P=0.002\end{array}$ & $0.1 \downarrow$ & $0.6 \downarrow$ \\
\hline $\begin{array}{l}\text { Nomikos }^{a} \\
2007 \text { (147) }\end{array}$ & 27 & 27:0 & 44.9 & 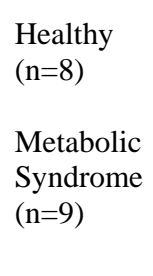 & $\begin{array}{l}\text { Control=7236 } \\
\text { kcal6.78g } \\
\text { protein } \\
\text { Artichoke } \\
=793.7 \mathrm{kcal} \\
9.98 \mathrm{~g} \text { protein }\end{array}$ & $\begin{array}{l}2,3,4 \mathrm{~h} \\
\text { after meal }\end{array}$ & $12.8 \pm 2.8$ & 12.49 & $0.31 \downarrow$ & $0.1 \downarrow$ & $0.77 \downarrow$ \\
\hline $\begin{array}{l}\text { Verhoef }^{\text {a }} \\
2005(18)\end{array}$ & 18 & 18:0 & 29 & Healthy & $\begin{array}{l}\text { LPD= } \\
\text { 3152kcal, 73g } \\
\text { protein, 1.6g } \\
\text { methionine }\end{array}$ & $\begin{array}{l}\text { 2-6h after } \\
\text { BF and } 2 \mathrm{~h} \\
\text { after L }\end{array}$ & $9.2 \pm 2.2$ & 9.0 & $0.2 \downarrow$ & $0.4 \downarrow$ & $1.4 \pm 1.3 \downarrow$ \\
\hline $\begin{array}{l}\text { Fokkema } \\
2003 \text { (148) }\end{array}$ & 16 & $8: 8$ & 44 & Healthy & $\begin{array}{l}\text { Not specified } \\
\text { B \& L }\end{array}$ & $\begin{array}{l}\text { 6h after } \\
\text { BF }\end{array}$ & 10.1 & 9.5 & $0.6 \downarrow$ & $0.5 \downarrow$ & $0.7 \downarrow$ \\
\hline \multirow[t]{2}{*}{$\begin{array}{l}\text { Nurk } \\
\text { 2001(153) }\end{array}$} & \multirow[t]{2}{*}{17,230} & \multirow[t]{2}{*}{$\begin{array}{l}\text { 8114: } \\
9116\end{array}$} & \multirow[t]{2}{*}{$40-67$} & \multirow[t]{2}{*}{$\begin{array}{l}\text { Not } \\
\text { specified }\end{array}$} & \multirow[t]{2}{*}{ Not specified } & \multirow[t]{2}{*}{$\begin{array}{l}\text { 1-6h after } \\
\text { last meal }\end{array}$} & $\begin{array}{l}\text { Fasted group } \\
\text { M: } 11.7 \\
(11.4-12.1)\end{array}$ & $\begin{array}{l}\text { Fed group } \\
\text { M: } 11.2 \\
(11.1-11.3)\end{array}$ & $\begin{array}{l}\mathrm{M}: 0.5 \downarrow \\
P=0.03\end{array}$ & $\begin{array}{l}\text { M: } 0.6 \downarrow \\
P=0.002\end{array}$ & $\begin{array}{l}\mathrm{M}: 0.7 \downarrow \\
P=0.08\end{array}$ \\
\hline & & & & & & & $\begin{array}{l}W: 10.2 \\
(9.9-10.6)\end{array}$ & $\begin{array}{l}\text { W: } 9.7 \\
(9.6-9.7)\end{array}$ & $\begin{array}{l}\text { W: } 0.5 \downarrow \\
P=0.003\end{array}$ & $\begin{array}{l}\text { W: } 0.9 \downarrow \\
P=<0.001\end{array}$ & $\begin{array}{l}\mathrm{W}: 0.2 \uparrow \\
P=0.56\end{array}$ \\
\hline
\end{tabular}




\section{Table 2.0 Continued}

\begin{tabular}{|c|c|c|c|c|c|c|c|c|c|c|c|}
\hline \multirow{3}{*}{$\begin{array}{c}\text { Study } \\
\text { (reference) }\end{array}$} & \multirow{3}{*}{$\mathrm{n}$} & \multirow{3}{*}{ M:F } & \multirow{3}{*}{ Age } & \multirow{3}{*}{$\begin{array}{l}\text { Health } \\
\text { status }\end{array}$} & \multirow{3}{*}{$\begin{array}{c}\text { Meal } \\
\text { description }\end{array}$} & \multirow{3}{*}{$\begin{array}{l}\text { Time } \\
\text { fasted } \\
\text { to fed }\end{array}$} & \multicolumn{5}{|c|}{ Homocysteine $(\mu \mathrm{mol} / \mathrm{L})$ mean \pm SD or $95 \% \mathrm{CI}$} \\
\hline & & & & & & & \multirow{2}{*}{$\begin{array}{l}\text { Fasted } \\
\geq 10 \mathrm{hr}\end{array}$} & \multirow{2}{*}{$\begin{array}{c}\text { Post- } \\
\text { prandial }\end{array}$} & \multicolumn{3}{|c|}{ Fasted to fed change } \\
\hline & & & & & & & & & Mean & Min & Max \\
\hline \multirow{3}{*}{$\begin{array}{l}\text { Candito } 1999 \\
(150)\end{array}$} & & \multirow{3}{*}{ NS } & \multirow{3}{*}{45.8} & \multirow{3}{*}{ CDV } & \multirow{3}{*}{$\begin{array}{l}\mathrm{B}=399 \mathrm{kcal} ; 7 \mathrm{~g} \\
\text { protein; } \mathrm{L}= \\
\text { 1800kcal } \\
\text { (all) }\end{array}$} & \multirow{3}{*}{$\begin{array}{l}\text { 2h after } \\
\text { lunch } \\
\text { (all) }\end{array}$} & $12.2 \pm 3.7$ & $13.6 \pm 4.4$ & & & \multirow[t]{3}{*}{$1.4 \uparrow(\mathrm{TT})$} \\
\hline & & & & & & & $12.4 \pm 7.6$ & $12.9 \pm 8.4$ & $\begin{array}{l}0.5 \uparrow \\
(\mathrm{CT})\end{array}$ & & \\
\hline & 16(CC) & & & & & & $10.5 \pm 4.3$ & $10.4 \pm 4.0$ & & $0.0(\mathrm{CC})$ & \\
\hline $\begin{array}{l}\text { Thirup } \\
1999 \text { (151) }\end{array}$ & 19 & $8: 11$ & 44 & Healthy & B\&L & $\begin{array}{l}4-7 \mathrm{~h} \\
\text { after BF } \\
0.5-3 \mathrm{~h} \\
\text { after L }\end{array}$ & 9.1 & 9.2 & $1.1 \uparrow$ & - & $3.6 \uparrow$ \\
\hline $\begin{array}{l}\text { Guttormsen }^{\mathrm{a}} \\
1994 \text { (149) }\end{array}$ & 13 & $3: 10$ & 24 & Healthy & $\begin{array}{l}\text { B1= } 561 \mathrm{Kcal} \\
15.6 \mathrm{~g} \text { protein } \\
\text { B2= } 445.5 \mathrm{Kcal} \\
11.5 \mathrm{~g} \text { protein }\end{array}$ & $\begin{array}{l}0.5, \\
1,2,3,4,6 \\
\text { after BF }\end{array}$ & $7.6 \pm 1.1$ & 7.4 & $0.1 \downarrow$ & 0.0 & $0.2 \downarrow$ \\
\hline $\begin{array}{l}\text { Ubbink } \\
1992 \text { (152) }\end{array}$ & 15 & $3: 12$ & 31.8 & Healthy & $\begin{array}{l}\mathrm{B}=751.5 \mathrm{kcal}, \\
26 \mathrm{~g} \text { protein, } \\
0.71 \mathrm{~g} \text { met }\end{array}$ & $\begin{array}{l}2,4,6,8 \mathrm{~h} \\
\text { after B }\end{array}$ & $8.8 \pm 3.0$ & $8.2 \pm 3.04$ & $\begin{array}{l}0.5 \downarrow \\
P=<0.001 \\
\text { (2h) }\end{array}$ & $\begin{array}{l}0.4 \downarrow \\
P=0.98 \\
\text { (8h) }\end{array}$ & $\begin{array}{l}0.7 \downarrow \\
P=0.011 \\
(4 \mathrm{~h})\end{array}$ \\
\hline
\end{tabular}

Abbreviations: CVD cardio vascular disease, CAD coronary artery disease, L lunch, B breakfast, LPD low protein diet, M men, W women, NS not specified $\uparrow$ increase, $\downarrow$ decrease

MTHFR C677T genotype: TT homozygous, CT heterozygous, CC wild type

Significant $P$ values reported $(<0.05)$

${ }^{\mathrm{a}}$ Total homocysteine concentrations calculated from original paper 


\subsection{Nitrous oxide}

\subsubsection{Nitrous oxide anesthesia}

Nitrous oxide is a gas used in medical practice to induce and help maintain anesthesia. It produces sedation and has mild analgesic effects (154). The possible mechanism of action for its sedative action is non-competitive inhibition of excitatory glutamatergic neurotransmission between neurons. Another potential mechanism involved in its anesthetic property is activation of potassium channels, thereby increasing potassium conductance resulting in hyperpolarization of neurons with a reduction in their firing threshold (13). The analgesic action of nitrous oxide is most likely exerted by activation of opioidergic and inhibition of noradrenergic neurons (13). Opiodergic neurons are involved in the regulation of endogenous opioids, which decrease perception and reaction to pain and increase tolerance to pain (155). Activation of the opioidergic neurons by nitrous oxide indirectly inhibits descending noradrenergic inhibiting neurons, which in turn stimulate adrenergic receptors leading to a reduction in pain impulses (13).

Nitrous oxide is administered along with a potent inhalational or intravenous anesthetic agent to produce surgical depth of anesthesia and allows for a reduction of other anesthetic drugs

presumably to reduce side effects and costs (14). However, nitrous oxide has limited potency, therefore the usual practice is to administer concentrations from 50 to $70 \%$ and proportionally the inspired oxygen concentration will be 50 to 30\% (156). Side effects include an increased risk of nausea and vomiting $(157,158)$. Other reported adverse effects of nitrous oxide anesthesia include impairment of cerebral blood flow-activity coupling (159), and inactivation of methionine synthase $(160,161)$. 
A recent survey of anesthesia consultants in the United Kingdom confirmed that pediatric anesthesiologists are more likely to perform inhalational inductions than anesthesiologists in adult practice: $74 \%$ of practitioners reported frequent use of $\mathrm{N}_{2} \mathrm{O}$ for induction, and $69 \%$ reported that they frequently use $\mathrm{N}_{2} \mathrm{O}$ for maintenance of anesthesia (162). No comparable data are available in North America; however nitrous oxide is routinely used at The Hospital for Sick Children.

\subsubsection{Metabolic effects of nitrous oxide}

Nitrous oxide irreversibly oxidizes the cobalt core of vitamin B12 from its reduced forms cobalamin (I) and (II) to cobalamin (III) oxidation state (163), as follows:

$$
\begin{aligned}
2 \mathrm{Co}^{+}+\mathrm{N}_{2} \mathrm{O} & \rightarrow 2 \mathrm{Co}^{++}+\mathrm{H}_{2} \mathrm{O}+\mathrm{N}_{2} \\
2 \mathrm{Co}^{++}+\mathrm{N}_{2} \mathrm{O} & \rightarrow 2 \mathrm{Co}^{+++}+\mathrm{H}_{2} \mathrm{O}+\mathrm{N}_{2}
\end{aligned}
$$

The cobalamin molecule has a corrin nucleus with a cobalt atom in the center, to which a functional group is attached. The active functional groups in humans and most animals are methyl $\left(\mathrm{CH}_{3}\right)$ and adenosyl (5'-deoxyadenosyl) bound to the cobalamin cobalt core, these constitute the active cofactors methylcobalamin and adenosyl-cobalamin. Nitrous oxide reacts with the cobalamin corrin nucleus oxidizing the cobalt atom. As a result, the molecule loses its power to form a carbon-cobalt bond with the methyl ligand $(164,165)$. Thus, nitrous oxide prevents the formation of methylcobalamin and inactivates circulating methionine synthase (see Figure 2.1) $(12,164)$. The rate of methionine synthase inactivation is directly associated with the duration of nitrous oxide exposure (161). While methionine synthase activity was found to be normal in human placenta after exposure to nitrous oxide for $\sim 25$ minutes during cesarean 
section (166), enzymatic activity was reduced by $50 \%$ in human liver samples after $\sim 2$ hours of exposure to $60 \%$ nitrous oxide (160). Recovery of methionine synthase to normal function usually occurs after 3 to 6 days after nitrous oxide discontinuation $(8,167,168)$. When administered to humans for 12 to 24 hours, nitrous oxide causes marked megaloblastic changes in the bone marrow and an abnormal deoxyuridine test similar to that produced by pernicious anemia $(169,170)$. A $~ 4$ days exposure resulted in agranulocytosis and a 7 days exposure resulted in death of two patients (171). With short exposure periods ( 2 to 3 hours), patients with vitamin B12 deficiency can develop severe neurologic symptoms (172-176), permanent neurological damage (177), or even death (178).

Nitrous oxide-induced inactivation of methylcobalamin is irreversible in animal and human tissues since only bacteria possess the enzymes to revert the oxidative damage to cobalamin by reducing the cobalt core in cobalamin to its monovalent form cobalamin (I) (179). Therefore, recovery of methionine synthetase activity requires replenishment of cobalamin (I) (161). Adenosylcobalamin formation is not affected presumably because the adenosyl group is able to bind to cobalamin (II) (180-182). Folate metabolism is impaired as a consequence of nitrous oxide-induced cobalamin oxidation (see Figure 2.1) (164). Synthesis of 5methyltetrahydrofolate is irreversible; this folate form is used only for the synthesis of methylcobalamin (see Figure 2.1). After donating the methyl group to cobalamin, free tetrahydrofolate undergoes transformations to yield other folate forms (see Figure 2.1). Hence, in the absence of active cobalamin or in vitamin B12 deficiency, 5-methyltetrahydrofolate accumulates but cannot be used for synthesis of methionine or transformation into another folate form (183). This phenomenon is known as the methyl-folate trap (183). Inactivation of vitamin B12 is characterized by increased circulating levels of folates in blood of patients treated with 
nitrous oxide (2, 3, 8). Methionine synthetase converts homocysteine to methionine. Nitrous

oxide indirectly causes an acute increase in homocysteine concentrations in the post-exposure period by oxidizing vitamin B12 and inactivating methionine synthase (184).

\subsection{Clinical implications and pathogenesis}

\subsubsection{Clinical implications of acute hyperhomocysteinemia}

No data was found referring to potential effect(s) of acute hyperhomocysteinemia in pediatric patients. Studies in adult patients have shown that nitrous oxide exposure $(\geq 70 \%$ nitrous oxide concentration, $\geq 75$ minutes) causes an elevation of postoperative plasma homocysteine concentration from $\sim 10$ to $300 \%$ in a dose dependent manner (3, 6-8). The highest concentrations of total homocysteine were observed 12 to 24 hours after induction of anesthesia $(6,8)$. A study by Nagele et.al. explored the influence of genetic mutations affecting homocysteine metabolism in patients undergoing orthopedic surgery for a minimum duration of 2 hours with a nitrous oxide concentration of $66 \%$. The authors reported that patients homozygous for the MTHFR C677T or A1298C polymorphisms (n=25) developed higher plasma homocysteine concentrations (median [interquartile range], 14.9 [10.0 - 26.4] $\mu \mathrm{mol} / \mathrm{L}$ ) than wild type or heterozygous patients (9.3 [7.5 - 15.5] $\mu \mathrm{mol} / \mathrm{L} ; \mathrm{n}=115)(2)$. In a subsequent analysis, Nagele et.al. found that a common polymorphism in methionine synthase reductase (MTRR 66A > G), which is associated with reduced enzyme activity had no effect on the homocysteine concentrations of patients exposed to nitrous oxide (1).

The ENIGMA Trial (Effectiveness of Nitrous oxide in the Gas Mixture for Anaesthesia) was an international, multi-centre, double blinded, randomized control trial to test the safety and 
effectiveness of nitrous oxide. The study sample consisted of 2050 adult patients who had major non-cardiac surgery expected to exceed 2 hours duration (185). Eligible participants of the study were subjects $\geq 18$ years of age, with no contraindications (e.g. bowel surgery) to nitrous oxide anesthesia. Nitrous oxide was administered in a concentration of $70 \%$. Surgeries included, but were not limited to: general surgery, urology, neurosurgery, orthopedic, vascular, gynecology, ear-nose-throat, and plastics (186). The ENIGMA II Trial is currently in process and started shortly after completion of the ENIGMA Trial, approximately 2 years ago (156). Participants of the ENIGMA II Trial are patients at risk of coronary artery disease undergoing non-cardiac surgery (156).

Results from the recently completed ENIGMA Trial published by Myles and collaborators, showed that postsurgery homocysteine concentrations of $\geq 13.5 \mu \mathrm{mol} / \mathrm{L}$ in adults were associated with an increased risk of major complications (see below) and cardiovascular events (risk ratio 2.8 [CI: 1.4-5.4] and 5.1 [95\% CI: 3.1-8.5], respectively) (3). Major postoperative complications included myocardial infarction, venous thromboembolism, stroke and death within 30 days of surgery (3). In the ENIGMA II Trial, nitrous oxide anesthesia induced a mean increase in homocysteine concentration of $4.9 \mu \mathrm{mol} / \mathrm{L}$ (95\% CI 2.8-7.0 $\mu \mathrm{mol} / \mathrm{L}$; $P=<0.0005$ ), and compromised endothelial function. Patients receiving anesthesia with $\mathrm{N}_{2} \mathrm{O}$ showed a significant decrease in flow mediated dilatation of forearm vessels (3.2\%; 95\% CI 0.15.3\%; $P=0.001$ ) and exposure to nitrous oxide was inversely correlated with flow mediated dilatation of forearm vessels $(\mathrm{r}=-0.60 \mathrm{P}=0.004)(4)$.

Badner et. al. conducted a study in adults undergoing carotid thromboendarterectomy and found that the relative risk of developing postoperative myocardial ischemia increases two-fold with a postoperative homocysteine concentration $>17 \mu \mathrm{mol} / \mathrm{L}$. The $\mathrm{N}_{2} \mathrm{O}$ exposed group had 
higher homocysteine concentrations $(15.5 \pm 5.9 \mu \mathrm{mol} / \mathrm{L}$ on arrival to the post anesthesia care unit and $18.8 \pm 14.7 \mu \mathrm{mol} / \mathrm{L} 48$ hours postoperatively), compared to the patients not receiving nitrous oxide $(11.4 \pm 5.2 \mu \mathrm{mol} / \mathrm{L}$ and $11.3 \pm 4.0 \mu \mathrm{mol} / \mathrm{L})$. Overall there was a higher incidence of ischemia in patients treated with nitrous oxide compared to those not receiving nitrous oxide (46 vs. $26 \%$, $P=<0.05$ ) (6). Given these observations, in a subsequent study Badner et. al., assessed the potential benefits of supplementing patients with a vitamin B complex containing folate (2.5 mg), B6 (25 mg) and B12 (500 $\mu \mathrm{g})$ prior to nitrous oxide exposure. Total homocysteine concentrations were effectively decreased by $9.1 \pm 11 \%$ in patients taking the vitamin B supplement; whereas the placebo group showed an increase in total homocysteine concentrations (15 \pm 31\%) after exposure to nitrous oxide (5). The Recommended Dietary Allowances for these vitamins in healthy adults are: $400 \mu \mathrm{g} /$ day for folate; 1.3mg/day for vitamin B6 and $2.4 \mu \mathrm{g} / \mathrm{day}$ for vitamin B12 (63). Therefore, the doses provided to patients in the latter study were about twice the recommendations for adults. In addition, it has been shown that folate supplementation can also prevent $\mathrm{N}_{2} \mathrm{O}$-induced bone marrow toxicity by administration of a folinic acid dose of 30 mg given immediately before and 12 hours after anesthesia. However, smaller doses were ineffective (187).

Several case reports of individuals with pre-existing vitamin B12 deficiency and/or altered folate metabolism and exposure to nitrous oxide have been published. These patients have an enhanced susceptibility to develop nitrous oxide-induced adverse side effects; thus $\sim 4$ hours of exposure could be sufficient to cause severe neuropathy and/or anemia (172-178). A recently published case-report documented severe hypothonia, tachypnea, lethargy, anemia and hematological changes indicative of bone marrow depletion in a 6 months old girl with 180 minutes of nitrous oxide exposure during elective surgery. The baby was exclusively breastfed 
and the mother was vegetarian who did not use vitamin supplements. Laboratory analyses revealed low serum levels of folate and vitamin B12 and elevated concentrations of homocysteine, cysteine and methylmalonic acid urinary excretion (177). Selzer et al. reported a notable case of a 3 month old boy who received a total of 315 minutes of $\mathrm{N}_{2} \mathrm{O}$ anesthesia at a concentration of $60 \%$ on two separate occasions before the detection of mutations on multiple MTHFR polymorphisms (heterozygous for the G1755A, the C677T, and the A1298C). The boy developed cerebral atrophy, severe demyelinization, cell depletion in the midbrain, medulla and cerebellum and died 46 days after the last nitrous oxide exposure (178).

Acute increases in homocysteine concentration may lead to endothelial dysfunction in healthy adult humans. This has been shown in studies inducing hyperhomocysteinemia ( $\geq 25$ $\mu \mathrm{mol} / \mathrm{L}$ ) by an oral methionine load (100mg free methionine/kg weight). Subjects in these studies experienced $\sim 18 \%$ reduction in the vasodilatatory function of brachial blood vessels during hyperhomocysteinemia (188-191). In one study, the endothelial dysfunction was

prevented by coadministration of ascorbic acid, a potent scavenger of reactive oxygen species (190).

\subsubsection{Chronic hyperhomocysteinemia and risk of ischemic heart disease and stroke}

In pediatric patients chronically elevated tHcy concentrations (>8 $\mu \mathrm{mol} / \mathrm{L})(105)$ are concurrent with reports of ischemic/hemorrhagic stroke (8.7, $9.3 \mu \mathrm{mol} / \mathrm{L})(106,192)$, thromboembolism (6.6 $\mu \mathrm{mol} / \mathrm{L})(113)$ and venous thrombosis (7.6 $\mu \mathrm{mol} / \mathrm{L})(111)$. However, chronic hyperhomocysteinemia in children is rare (192). 
Between the age of 15 and 65 years, hyperhomocysteinemia is defined as $>12 \mu \mathrm{ml} / \mathrm{L}$ in individuals eating food fortified with folic acid or taking folic acid supplements, and $>15 \mu \mathrm{ml} / \mathrm{L}$ with nonsupplemented diet (105). Chronic hyperhomocysteinemia is concurrent with ischemic heart disease (coronary heart disease, myocardial infarction), and cerebrovascular disease, (fatal and hemorrhagic stroke) (193). Whether concurrence of ischemic heart disease and stroke with chronic hyperhomocysteinemia is due to a direct pathogenic effect of homocysteine (causational) or elevated homocysteine concentrations are an associated marker, remains controversial.

Several large randomized controlled trials have been conducted to evaluate the clinical effects of lowering homocysteine concentrations (20-30\% reduction) by treatment with folic acid, vitamin B12 and/or vitamin B6 versus a placebo in adult patients with a history of cardiovascular disease and/or stroke. However, in the latest published meta-analyses (2006), trials failed to demonstrate a favorable clinical response on ischemic heart disease by reducing homocysteine concentration $(194,195)$.

Conversely, lowering tHcy $>20 \%$ of baseline concentration reduced the risk of stroke by 18\% (RR: $0.83,95 \%$ CI: $0.68-1.00, P=0.45$ ) in a recent (2007) meta-analysis that included 8 randomized, controlled trials with a total sample size of 16,841 individuals (196). Lower incidence of stroke was observed with $\sim 30 \%$ reduction of tHcy concentration in a meta-analysis (195), and a systematic review of large homocysteine-lowering trials (60). A number of metaanalyses using a mendelian randomization approach, found greater odds for stroke in subjects presenting with elevated homocysteine concentrations (197-199). The mendelian meta-analyses compounded the results of studies reporting the incidence of stroke according to MTHFR C677T genotype and the difference in tHcy concentrations between genotypes (197-199). In the largest mendelian randomization meta-analysis (81 studies, 31,355 individuals), the odds ratio for stroke 
was 1.26 (95\% CI 1.14 to 1.40) for homozygous (TT) versus homozygous (CC) individuals (198). Analyses of data were adjusted for age group, ethnic background and geographical location (198).

Recently, the Western Norway B Vitamin Intervention Trial was completed. This trial is one of the largest trials to assess the clinical effects of lowering tHcy concentrations by multiple schemes of treatment with B-vitamins supplements (200). The authors found a $1.4 \%$ lower incidence of stroke in the treatment group ( $\sim 30 \%$ reduction in tHcy) when compared to the control group (no tHcy reduction), but this difference did not reach significance (200). The latter study found no protective effect of lowering tHcy concentrations on the risk of myocardial infarction, angina and overall cause of death (200).

Epidemiological studies were first to observe a link between homocysteine and stroke (201). A population-based cohort study reported the simultaneous significant decrease in stroke and reduction of tHcy concentrations in Canada and the U.S., concurrent with the introduction of mandatory fortification of the food supply with folic acid in 1998 (202). The decrease in the mortality rate for stroke $(-2.9 \%, 95 \%$ CI -3.5 to -2.3$)$ was not attributable to changes in other potentially influential factors (202).

\subsubsection{Pathogenesis of vascular disease due to hyperhomocysteinemia}

The mechanisms whereby homocysteine can cause endothelial damage and vascular disease are not fully understood. Some of the hypotheses involve proliferation of vascular smooth muscle cells originating from inflammatory damage to vessels $(203,204)$ and oxidative stress (204). The specific oxidative stress mechanisms proposed include impaired synthesis of 
antioxidants $(205,206)$ and nitric oxide $(207-210)$, as well as generation of reactive oxygen species (208, 211-214), which may cause dysfunction of vascular endothelium cells (215).

High homocysteine concentrations can increase the generation of reactive oxygen species: superoxide anions $\left(\mathrm{O}_{2}^{-}\right)$and hydrogen peroxide $\left(\mathrm{H}_{2} \mathrm{O}_{2}\right)$, since these originate from the auto-oxidation of homocysteine $(208,216)$. In elevated concentrations, reactive oxygen species promote loss of membrane function and increased membrane permeability (lipid peroxidation) (204).

A clinical trial in healthy adults showed that acute hyperhomocysteinemia decreased nitric oxide bioavailability (210). In children homocysteine concentrations were inversely associated with nitric oxide bioavailability (209). Endothelial cells use nitric oxide to signal surrounding smooth muscle cells to relax resulting in vasodilatation (210). In addition, nitric oxide contributes to the inhibition of platelet and leukocyte aggregation and adhesion to the endothelium (207).

Superoxide rapidly reacts and inactivates nitric oxide (214). Either the decreased production of nitric oxide (208), or the increased formation of superoxide $(207,214)$, or both may result in endothelial cell dysfunction (204).

Acutely induced high homocysteine concentrations may reduce nitric oxide bioavailability by limiting the supply of L-arginine (a substrate for nitric oxide synthesis) to endothelial cells (208). In vitro, treatment with ascorbic acid blocked the homocysteine-induced decrease in L-arginine uptake. Similarly, supplementation of L-arginine prevented the reduction in endothelium-dependent vasodilatation (208).

Another arginine-related mechanism undergoing extensive investigation suggests that homocysteine and potentially S-adenosylhomocysteine may inhibit the enzyme protein-arginine 
methyltransferase which is required for metabolism of arginine (217). Thus, inhibition of this enzyme may result in decreased endothelial function (217). Hyperhomocysteinemia may weaken the endothelial cells’ defense mechanisms against oxidative stress by diminishing the activity of the anti-oxidative enzyme glutathione peroxidase-1, which reduces hydrogen peroxide and lipid peroxides (205, 206). Hyperhomocysteinemia may also detach superoxide dismutase from the endothelium leading to an elevation of superoxide (213). The observation that antioxidants prevent endothelial dysfunction in vivo (healthy humans) (190) and in vitro (208) suggests that the effects of acute hyperhomocysteinemia may be caused by oxidative stress.

\subsection{Reference values and cutoffs}

\subsubsection{Homocysteine concentrations}

Data from international studies examining the homocysteine concentrations in children, including U.S. data obtained in the post folic acid fortification of the food supply era (1998), are presented in Table 2.1. Healthy babies appear to have homocysteine concentrations in the range of 5.0 and $7.0 \mu \mathrm{mol} / \mathrm{L}$; school age children generally have homocysteine concentrations between the 4.0 and $7.0 \mu \mathrm{mol} / \mathrm{L}$. In adolescents homocysteine ranges from 6.0 to $8.0 \mu \mathrm{mol} / \mathrm{L}$ with girls presenting significantly lower concentrations than boys (138, 218-220). Differences observed among countries may be attributable to ethnicity, lifestyle, diet, and vitamin consumption. Based on a comprehensive assessment of published literature, Refsum et al, set the upper reference limit for total homocysteine concentration in children $<15$ years at $8 \mu \mathrm{mol} / \mathrm{L}$ (105). Chronic elevation above this concentration is consistent with findings of stroke and thromboembolic events in children $(111,113,192,221-223)$. 
Table 2.1 Homocysteine concentrations of children in health and disease

\begin{tabular}{|c|c|c|c|c|c|c|c|}
\hline \multirow{3}{*}{$\begin{array}{l}\text { Study \& location } \\
\text { (reference) }\end{array}$} & \multirow{3}{*}{$\begin{array}{l}\text { Health } \\
\text { status }\end{array}$} & & \multicolumn{5}{|c|}{ Total homocysteine concentrations $(\mu \mathrm{mol} / \mathrm{L})$} \\
\hline & & \multirow{2}{*}{$\begin{array}{c}\mathrm{n} \\
\mathrm{M}: \mathrm{F}\end{array}$} & \multirow{2}{*}{ All ages } & \multicolumn{4}{|c|}{ Age group } \\
\hline & & & & $0-1$ & $2-5$ & $6-10$ & $>10$ \\
\hline $\begin{array}{l}\text { Hogeveen } 2008^{1, \mathrm{a}} \\
\text { Netherlands (218) }\end{array}$ & Healthy & $\begin{array}{l}186 \\
92: 94\end{array}$ & 6.44 & $5.3^{*}$ & $4.6^{*}$ & $6.0^{*}$ & $7.3^{*}$ \\
\hline \multirow{2}{*}{$\begin{array}{l}\text { Sirachainan } \\
\text { 2008/2006 }{ }^{2} \\
\text { Thailand (106, } \\
\text { 221) }\end{array}$} & $\begin{array}{l}\text { Ischemic } \\
\text { Stroke }\end{array}$ & $\begin{array}{l}32 \\
18: 14\end{array}$ & $8.7 \pm 3.6^{*}$ & - & - & $\begin{array}{l}8.4 \pm 4.2 \\
(\mathrm{CC}) \\
9.8 \pm 3.0 \\
(\mathrm{CT})\end{array}$ & - \\
\hline & Healthy & $\begin{array}{l}96 \\
52: 44\end{array}$ & $7.5 \pm 2.4^{*}$ & - & - & $\begin{array}{l}7.0 \pm 2.2 \\
(\mathrm{CC}) \\
8.2 \pm 2.8 \\
(\mathrm{CT})\end{array}$ & - \\
\hline $\begin{array}{l}\text { Papandreou } \\
2006^{1} \text { Greece } \\
\text { (219) }\end{array}$ & Healthy & $\begin{array}{l}520 \\
274: 246\end{array}$ & $\begin{array}{l}6.8 \\
(3.5-22.2)^{\mathrm{a}}\end{array}$ & - & - & $\begin{array}{l}6.5 \\
(3.5-11.3)^{*}\end{array}$ & $\begin{array}{l}7.1 \\
(4.1-22.2)^{*}\end{array}$ \\
\hline \multirow[t]{2}{*}{$\begin{array}{l}\text { Kosch } 2004^{3} \\
\text { Germany (113) }\end{array}$} & TEB & 163 & $\begin{array}{l}6.6 \\
(2.9-20.4)^{*}\end{array}$ & $\begin{array}{l}6.6 \\
(3.0-17.0)\end{array}$ & $\begin{array}{l}6.0 \\
(2.9-16.9)\end{array}$ & $\begin{array}{l}6.9 \\
4.0-16.3)\end{array}$ & $\begin{array}{l}7.7 \\
(3.6-20.4)\end{array}$ \\
\hline & Healthy & 255 & $\begin{array}{l}5.7 \\
(2.0-14.0)^{*}\end{array}$ & $\begin{array}{l}6.0 \\
(2.0-12.0)\end{array}$ & $\begin{array}{l}5.0 \\
(2.4-14.0)\end{array}$ & $\begin{array}{l}6.0 \\
(2.0-10.0)\end{array}$ & $\begin{array}{l}6.3 \\
(2.3-12.5)\end{array}$ \\
\hline $\begin{array}{l}\text { van Beynum } \\
2005^{4}\end{array}$ & Healthy & $\begin{array}{l}234 \\
115: 119\end{array}$ & $\begin{array}{l}6.2 \\
(5.9-6.6)\end{array}$ & $\begin{array}{l}5.1 \\
(4.6-5.5)^{*}\end{array}$ & $\begin{array}{l}4.6 \\
(4.2-5.1)^{*}\end{array}$ & $\begin{array}{l}6.2 \\
(5.6-6.9)^{*}\end{array}$ & $\begin{array}{l}7.3 \\
(6.7-8.0)^{*}\end{array}$ \\
\hline \multicolumn{8}{|l|}{ Netherlands (220) } \\
\hline \multirow{2}{*}{$\begin{array}{l}\text { Ganji 2005,b } \\
\text { USA (138) }\end{array}$} & \multirow{2}{*}{ General } & F: 843 & $4.6 \pm 0.1^{*}$ & - & $4.0 \pm 0.2$ & $4.4 \pm 0.1$ & $4.9 \pm 0.1$ \\
\hline & & M: 1722 & $4.9 \pm 0.1^{*}$ & - & $4.1 \pm 0.2$ & $4.5 \pm 0.1$ & $5.2 \pm 0.1$ \\
\hline $\begin{array}{l}\text { Refsum 2004² } \\
\text { Norway (224) }\end{array}$ & General & 4985 & Neonates & $7.0 \pm 3.0$ & - & - & - \\
\hline $\begin{array}{l}\text { Monsen } 2003^{6} \\
\text { Norway }(140)\end{array}$ & Healthy & $\begin{array}{l}697 \\
395: 302\end{array}$ & $\begin{array}{l}6.7 \\
(4.6-9.1)\end{array}$ & $\begin{array}{l}7.4 \\
(6.1-9.2)\end{array}$ & $\begin{array}{l}5.2 \\
(4.7-5.9)\end{array}$ & $\begin{array}{l}6.5 \\
(5.7-7.7)\end{array}$ & $\begin{array}{l}7.7 \\
(6.6-9.1)\end{array}$ \\
\hline \multirow[t]{2}{*}{$\begin{array}{l}\text { Hogeveen } 2002^{4} \\
\text { Netherlands (192) }\end{array}$} & Stroke $^{c}$ & 24 & Infants & $\begin{array}{l}9.3 \\
(9.1-9.6)^{*}\end{array}$ & - & - & - \\
\hline & Control & 94 & & $\begin{array}{l}7.4 \\
(7.1-7.7)^{*}\end{array}$ & - & - & - \\
\hline
\end{tabular}


Table 2.1 Continued

\begin{tabular}{|c|c|c|c|c|c|c|c|}
\hline \multirow{3}{*}{$\begin{array}{l}\text { Study \& location } \\
\text { (reference) }\end{array}$} & \multirow{3}{*}{$\begin{array}{l}\text { Health } \\
\text { status }\end{array}$} & \multirow{3}{*}{$\begin{array}{c}\mathrm{n} \\
\mathrm{M}: \mathrm{F}\end{array}$} & \multicolumn{5}{|c|}{ Total homocysteine concentrations $(\mu \mathrm{mol} / \mathrm{L})$} \\
\hline & & & \multirow{2}{*}{ All ages } & \multicolumn{4}{|c|}{ Age group } \\
\hline & & & & $0-1$ & $2-5$ & $6-10$ & $>10$ \\
\hline \multirow[t]{3}{*}{$\begin{array}{l}\text { Delvin } 2000^{3, \text { a }} \\
\text { Canada (115) }\end{array}$} & \multirow{3}{*}{ Healthy } & $\begin{array}{l}52 \text { (CC) } \\
26: 26\end{array}$ & $\begin{array}{l}6.4 \\
(2.7-14.9)\end{array}$ & & $\begin{array}{l}4.7 \\
(2.7-8.4)\end{array}$ & & $\begin{array}{l}8.1 \\
(3.9-14.9)\end{array}$ \\
\hline & & $\begin{array}{l}53(\mathrm{CT}) \\
20: 33\end{array}$ & $\begin{array}{l}5.9 \\
(2.6-21.1)\end{array}$ & - & $\begin{array}{l}4.6 \\
(2.6-21.1)\end{array}$ & - & $\begin{array}{l}7.2 \\
(4.1-21.1)\end{array}$ \\
\hline & & $\begin{array}{l}22(\mathrm{TT}) \\
12: 10\end{array}$ & $\begin{array}{l}7.7 \\
(2.8-24.3)\end{array}$ & & $\begin{array}{l}4.9 \\
(2.8-8.9)\end{array}$ & & $\begin{array}{l}10.6 \\
(4.7-24.3)\end{array}$ \\
\hline \multirow{2}{*}{$\begin{array}{l}\text { Minet } 2000^{2} \\
\text { Switzerland (225) }\end{array}$} & \multirow{2}{*}{ Healthy } & $\mathrm{BF} 30$ & \multirow[t]{2}{*}{ Neonates } & $10.4 \pm 3.4^{*}$ & - & - & - \\
\hline & & FF 30 & & $7.0 \pm 1.7^{*}$ & - & - & - \\
\hline \multirow[t]{2}{*}{$\begin{array}{l}\text { Cardo199933 } \\
\text { Spain (222) }\end{array}$} & Stroke $^{c}$ & 67 & $\begin{array}{l}8.3 \\
(2.6-31.2)^{\mathrm{a}}\end{array}$ & - & $\begin{array}{l}6.7 \\
(2.6-24)^{*}\end{array}$ & - & $\begin{array}{l}9.3 \\
(4.4-31.2)^{*}\end{array}$ \\
\hline & Control & $\begin{array}{l}195 \\
112: 83\end{array}$ & $\begin{array}{l}6.8 \\
(3.7-10.8)^{\mathrm{g} 2}\end{array}$ & - & $\begin{array}{l}5.8 \\
(3.7-8.0)^{* \mathrm{~g}^{3}}\end{array}$ & - & $\begin{array}{l}6.6 \\
(5.1-9.3)^{* 94}\end{array}$ \\
\hline \multirow[t]{5}{*}{$\begin{array}{l}\text { Koch } 1999^{\S h} \\
\text { Germany (111) }\end{array}$} & \multirow[b]{2}{*}{ VT } & 28 (CC) & $\begin{array}{l}5.1 \\
(3.0-6.5)^{*}\end{array}$ & \multirow[b]{2}{*}{-} & \multirow[b]{2}{*}{-} & \multirow[b]{2}{*}{-} & \multirow[b]{2}{*}{-} \\
\hline & & 26 (CT) & $\begin{array}{l}7.6 \\
(4.0-12.0)^{*} \\
14.2 \\
(9.6-27.0)^{*}\end{array}$ & & & & \\
\hline & \multirow{3}{*}{ Control } & $44(\mathrm{CC})$ & $\begin{array}{l}5.5 \\
(4.0-7.2)\end{array}$ & \multirow{3}{*}{-} & \multirow{3}{*}{-} & \multirow{3}{*}{-} & \multirow{3}{*}{-} \\
\hline & & $28(\mathrm{CT})$ & $\begin{array}{l}7.0 \\
(3.9-9.8)\end{array}$ & & & & \\
\hline & & $8(\mathrm{TT})$ & $\begin{array}{l}12.1 \\
(7.7-13.3)\end{array}$ & & & & \\
\hline
\end{tabular}

Abbreviations: M:F= Male:Female, TEB thromboembolism, BF breast fed, $\mathrm{FF}$ formula fed, VT venous thrombosis MTHFR C667T genotype: TT homozygous, CT heterozygous, CC wild type

General sample: children participants in population survey or screening

Control sample: presumably healthy children recruited in hospital setting

${ }^{1}$ Homocysteine expressed in geometric means and ranges

${ }^{2}$ Homocysteine expressed in means \pm SD

${ }^{3}$ Homocysteine expressed in median and range

${ }^{4}$ Geometric means $(95 \% \mathrm{CI})$

${ }^{5}$ geometric means $\pm \mathrm{SE}$

${ }^{6}$ median and interquartile range

*Significantly different values at the $<0.05$ level within same study

${ }^{a}$ Homocysteine values estimated from original article

${ }^{\mathrm{b}}$ Data from non Hispanic whites

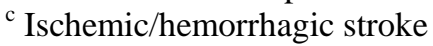




\subsubsection{Indicators of vitamin status}

Folate is taken up only by the developing erythrocyte in the bone marrow but not by the circulating, mature erythrocyte during its 120-day lifespan. Thus, erythrocyte folate concentration (Red Blood Cells [RBC] folate) is an indicator of long-term status (62). Plasma or serum folate levels are the first to decrease in folate deficiency and are therefore more sensitive to short-term fluctuations in folate levels (226).

Serum cobalamin reflects both the vitamin B12 intake and stores. However, the major fraction of serum cobalamin is in a protein-bound form not available for uptake by most cells and may be influenced by changes in the binding protein concentration (227). The metabolite methylmalonic acid (MMA) is a sensitive and specific biomarker of vitamin B12 status (62, 227229). Plasma MMA concentrations are considered the gold-standard indicator of vitamin B12 status (230). Cobalamin deficiency raises MMA levels because methylmalonyl coenzyme-A mutase requires adenosylcobalamin as a cofactor and without cobalamin this coenzyme accumulates and gets degraded to MMA (231). Hotranscobalamin is the physiologically active metabolite of vitamin B12 for all DNA synthesizing cells (62). Given that holotranscobalamin has a short half-life (62), its concentration in plasma or serum is the earliest indicator of vitamin B12 status (232). One recently published study measured holotranscobalamin concentrations in infants (67). No other reports in children were found. Scarce reference values of holotranscobalamin may limit the use of this biomarker in pediatric data.

Plasma pyridoxal-5-phosphate is the biologically active form of vitamin B6 (233, 234). It is also one of the major vitamin B6 forms found in human tissues (63). Circulating levels are considered the single best indicator of long-term vitamin B6 status (63). 


\subsubsection{Reference values: folate, vitamin B12 and vitamin B6}

Reference levels for B vitamins in children 4 to 11 years old are shown in Table 2.2. Folate and vitamin B12 values are derived from the NHANES Survey 1999 - 2004 (235), vitamin B6 levels are data from the British National Diet and Nutrition Survey obtained in 1997 (135), and MMA values are from samples of healthy Dutch children collected during 1997 (218). Reference values presented in the tables of this section correspond to data collected from population surveys or screenings, therefore may or may not relate to vitamin deficiency or a healthy status.

Data from children under 4 years old is limited. Interestingly infants fed human milk have significantly lower serum cobalamin levels and significantly higher tHcy concentrations compared to their formula fed counterparts $(67,225,236)$. For instance, Minet et.al. reported that breast fed babies presented with median serum cobalamin concentrations of 263 pmol/L (95th percentile range 62-703 pmol/L), whereas formula fed babies presented with 456 pmol/L (121$886 \mathrm{pmol} / \mathrm{L}$ ). Mean tHcy concentrations were $10.4 \pm 3.4$ and $7.0 \pm 1.7 \mu \mathrm{mol} / \mathrm{L}$, respectively.

Likely the lower plasma/serum cobalamin levels found in breastfed infants compared to formula fed infants relates to the cobalamin content in human milk and infant formula. Breast milk expressed by women with adequate cobalamin status contains $\sim 0.4 \mu \mathrm{g}$ cobalamin/L (237), whereas most infant formulas may contain over $1 \mu \mathrm{g}$ cobalamin/L (238).

Data from two studies looking at vitamin levels in infants is shown in Table 2.3. The first and second columns correspond to a study conducted in Switzerland published in 2000 (225), the third column corresponds to a Norwegian study published in 2003 (140), The serum holotranscobalamin value corresponds to Norwegian samples collected in 1997 (67). 
Table 2.2 Reference values: RBC and total folate, vitamin B12, MMA and vitamin B6 for children $>1$ year age

\begin{tabular}{|c|c|c|c|c|c|c|c|c|c|c|c|}
\hline \multirow[b]{2}{*}{ Biomarker $^{1}$} & \multirow[b]{2}{*}{$n$} & \multirow{2}{*}{$\begin{array}{l}\text { Median } \\
(95 \% \mathrm{CI})\end{array}$} & \multicolumn{9}{|c|}{ Percentiles } \\
\hline & & & 2.5 & 5 & 10 & 25 & 50 & 75 & 90 & 95 & 97.5 \\
\hline $\begin{array}{l}\text { Serum folate } \\
\mathrm{nmol} / \mathrm{L}\end{array}$ & 4627 & $\begin{array}{l}35.3 \\
(34-37)\end{array}$ & 7.4 & - & - & - & 20 & - & - & - & 61 \\
\hline $\begin{array}{l}\text { RBC folate } \\
\mathrm{nmol} / \mathrm{L}\end{array}$ & 4660 & $\begin{array}{l}580 \\
(560-603)\end{array}$ & 229 & - & - & - & 453 & - & - & - & 874 \\
\hline $\begin{array}{l}\text { Serum vitamin } \\
\text { B12 pmol/L }\end{array}$ & 3594 & $\begin{array}{l}534 \\
(522-552)\end{array}$ & 248 & - & - & - & 527 & - & - & - & 1084 \\
\hline $\begin{array}{l}\text { Plasma MMA } \\
\mu \mathrm{mol} / \mathrm{L}\end{array}$ & 186 & $\begin{array}{l}0.17^{2} \\
(0.07-0.42)\end{array}$ & - & - & 0.11 & 0.13 & 0.17 & 0.23 & 0.30 & - & - \\
\hline $\begin{array}{l}\text { Plasma vitamin } \\
\text { B6 nmol/L }\end{array}$ & 298 & $\begin{array}{l}56.4 \\
(42.3-74.0)^{2}\end{array}$ & - & 31 & - & - & 56.3 & - & - & 106 & - \\
\hline
\end{tabular}

Table 2.3 Reference values: RBC and total folate, vitamin B12, MMA, holotranscobalamin and vitamin $B 6$ levels for infants 0-6 months age

\begin{tabular}{|c|c|c|c|c|}
\hline Biomarker $^{1}$ & $\begin{array}{l}\text { Neonates }^{2} \\
\text { tHcy } \leq 11 \mu \mathrm{mol} / \mathrm{L} \\
\mathrm{n}=104\end{array}$ & $\begin{array}{l}\text { Neonates }^{2} \\
\text { tHcy }>11 \mu \mathrm{mol} / \mathrm{L} \\
\mathrm{n}=19\end{array}$ & $\begin{array}{l}\text { Neonates }^{3} \text { breast } \\
\text { fed } \\
n=173\end{array}$ & $\begin{array}{l}6 \text { months }^{3} \\
n=118\end{array}$ \\
\hline Serum folate $\mathrm{nmol} / \mathrm{L}$ & 36.8 (17.9-123) & $23.8(12.0-99.7)$ & $27.0(20.4-36.3)$ & $31.6(21.3-43.3)$ \\
\hline RBC folate nmol/L & $1376.8 \pm 488.0$ & $1121.4 \pm 408.6$ & $532(438-723)$ & $299(239-384)$ \\
\hline Serum vitamin B12 pmol/L & 323 (91-939) & 136.5 (62-279) & 314 (238-468) & 217 (147-290) \\
\hline Plasma MMA $\mu \mathrm{mol} / \mathrm{L}$ & - & - & $0.29(0.24-0.39)$ & $0.78(0.36-1.51)$ \\
\hline $\begin{array}{l}\text { Serum holotranscobalamin } \\
\mathrm{pmol} / \mathrm{L}(\mathrm{n}=328)\end{array}$ & - & - & - & $(33-238)$ \\
\hline Plasma vitamin B6 nmol/L & $45.5(10.1-202)$ & 26.7 (8.1-113) & - & - \\
\hline
\end{tabular}




\subsubsection{Cutoffs: folate, vitamin B12 and vitamin B6}

The cutoff for a folate level (plasma or serum) indicative of vitamin deficiency is $\leq 6.8$ $\mathrm{nmol} / \mathrm{L}$ (235). Circulating folate levels $\leq 6.8 \mathrm{nmol} / \mathrm{L}$ are concurrent with folate deficient erythropoiesis and anemia in adults (226). Currently there is no agreement on a cutoff for excess folate levels (serum or plasma) (63). In an analysis of NHANES data (1988 - 2004), Pfeiffer et. al. defined "high serum folate" as concentrations $>53.3 \mathrm{nmol} / \mathrm{L}$ based on the 95th percentile for the U.S. population before fortification of food supply with folic acid (235).

Cobalamin deficiency is currently defined as a vitamin B12 concentration $<148 \mathrm{pmol} / \mathrm{L}$ (230). Serum vitamin B12 concentrations < $148 \mathrm{pmol} / \mathrm{L}$ are concurrent with anemia and cognitive impairment in the elderly U.S. population (NHANES 1999-2002) (239). Vegetarian adolescents with a history of macrobiotic diet (vegan type) earlier in childhood and cobalamin concentrations $<229 \mathrm{pmol} / \mathrm{L}$ ranked low in cognitive performance tests (72). No upper limit for vitamin B12 concentration in blood has been set (62). Recently, a plasma MMA concentration $>0.21 \mu \mathrm{mol} / \mathrm{L}$ was proposed for cutoff indicative of vitamin B12 deficiency based on the 95th percentile for vitamin B12 in subjects with normal renal function (NHANES 1999-2000) (240). MMA concentrations $>0.21 \mu \mathrm{mol} / \mathrm{L}$ correlate with high homocysteine concentrations in children (140).

The cutoff for a vitamin B6 (pyridoxal-5-phosphate) indicative of vitamin deficiency is $\leq 20 \mathrm{nmol} / \mathrm{L}$. Circulating plasma pyridoxal-5-phosphate concentrations $>20 \mathrm{nmol} / \mathrm{L}$ are not accompanied by observable health risks and allow a moderate safety margin to protect against the development of signs or symptoms of deficiency (63). No upper limit for vitamin B12 concentration in blood has been set (62). 
The 2005 World Health Organization Expert Consultation set the cutoff values for suboptimal vitamin B12 status in the general population as serum vitamin B12 levels $<150$ $\mathrm{pmol} / \mathrm{L}$ based on the lowest MMA levels and 300 pmol/L based on the lowest tHcy concentrations $(241,242)$. In the same report cutoff values for serum folate status were set as 10 $\mathrm{nmol} / \mathrm{L}$ for serum folate and $340 \mathrm{nmol} / \mathrm{L}$ for red blood cell folate, based on the lowest plasma homocysteine (241, 242). 


\section{CHAPTER 3 THE EFFECT OF NITROUS OXIDE EXPOSURE DURING SURGERY ON THE HOMOCYSTEINE CONCENTRATIONS OF CHILDREN}

\subsection{INTRODUCTION}

\subsubsection{Rationale}

It has been known for some time that exposure to nitrous oxide increases homocysteine concentrations in adults (1-9). However, recently the increase observed in adults during routine anesthesia has been shown to be associated with a number of negative health concerns. Homocysteine is an intermediary metabolite in the metabolism of sulfur-containing amino acids. It is produced by de-methylation of methionine and is a substrate for synthesis of cystathionine and then cysteine (10). Under normal conditions, homocysteine is re-methylated back to methionine by the enzyme methionine synthetase, which requires the reduced form of vitamin B12 as a coenzyme and 5-methyltetrahydrofolate as the methyl donor (23). Nitrous oxide oxidizes vitamin B12 thereby inactivating methionine synthase $(160,161)$, which results in accumulation of homocysteine in blood (8).

Recent data from adult studies provide evidence that postoperative tHcy concentrations $\geq 13.5$ $\mu \mathrm{mol} / \mathrm{L}$ are an independent risk factor for myocardial infarction and stroke in the postsurgical period (3) and a post-surgical tHcy concentration $>17 \mu \mathrm{mol} / \mathrm{L}$ increases the risk of myocardial ischemia twofold (6). Furthermore, post-surgical elevation of homocysteine concentration (14.1_ $5.7 \mu \mathrm{mol} / \mathrm{L}$ ) induced by exposure to nitrous oxide have been shown to be associated with impaired endothelial function (4). In healthy adults, acute hyperhomocysteinemia ( $\geq 25 \mu \mathrm{mol} / \mathrm{L})$ induced by an oral methionine load has been shown to reduce the vasodilatation of blood vessels 
(189-191). These observations in healthy, non-surgical adults suggest that elevated homocysteine concentrations may be directly responsible for adverse vascular clinical outcomes in postsurgical patients exposed to nitrous oxide. In one study in adults, supplementation of with folic acid, vitamin B12 and vitamin B6 prior to surgery prevented the rise in postoperative homocysteine concentrations induced by nitrous oxide anesthesia (5).

Nutritional and genetic factors may mediate the relationship between exposure to nitrous oxide and homocysteine concentration. Folate, vitamin B12 and vitamin B6 status are main determinants of homocysteine concentration on a population level (15). Synthesis of 5methyltetrahydrofolate is regulated by the enzyme MTHFR (23); the common single nucleotide polymorphism MTHFR C677T yields an enzyme of reduced activity $(100,101)$. The genotype for MTHFR C677T has been considered by some as the most important genetic determinant of homocysteine concentration in the blood (110).

Nitrous oxide is routinely used in pediatric anesthesia practice (162). Despite the increased risk of postoperative adverse events associated with hyperhomocysteinemia in adults, to date no pediatric data are available to estimate the effect of nitrous oxide on the homocysteine concentrations in children. To evaluate if children exposed to nitrous oxide are at risk of developing an acute increase in homocysteine and if their preoperative vitamin status may mediate this relationship, I have addressed the following research questions.

\subsubsection{Research questions}

1. What is the effect of a prolonged exposure to nitrous oxide on the total homocysteine concentration in pediatric patients? 
2. Do blood levels of folate, vitamin B12 and vitamin B6 prior to nitrous oxide anesthesia impact the postanesthesia homocysteine levels in children?

3. Do the MTHFR C677T polymorphisms impact post-anesthesia homocysteine concentrations?

\subsubsection{Objectives}

1. To determine whether and to what extent homocysteine increases after nitrous oxide exposure in pediatric patients.

2. To determine the effect of pre-anesthesia vitamins B12, B6 and folate levels on the homocysteine concentrations after nitrous oxide exposure.

3. To determine whether the genotype for the MTHFR C677T impacts post-exposure homocysteine concentrations.

\subsection{SUBJECTS AND METHODS}

\subsubsection{Subjects}

Children were recruited from preoperative clinics in the Plastics Surgery Division at The Hospital for Sick Children from February to July 2009. To be eligible for the study, children needed to weigh $\geq 3 \mathrm{~kg}$, be under 11 years of age and scheduled for surgery expected to last 2 hours or more using nitrous oxide at an inspired concentration of 50 to $70 \%$. Children were not eligible if they were over 11 years of age, as puberty is known to produce sex differences in homocysteine concentration (139). Children exposed to nitrous oxide 30 days prior to surgery were also excluded as were those diagnosed with active disease and/or using medication(s) 
known to affect homocysteine concentration (e.g. kidney disease, methotrexate treatment). Patients who required a blood transfusion during surgery or prior to collection of the postexposure blood sample were excluded. Free amino acids present in parenteral nutrition solutions (e.g. methionine) are strong affecters of homocysteine concentration (243), therefore parenterally fed children were excluded.

The study protocol, consent forms and data collection forms were approved by The Human Research Ethics Committee at The Hospital for Sick Children. Permission was obtained from the Plastics Surgery Division Director as well as attending physicians before enrolment began. Written informed consent was obtained from parent(s) of children during preoperative clinic visits and assent was obtained from children 7 years and older (see Study Consent Forms on Appendix A).

\subsubsection{Study design}

We designed the present study with each subject serving as their own control. A blood sample was obtained immediately after induction of anesthesia (preoperative or pre-exposure sample) and a second specimen was collected 12 to 24 hours thereafter (postoperative or postexposure sample). Total homocysteine concentrations in plasma were determined from the preoperative and post-exposure blood samples. Biomarkers of folate, vitamin B12 and vitamin B6, which are important cofactors in homocysteine metabolism, were measured in blood collected preoperatively. Biomarkers included: total plasma folate, serum vitamin B12 and

plasma MMA for cobalamin status and plasma pyridoxal-5-phosphate for vitamin B6 status (63, 241). In addition, a whole blood sample was obtained for MTHFR C677T genotyping. 


\subsubsection{Collection and analyses}

\subsubsection{Sample collection and laboratory analyses}

All blood samples were obtained while the child was in the supine position to avoid position related variations in tHcy (244). Fasting conditions for the pre-exposure blood sample were: $\geq 8$ hours since the last ingestion of solid foods $\geq 6$ hours from the last ingestion of formula milk, $\geq 4$ hours from the last ingestion of breast milk and $\geq 2$ hours from the last ingestion of clear fluids. For ethical reasons, children were not fasted prior to collection of the post-exposure blood sample. Given the age and size of the children, a limited volume of blood could be drawn. In the event that there was insufficient plasma or serum to perform all planned biochemical analyses, they were prioritized as follows: (1) plasma total homocysteine, (2) plasma folate, (3) plasma MMA, (4) serum vitamin B12, (5) MTHFR C677T genotype, (6) plasma vitamin B6. EDTAtreated tubes were used to collect whole blood samples for genotyping of the MTHFR C677T polymorphisms as well as for all vitamin determinations in plasma except vitamin B12. Blood samples for determination of vitamin B12 in serum were collected in SST-treated tubes. All blood samples were cooled and kept on ice until they were centrifuged $\left(1241 \mathrm{~g}, 4^{\circ} \mathrm{C}, 15\right.$ minutes), within 30 minutes after being drawn. All plasma and serum aliquots were stored at $80^{\circ} \mathrm{C}$ and thawed until analyses within 1 to 8 months of being collected. With the exception of plasma folate, all study blood samples were analyzed in a single run for each study analyte.

Determination of total homocysteine concentration was carried out as described by Rafii et at (19). Briefly, 20 $\mu$ l aliquots of the study samples/quality controls/calibrators were mixed with $20 \mu \mathrm{l}$ of $10 \mu \mathrm{M}$ DL- $\left[{ }^{2} \mathrm{H}_{8}\right]$ Hcy-Hcy (98\%) internal standard. Disulfide bonds were reduced by addition of 40 $\mu$ l of 500mM DL-dithiothreitol (Sigma-Aldrich Canada, Oakville, ON, Canada). Then $320 \mu \mathrm{l}$ of a 5:3 mixture of $0.1 \%$ formic acid and $0.025 \%$ trifluoroacetic acid in 
water/methanol (5:3) was added and samples were centrifuged to precipitate proteins. The clear supernatant was transferred to autosampler vials. Finally, tHcy concentrations were measured by liquid chromatography-electrospray tandem mass spectrometry (LC/MS/MS), API-4000 (Applied Biosystems/MDS Sciex, Foster City, CA, USA). Calibrators were prepared by spiking pooled human plasma with known amounts of DL-Homocystine (Sigma Chemical, St. Louis, MO, USA). The Internal Standard consisted of a $10 \mu \mathrm{M} \mathrm{d}_{8}-\mathrm{Hcy}-\mathrm{Hcy}$ solution (DL- $\left[{ }^{2} \mathrm{H}_{8}\right] \mathrm{Hcy}-\mathrm{Hcy}$ [98\%], Cambridge Isotope Laboratories, Mississauga, ON, Canada). Quality controls of Lhomocysteine in human serum were analyzed in triplicates and purchased from Abbott Laboratories (Abbott Park, IL, USA). Manufacturer specified amounts were 7, 12.5 and 25 $\mu \mathrm{mol} / \mathrm{L}$ for the low, medium and high quality controls. The intra-assay coefficient of variation (CV) for the LC-MS/MS method ranged from 3\% - 6\%. We obtained a value $6.5 \pm 0.3,11.2 \pm$ 0.8 and $21.8 \pm 1.0 \mu \mathrm{mol} / \mathrm{L}$ for the low, medium and high to quality controls respectively.

Total plasma folate concentrations were determined by a microbiological assay as described by Molloy and Scott et al., (20) by using the test organism Lactobacillus rhamnosus (ATCC 7649; American Type Tissue Culture Collection, Manassas, VA, USA) (245). The accuracy of the assays was assessed by using a whole-blood standard control with a certified value (29.5 nmol/L) (Whole Blood 95/528; National Institute of Biological Standards and Control, Hertfordshire, United Kingdom). Quality control analysis in our laboratory yielded a folate content of $30.4 \pm 2.1$.

Serum vitamin B12 was analyzed in the Core laboratory facility at The Hospital for Sick Children by solid phase competitive chemiluminescent enzyme immunoassay involving an automated alkaline denaturation procedure. Serum samples were treated using the IMMULITE $^{\circledR}$ 2500 Vitamin B12 kit and levels were measured in IMMULITE $^{\circledR} 2500$ Analyzer equipment 
(Diagnostics Products Corporation, Los Angeles, CA, USA). Quality control solutions target three levels of concentrations: low 164 pmol/L, medium 295 pmol/L, and high 522 pmol/L. The measured concentrations for quality control solutions were $173 \pm 19,284 \pm 27$ and $580 \pm 51$ nmol/L for the low, medium and high values, respectively

The concentrations of MMA in plasma was measured at The Toronto Medical Laboratories of the Toronto General Hospital by chemical ionization gas chromatography mass spectrometry according to the method described by Yazdanpanah and collaborators (21). Quality control solutions for low, medium and high concentrations target $0.16,0.32$ and $0.96 \mu \mathrm{mol} / \mathrm{L}$, respectively. Obtained values for low, medium and high concentration solutions were $0.16 \pm$ $0.02,0.35 \pm 0.02$ and $0.99 \pm 0.10 \mu \mathrm{mol} / \mathrm{L}$, respectively.

Vitamin B6 (pyridoxal-5-phosphate) levels in plasma were measured in the core laboratory at The Hospital for Sick Children by HPLC with on-line derivatization and fluorescence detection based on the method by Rybak et.al (246). The quality control solutions used targeted concentrations of 25, 72, and $240 \mathrm{nmol} / \mathrm{L}$. The measured concentrations for quality control solutions were $24 \pm 1.4,71 \pm 2.8$ and $238 \pm 1.5 \mathrm{nmol} / \mathrm{L}$ for the low medium and high values, respectively.

DNA extraction was carried out from whole blood samples using the MasterPure ${ }^{\mathrm{TM}}$ DNA Purification Kit for Blood Version II (EPICENTRE ${ }^{\circledR}$ Biotechnologies, Madison, WI, USA) based on the method described by Miller et al. (247). Genotyping of the MTHFR C677T polymorphisms (CC, CT, TT) was determined by allele-specific real time polymerase chain reaction as described by Eny and Wolever et al. (22), using the TaqMan ${ }^{\circledR}$ SNP Genotyping Assay for MTHFR (Applied Biosystems, Foster City, CA, USA). 


\subsubsection{Analysis and collection of data}

Data on ethnic background and intake of vitamins supplements were obtained by interviewing a parent or guardian. Information on food consumption prior to the collection of the post-exposure blood sample was obtained from an interview with the attending nurse practitioner, parent(s) or guardian(s). Fasted vs. fed status and time of last ingestion of food/liquids were recorded. The following data were collected from review of the medical records: age, sex, relevant medical history, weight, current diagnosis, type of surgery, fasting conditions prior to surgery, intraoperative medications, nitrous oxide exposure time, inspiratory nitrous oxide concentration, total duration of anesthesia, intraoperative fluid administration as well as total length of hospitalization.

Nutrient composition of food consumed prior to collection of the postoperative blood sample was analyzed using The Food Processor SQL Edition version 10.2, analysis software for Windows 2003 (ESHA Research, Salem, OR, USA.)

\subsubsection{Statistical analyses}

The sample size was calculated to be able to detect a 0.55 SD change in tHcy concentration prior to and after exposure to nitrous oxide exposure with $80 \%$ power at an alpha level of 0.05. A thorough review of the adult literature pertaining to the use of nitrous oxide during anesthesia and homocysteine, suggested that normally a 0.55 SD increase in tHcy concentration is observed (1-9). We estimated a final sample size of 28 children.

Tests of normality were conducted for all continuous variables and calculated residuals. The difference between pre-to-postoperative tHcy concentrations ( $\mu \mathrm{mol} / \mathrm{L}$ ) was the primary 
outcome variable for the study. Other main outcomes were the initial and post-exposure tHcy concentrations $(\mu \mathrm{mol} / \mathrm{L})$. The difference between (1) preoperative and (2) post-exposure tHcy concentrations were determined using Wilcoxon’s Signed Rank test, given that these variables were positively-skewed and could not be transformed to yield a normal distribution. T-test or Wilcoxon summed rank test (for non-parametric data) were used to compare pre-exposure tHcy concentrations of subjects stratified by sex, supplement users versus non users, MTHFR C677T genotype (homozygous+heterozygous, wild type) and to compare the difference between pre-topostoperative tHcy concentrations in subjects exposed to $>3.5$ hours of nitrous oxide. One-way ANOVA and post-hoc Tukey test were conducted to determine preoperative homocysteine difference in subjects stratified by type of diet consumed.

Spearman correlations were used in order to ascertain correlations between expected predictor variables (circulating folate, vitamin B12, vitamin B6 and MMA concentrations, MTHFR C677T genotype and initial tHcy concentration). Then, univariate linear regression analyses were performed to measure the strength of the relationship between the main outcome variables: (1) difference between pre-to-postoperative tHcy concentrations (2) preoperative tHcy concentration and the variables showing a significant correlation with the aforementioned main outcome variables. Expected predictor variables tested in the univariate analyses were selected for inclusion in multivariate analyses if the $P$ value was $<0.05$ and if the combined $r^{2}$ value for the model increased after introduction of the variable. Predictor variables satisfying the aforementioned criteria were excluded from multivariate analyses if associated with other included variable. The General Linear Model (GLM) was used to conduct multivariate regression analyses and analysis of covariance. The dependent variables were (1) the difference in pre-to-postoperative and (2) initial tHcy concentrations. The independent variables were 
duration of exposure, initial tHcy concentrations and vitamin B12 status (low: $\leq 50$ th vs. high: >50th percentiles).

We conducted post-hoc analyses in order to determine the sample size requirement to confidently detect a significant difference in pre-to-postoperative tHcy based on folate and vitamin B6 status (low: $\leq 50$ th vs. high: $>$ 50th percentiles).

Parametric data are reported as mean_-SD and non-parametric data as median (1st, 3rd quartiles). All statistical analyses were performed with SAS software (version 9.1; SAS Institute Inc., Cary, NC, USA). All analyses conducted were 2-tailed and a $P$-value $<0.05$ was considered significant.

\subsection{RESULTS}

\subsubsection{Participation}

As shown in Figure 3.3.1, 52 pediatric patients and their families were approached about the study; informed consent was obtained from 40 subjects. Reasons for refusal to participate were: not interested in research $(n=9)$, concern about additional blood loss $(n=2)$, and unable to understand research consents in English ( $n=1)$. Preoperative blood samples were collected from 34 children. There were a total of 8 withdrawals from the 40 consented subjects. Reasons for withdrawal included the child did not receive nitrous oxide anesthesia as planned $(n=3)$, because we reached the entire sample size requirement prior to a child's surgery being scheduled $(n=2)$, unable to collect postoperative blood sample $(n=2)$ and voluntary withdrawal $(n=1)$. 
Figure 3.3.1 Participation flow chart

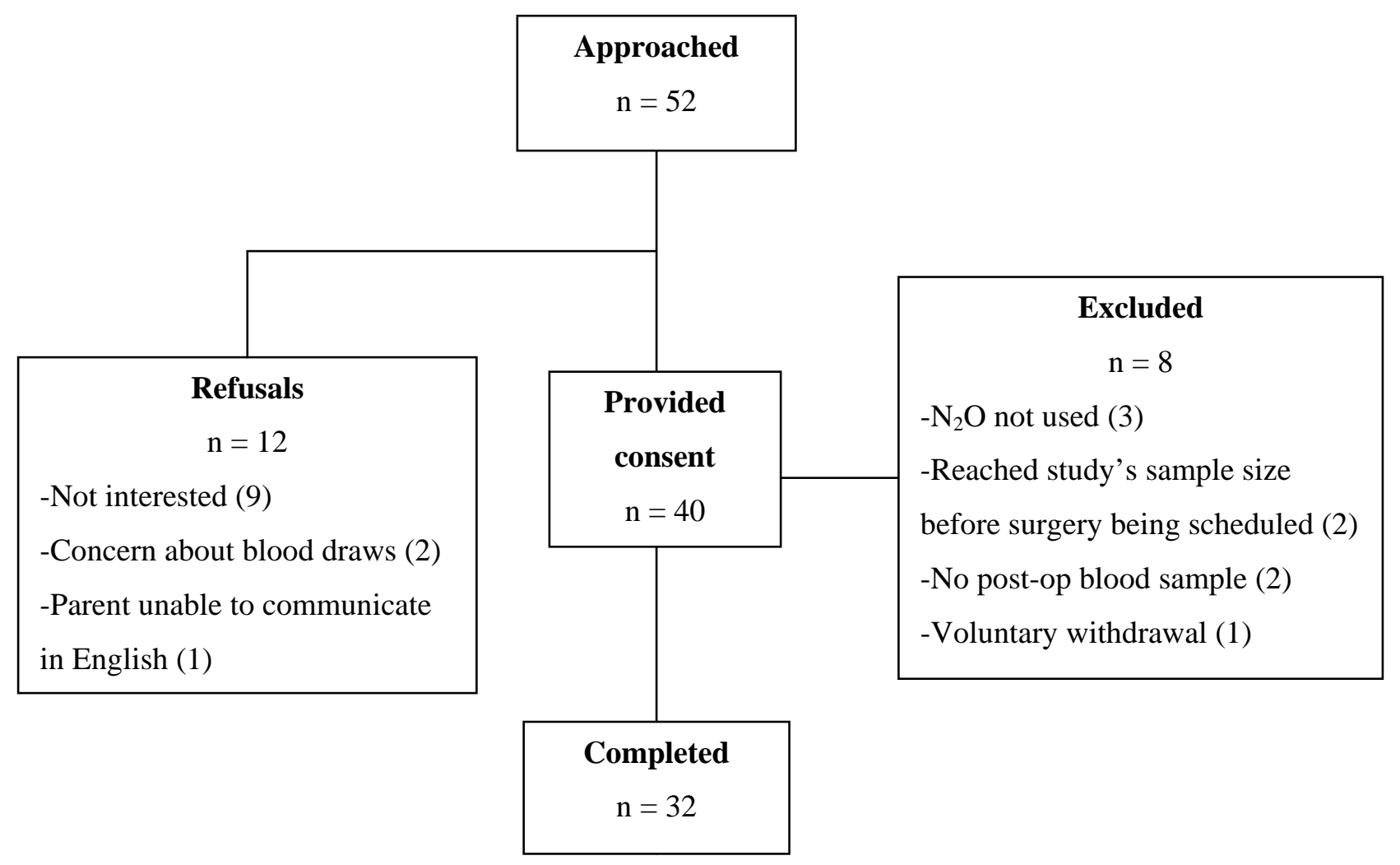

\subsubsection{Participant characteristics}

A total of 32 children completed the study. Subject and intraoperative characteristics are shown in Table 3.3.1. The sample consisted of 18 infants ( $\leq 12$ months), 4 toddlers (13 to 24 months) and 10 children (>2 to 10 years of age). Twenty-two of 32 were Caucasian, 4 children were of South Asian descent and the remaining 6 children belonged to various other ethnic backgrounds. Overall, the children were considered healthy; twenty-nine of 32 children were schedule for surgery to repair a birth defect or injury that did not compromise any major organ 
function. The remaining three subjects had a history of severe systemic disease that had resolved $>2$ years prior to participation in the study. The median length of total hospitalization as a result of surgery was 35.4 hrs. (1st, 3rd quartile: 29.0, 54.5 hrs). The inspired nitrous oxide concentration varied from surgery to surgery from 50 to $70 \%$ in the anesthetic gas mixture.

Fourteen babies consumed all their milk feeds as commercially prepared infant formula and 9 had been introduced to solids. Four babies consumed all their milk feeds as human milk and 1 had been introduced to solids. Twelve children (>12 months) consumed a mixed diet. Seven of 30 children consumed a vitamin supplement a mean of $4.8 \pm 2.2$ times a week.

Remaining children did not have a history of vitamin or mineral supplement use. Of these seven children using supplements, 4 consumed vitamin D drops exclusively (all $\leq 14$ months of age) and three consumed multi-vitamin supplements containing folic acid (260 or $400 \mu \mathrm{g}$ ), vitamin B12 (6 $\mu \mathrm{g})$ and B6 (2 mg). 


\section{Table 3.3.1 Subjects characteristics and intraoperative data}

\begin{tabular}{|c|c|c|}
\hline Characteristic & & $\begin{array}{l}\mathrm{n}(\%) \text { or } \\
\text { median (1st, 3rd quartile) }\end{array}$ \\
\hline Male sex & & $18(56.2)$ \\
\hline Age in months & & $11.0(5.0-40.5)$ \\
\hline Weight in kilograms & & $9.2(7.1-15.5)$ \\
\hline \multirow[t]{3}{*}{ MTHFR C677T genotype $^{1}$} & CC & $15(48.4)$ \\
\hline & $\mathrm{CT}$ & $14(45.2)$ \\
\hline & $\mathrm{TT}$ & $2(6.4)$ \\
\hline \multirow[t]{3}{*}{ ASA physical status } & I & $18(56.3)$ \\
\hline & II & $13(40.6)$ \\
\hline & III & $1(3.1)$ \\
\hline \multirow[t]{5}{*}{ Surgery } & Oral cleft repair & $17(53.1)$ \\
\hline & Speech repair & $3(9.4)$ \\
\hline & Brachial plexus repair & $3(9.4)$ \\
\hline & Facial correction & $4(12.5)$ \\
\hline & Other & $5(15.6)$ \\
\hline \multirow[t]{3}{*}{$\operatorname{Diet}^{2}$} & Formula fed & $14(46.7)$ \\
\hline & Human milk fed & $4(13.3)$ \\
\hline & Mixed diet & $12(40)$ \\
\hline \multirow[t]{3}{*}{ Vitamins supplementation ${ }^{2}$} & Vitamin D drops & $4(13)$ \\
\hline & $\begin{array}{l}\text { Multivitamin with B12, B6 } \\
\text { and folic acid }\end{array}$ & $3(10)$ \\
\hline & Non-consumers & $23(77)$ \\
\hline
\end{tabular}

MTHFR = methylene tetrahydrofolate reductase. ASA =American Society of Anesthesiologist physical status= I healthy, II mild systemic disease, III severe systemic disease. Values in table are based on sample of 32 subjects unless otherwise stated. ${ }^{1} \mathrm{n}(\%)$ calculated on data for 31 subjects. ${ }^{2} \mathrm{n}(\%)$ calculated on data for 30 subjects. 
Biomarkers of folate, vitamin B12 and vitamin B6 status are presented in Table 3.3.2. Determinations of plasma total homocysteine and folate concentrations were possible for all 32 participants of the study. We had sufficient volume of blood to obtain preanesthesia measurements of vitamin B12 and MMA for 27 children whereas vitamin B6 levels were measured in 13 participants. All children had folate levels above cutoff values indicative of deficiency (6.8 nmol/L) (235). One child presented with a vitamin B6 level $18 \mathrm{nmol} / \mathrm{L}$, the remaining children had levels above the cutoff indicative of deficiency (20 nmol/L) (63). All 27 children where sufficient serum was available to measure vitamin B12 had levels above the cutoff for marginal B12 status ( $<221 \mathrm{pmol} / \mathrm{L}$ ) (230). In total five of the 27 children, where MMA measurement was possible had an MMA concentration indicative of vitamin B12 deficiency ( $>0.21 \mu \mathrm{mol} / \mathrm{L})(240)$. Seven children had initial tHcy concentrations above the cutoff for chronic tHcy concentrations in children ( $\geq 8 \mu \mathrm{mol} / \mathrm{L})(105)$. Three of the 5 children with an MMA concentration $>0.21 \mu \mathrm{mol} / \mathrm{L}$ (indicative of vitamin B12 deficiency) presented with an initial tHcy concentration $\geq 8 \mu \mathrm{mol} / \mathrm{L}$. Hematocrit measurement was possible for all children. Twelve children presented with hematocrit level below the level of adequacy $(\geq 0.33,1 / 1$ proportion) (248).

For ethical reasons the study protocol did not require that subjects fast prior to collection of the postoperative blood sample. A detailed food record was obtained for a total of 24 subjects. Two of the 24 subjects did not consume food prior to collection of the postoperative blood sample. Data on energy and nutrient composition corresponding to subjects', food intake before the post-exposure sample collected are summarized in Table 3.3.3. 


\section{Table 3.3.2 Pre-exposure biomarkers values}

\begin{tabular}{llll}
\hline Biomarker & $\mathrm{n}(\%)^{1}$ & Median $(1 \mathrm{st}, 3$ rd quartile) & Cut-off $^{2}$ \\
\hline Plasma tHcy $(\mu \mathrm{mol} / \mathrm{L})$ & $32(100)$ & $5.1(4.1,6.4)$ & $\geq 8.0$ \\
Plasma folate $(\mathrm{nmol} / \mathrm{L})$ & $32(100)$ & $76.6(54.5,99.0)$ & $<6.8$ \\
Serum vitamin B12 (pmol/L) & $27(84)$ & $638(457,737)$ & $<221$ \\
Plasma MMA $(\mu \mathrm{mol} / \mathrm{L})$ & $27(84)$ & $0.10(0.07,0.15)$ & $>0.21$ \\
Plasma vitamin B6 (nmol/L) & $15(40.6)$ & $92(75,133)$ & $<20$ \\
Hemoglobin $(\mathrm{g} / \mathrm{L})$ & $21(65.6)$ & $112(107,120)$ & $<110$ \\
Hematocrit $(1 / 1)$ & $32(100)$ & $0.34(0.32,0.36)$ & $<0.33$ \\
\hline
\end{tabular}

${ }^{1} \mathrm{n}(\%)$ of data obtained per biomarker with respect to total sample size $(\mathrm{n}=32) .{ }^{2}$ Cut-off values from references: homocysteine (105), folate (235), vitamin B12 (230), MMA (240), vitamin B6 (63), hemoglobin and hematocrit (248). Abbreviations: tHcy total homocysteine, MMA methylmalonic acid. Vitamin B6 was measured as plasma pyridoxal-5-phosphate.

\section{Table 3.3.3 Energy and nutrient composition of food consumed prior to collection of postoperative sample}

\begin{tabular}{lc}
\hline Energy / Nutrient & Median (1st, 3rd quartile) \\
\hline Energy (kcal/kg weight) & $14.4(9.1,19.6)$ \\
Proteins (grams/kg weight) & $0.26(0.2,0.5)$ \\
Carbohydrates (grams/kg weight) & $1.73(1.1,2.7)$ \\
Fat (grams/kg weight) & $0.6(0.2,0.9)$ \\
\hline
\end{tabular}

Values correspond to 24 subjects 


\subsubsection{Effect of nitrous oxide exposure}

Change in pre-to-postoperative tHcy concentrations

There was a $25 \%$ increase in the median postoperative tHcy concentration from the preexposure concentration $(6.4[4.7,8.9]$ vs. 5.1[4.1, 6.4] $\mu \mathrm{mol} / \mathrm{L}, P<0.01)$ (Figure 3.3.2). The rise in tHcy concentration observed from pre-to-postanesthesia remained statistically significant after removal of three outliers (5.2 \pm 1.5 vs. $6.7 \pm 2.8 \mu \mathrm{mol} / \mathrm{L}$, respectively; $P<0.0003)$. Two of these outliers were exposed to nitrous oxide for more than 700 minutes. The third outlier presented with a preoperative MMA concentration $(0.88 \mu \mathrm{mol} / \mathrm{L})$, indicative of vitamin B12 deficiency.

Figure 3.3.2 Comparison between pre and post-exposure total homocysteine (tHcy) concentrations

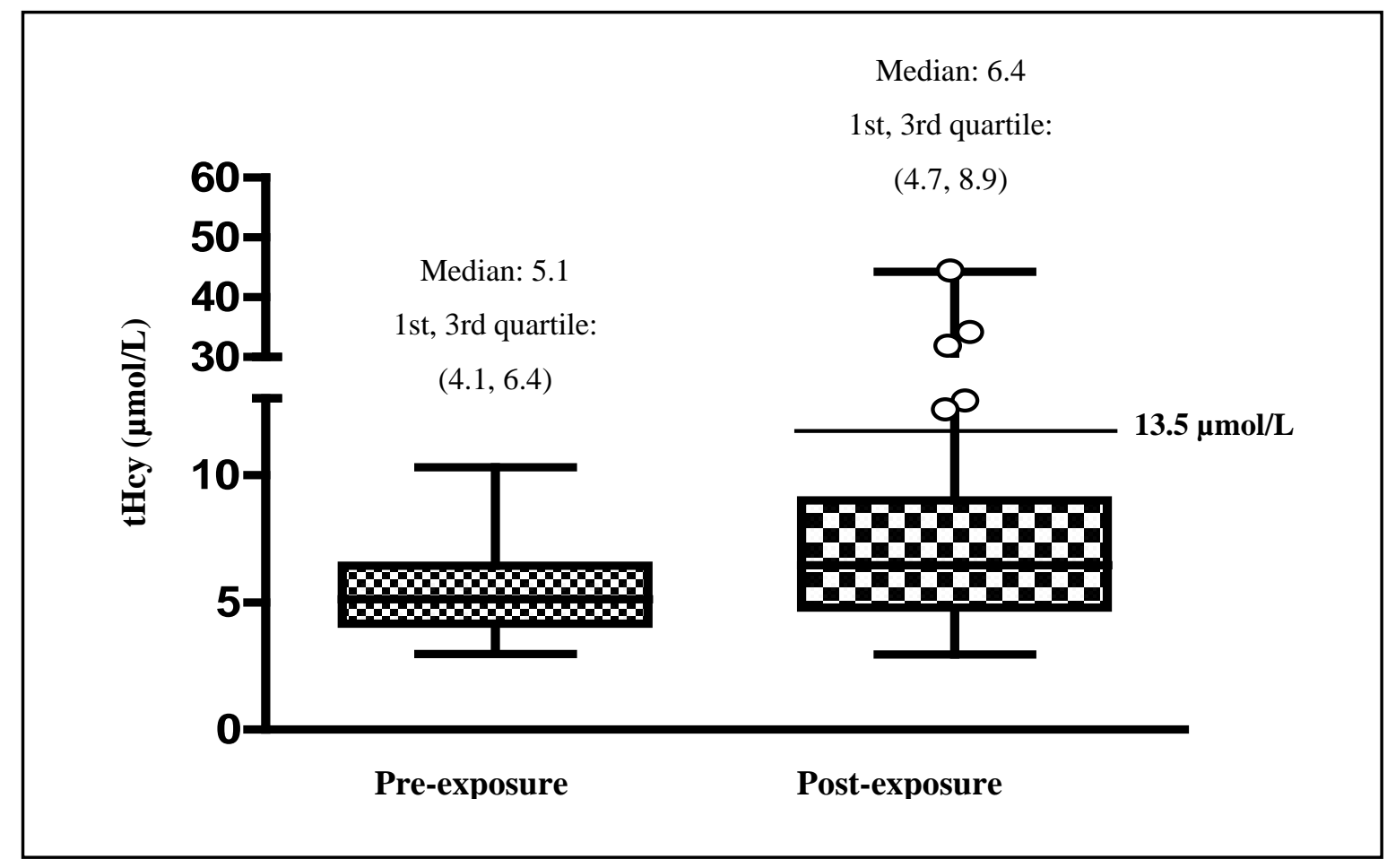

The difference between pre to postoperative tHcy concentrations was statistically significant $(P<0.01)$ Open circles denote tHcy concentration above the level associated with increased risk of postoperative complications $(13.5 \mu \mathrm{mol} / \mathrm{L})$ in adult patients (3) 
Exposure to nitrous oxide

Nitrous oxide was used at a mean of $60 \pm 6.4 \%$ concentration in the inhaled gas mixture. The inhaled concentration of nitrous oxide was not associated with any study variable. The median time of exposure to nitrous oxide was 180 minutes (142.0 - 217.5 minutes). The duration of exposure to nitrous oxide was highly correlated with the difference between preoperative and post-exposure tHcy concentration (Spearman $\mathrm{r}=0.592, P=0.0004$ ) (Figure 3.3.3). For instance, the highest postoperative increase ( $34 \mu \mathrm{mol} / \mathrm{L}$ ) corresponded to a child exposed to 895 minutes of nitrous oxide during surgery. Nine children were exposed to $>3.5$ hours of nitrous oxide (median 246 [225, 667] minutes) and experienced an approximately 80\% increase from preoperative to postoperative tHcy concentrations (median 4.1 [4.0, 6.1] vs. 7.5 [4.7, 19.3] $\mu \mathrm{mol} / \mathrm{L}$, respectively $)(P=0.0078)$.

Figure 3.3.3 Correlation between pre-to-post difference in total homocysteine (tHcy) concentrations and duration of exposure to nitrous oxide anesthesia

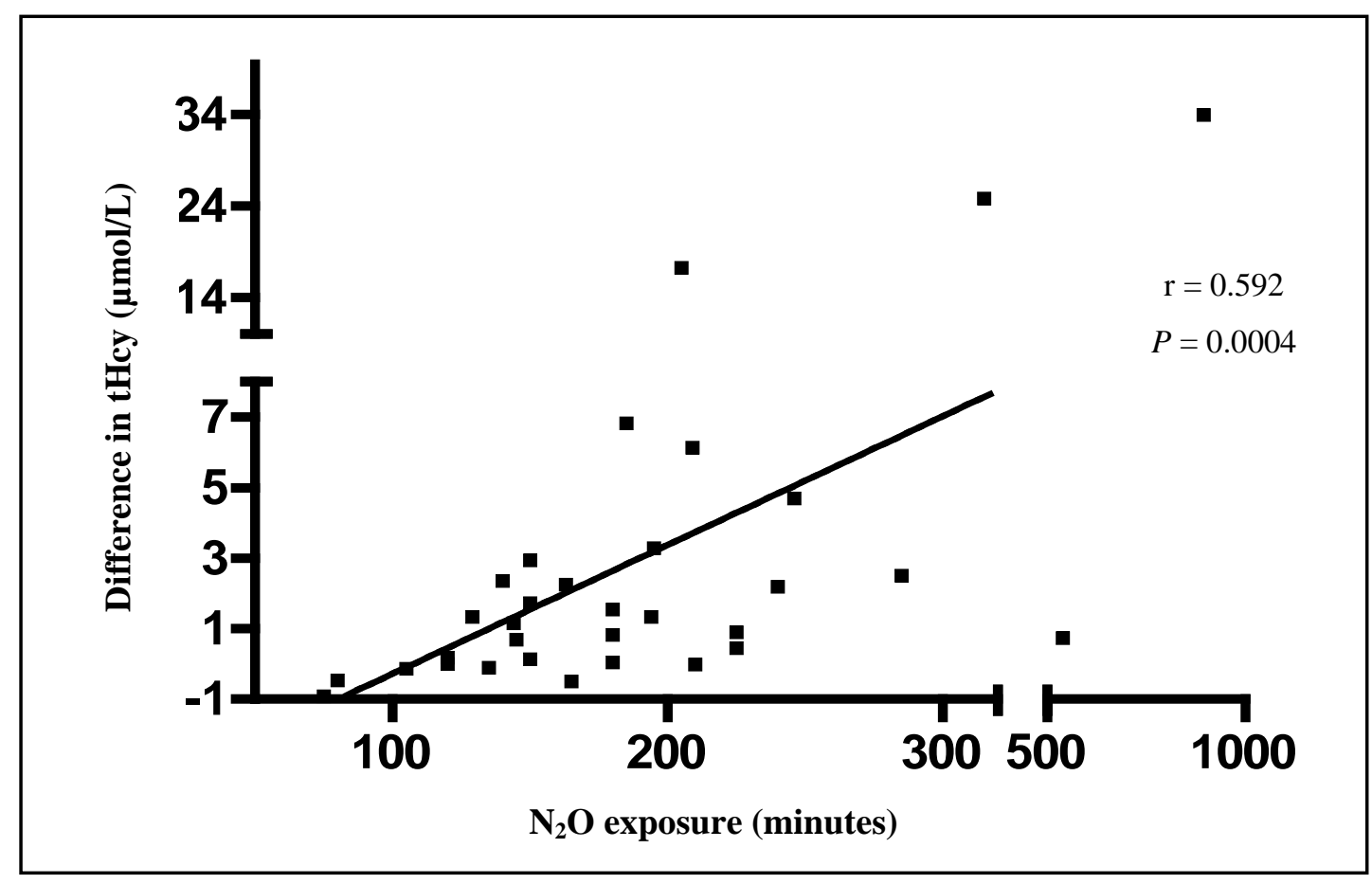


Time elapsed between collection of preoperative and postoperative blood samples

The mean time elapsed between collection of blood samples was $23.8 \pm 2.9$ hours and was correlated with duration of exposure to nitrous oxide (Spearman $r=0.660, P=<0.0001$ ) as well as with the increase in tHcy concentrations (Spearman $r=0.449, P=0.009$ ). The median time elapsed between the end of exposure to nitrous oxide (end of surgery) and collection of the postoperative blood sample was 21 hours (18, 22 hours) and was not associated with the difference between pre-to-postoperative homocysteine concentrations.

\section{Initial tHcy concentrations}

There was a positive correlation between preoperative tHcy concentration and the pre-topostoperative difference in tHcy concentrations (Spearman $r=0.407, P=0.020$ ) (Figure 3.3.4).

Figure 3.3.4 Correlation between pre-to-post difference in total homocysteine (tHcy) concentrations and pre-exposure tHcy concentrations.

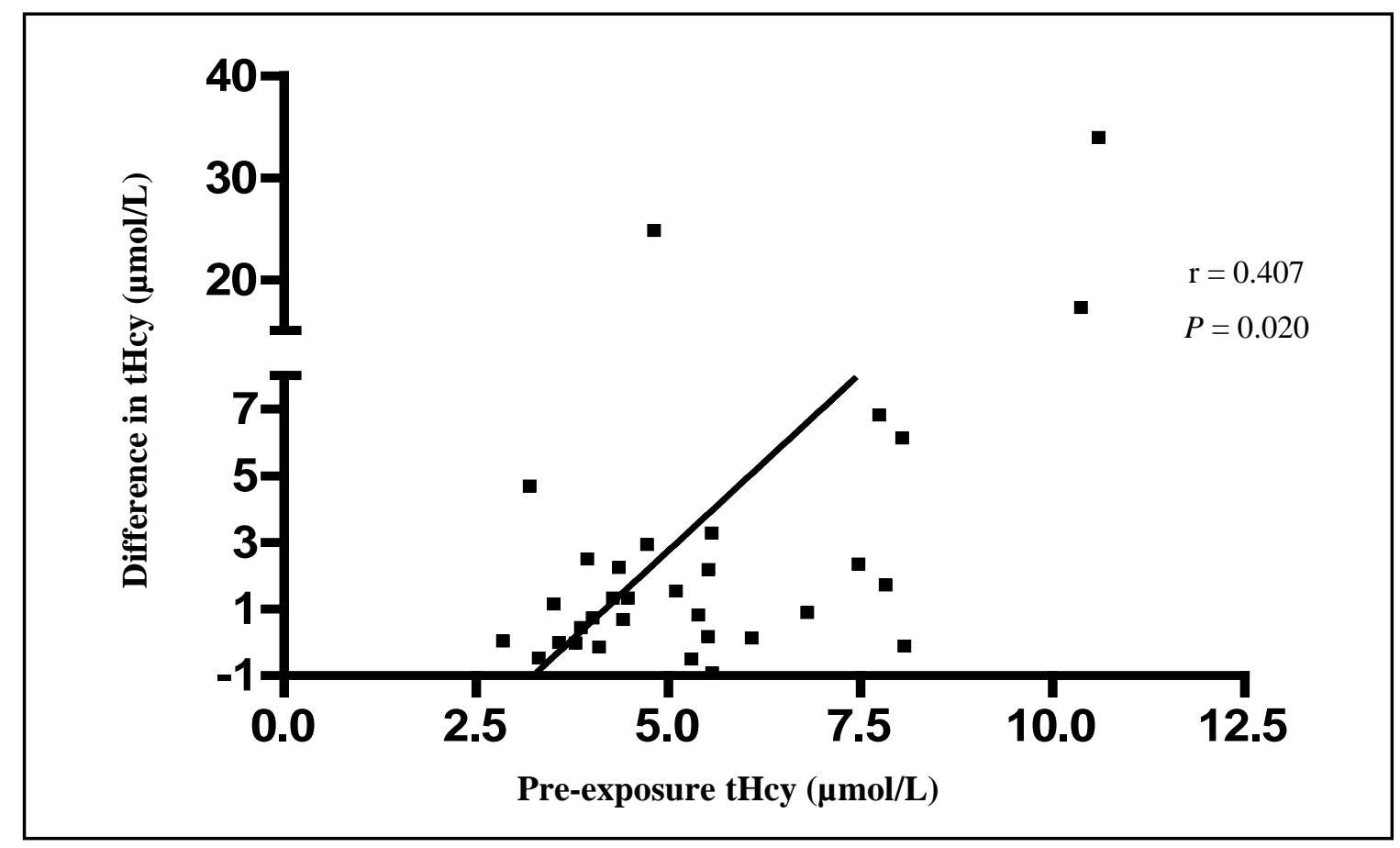


MTHFR C677T genotype, age and sex

There was no difference in mean preoperative homocysteine concentration between carriers of the $T$ allele C677T ( $5.3 \pm 1.5 \mu \mathrm{mol} / \mathrm{L})$ versus children who were CC homozygous (5.9 $\pm 2.2 \mu \mathrm{mol} / \mathrm{L})(P=0.332)$. Likewise there was no association between MTHFR C677T genotype and postoperative tHcy $\left(r^{2}=0.032, P=0.332\right)$. Subjects' age and weight were not associated with the preoperative, postoperative or change in pre-to-postoperative tHcy concentrations. There was a trend toward higher preoperative tHcy concentrations among males versus females (5.5 [4.6, 7.7] vs. 4.3 [3.9, 5.6] $\mu \mathrm{mol} / \mathrm{L}$, respectively; $P=0.060$ ). However, there was no effect of sex on the change in postoperative tHcy concentration.

Biomarkers of folate, vitamin B12 and vitamin B6

Plasma folate and vitamin B6 were not associated with preoperative or postoperative tHcy concentrations. There was a significant inverse correlation between vitamin B12 levels and initial homocysteine concentrations (Spearman $\mathrm{r}=-0.466, P=0.014$ ) (Figure 3.3.5). Although as a continuous variable MMA levels were not correlated with any outcome variable. Subjects with a MMA status indicative of vitamin B12 deficiency (defined as $\geq 0.21 \mu \mathrm{mol} / \mathrm{L}$ ) had significantly higher initial tHcy concentrations $(7.0 \pm 1.9$ vs. $5.3 \pm 1.7 \mu \mathrm{mol} / \mathrm{L}, P=0.0204)$ than children with MMA concentrations in the normal range. There were 5 subjects with MMA concentrations $\geq 0.21 \mu \mathrm{mol} / \mathrm{L}$. 
Figure 3.3.5 Correlation between preoperative total homocysteine (tHcy) and vitamin B12 concentrations

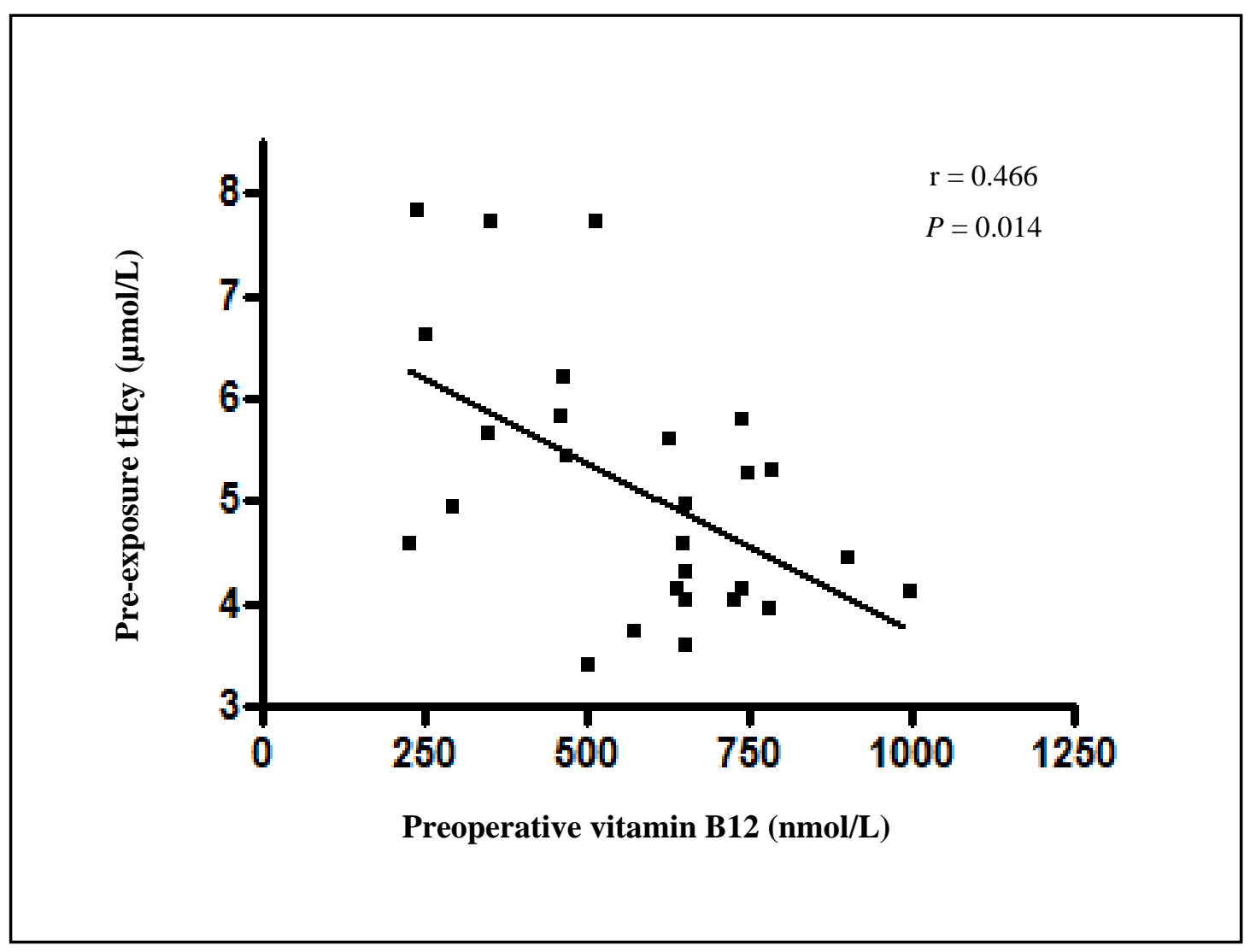

Type of diet and food intake

Human milk fed infants $(n=4)$ presented with significantly higher initial tHcy concentrations when compared to their formula fed counterparts $(n=11)$ or older children consuming a mixed diet $(8.1 \pm 1.0 \mu \mathrm{mol} / \mathrm{L}, 4.8 \pm 1.2$ and $5.0 \pm 1.2 \mu \mathrm{mol} / \mathrm{L}$, respectively; $P=$ $<0.05)$. The post-exposure mean percentage of increase in breastfed babies was $89 \%$ from the initial tHcy concentration. The duration of exposure to nitrous oxide in this group of babies ranged from 135 to 209 minutes. 
The amount of protein/kg weight consumed prior to collection of the postoperative blood sample showed no association with the increase in tHcy after exposure to nitrous oxide before or after adjusting for nitrous oxide exposure $\left(r^{2}=0.105, P=0.123\right)$.

Intraoperative factors

Type of surgery, ASA classification, and use of antibiotics showed no relevant correlations with homocysteine concentrations or with other variables. In addition, length of hospitalization was not associated with preoperative and postoperative tHcy concentrations or with the increase in post-exposure tHcy concentrations. There was no association between hematocrit or hemoglobin and homocysteine main outcome variables. However, there was a modest inverse correlation between hemoglobin and length of hospitalization (Spearman r= 0.447, $P=0.042)$.

Univariate linear regression analyses

Detailed results of the univariate linear regression analyses comparing (A) preoperative tHcy concentrations and (B) the change in post-exposure tHcy concentrations versus various predictors are presented in Table 3.3.4. The vitamin B12 level was associated with initial tHcy as well as with the change in post-exposure tHcy $\left(r^{2}=0.277, P=0.004\right.$ and $r^{2}=0.149, P=0.046$ respectively). The strongest association observed with the increase on postoperative tHcy concentration was duration of exposure to nitrous oxide $\left(r^{2}=0.696, P=<0.001\right)$. For every 149 minutes (0.83 SD) exposure to nitrous oxide, there would be a $7.6 \mu \mathrm{mol} / \mathrm{L}$ (1 SD) increase in postoperative tHcy concentration. The preoperative tHcy concentration was significantly associated with the increase in post-exposure tHcy and explained 30\% of the variance in the increase on total homocysteine concentration $\left(r^{2}=0.305, P=0.0010\right)$. 
Table 3.3.4 Results from univariate linear regression analyses comparing (A) preoperative tHcy concentration and $(B)$ the change in post-exposure tHcy concentrations versus various predictors

\begin{tabular}{|c|c|c|c|c|c|c|}
\hline & \multicolumn{3}{|c|}{ (A) } & \multicolumn{3}{|c|}{ (B) } \\
\hline Predictor variable & $\begin{array}{l}\text { Preoperative } \\
\text { tHcy } r^{2}\end{array}$ & $\begin{array}{l}\text { Standardized } \\
\text { coefficient }(\beta)\end{array}$ & $P$ value & $\begin{array}{l}\text { Change in } \\
\text { tHcy } \mathrm{r}^{2}\end{array}$ & $\begin{array}{l}\text { Standardized } \\
\text { coefficient }(\beta)\end{array}$ & $P$ value \\
\hline Preoperative tHcy & - & - & - & 0.305 & 0.552 & 0.0010 \\
\hline Duration of $\mathrm{N}_{2} \mathrm{O}$ exposure & - & - & - & 0.696 & 0.835 & $<0.0001$ \\
\hline Vitamin B12 & 0.277 & -0.526 & 0.004 & 0.149 & -0.387 & 0.0462 \\
\hline MTHFR C677T genotype & 0.050 & -0.226 & 0.230 & 0.038 & -0.197 & 0.297 \\
\hline $\begin{array}{l}\text { MMA status } \\
(\geq 0.21 \mu \mathrm{mol} / \mathrm{L} \text { deficient })\end{array}$ & 0.196 & 0.446 & 0.020 & 0.001 & 0.037 & 0.853 \\
\hline
\end{tabular}

Abbreviations: tHcy total homocysteine; MMA methylmalonic acid

Standardized coefficient: interpreted as the amount of change in preoperative tHcy concentrations as a result of a change (SD units) in each the predictor variable

Multivariate linear regression analyses

A multiple linear regression analysis was conducted in order to control for the influence of duration of exposure to nitrous oxide and initial tHcy concentration in the change on postoperative tHcy concentration. Data from the final model is presented in Table 3.3.5. The predictor variables: duration of exposure to nitrous oxide and initial tHcy concentrations were included in the multivariate regression given that $69 \%$ of variance originated form duration of nitrous oxide exposure, whereas the initial tHcy concentration explained 30\% of the variance; 
when combined, these two factors explained $82 \%$ of variance and produced the strongest statistical model $\left(\mathrm{r}^{2}=0.821\right)$. After adjusting for duration of exposure to nitrous oxide and initial tHcy concentration, the increase in tHcy concentration induced by exposure to nitrous oxide remained significant (intercept’s $P=<0.0001$ ).

Table 3.3.5 Multivariate model data: change in postoperative tHcy concentrations adjusted for duration of $\mathrm{N}_{2} \mathrm{O}$ exposure and preoperative tHcy concentration

\begin{tabular}{llll}
\hline Parameter & $\begin{array}{l}\text { Estimate } \\
\text { (b) }\end{array}$ & $\begin{array}{l}\text { Standardized coefficient } \\
(\beta)\end{array}$ & $P$-value \\
\hline Intercept & $\mathrm{b}_{0}-11.464$ & - & $<0.0001$ \\
Duration of exposure to $\mathrm{N}_{2} \mathrm{O}$ & $\mathrm{b}_{1} 0.030$ & 0.743 & $<0.0001$ \\
Pre-exposure tHcy concentration & $\mathrm{b}_{2} 1.479$ & 0.365 & 0.0001 \\
\hline
\end{tabular}

Model $r^{2}=0.821$

Abbreviations: tHcy total homocysteine, $\mathrm{N}_{2} \mathrm{O}$ nitrous oxide

Standardized coefficient: interpreted as the amount of change in preoperative tHcy concentrations as a result of a change (SD units) in each the predictor variable

$\mathrm{b}_{0}$ : value of change in postoperative tHcy concentrations when predictors are set at zero

$b_{1}$ and $b_{2}$ : the change in postoperative tHcy concentrations as each predictor variable changes

Vitamin B12 level was excluded from the model shown in Table 3.3.5, because it was significantly associated with pre-exposure tHcy concentration $\left(r^{2}=0.277, P=0.004\right)$. For exploratory purposes we repeated the aforementioned model including vitamin B12 levels rather than preoperative tHcy concentrations and found that it was less explanatory of the variance in 
the change between preoperative and postoperative tHcy concentrations but overall yielded similar results $\left(\mathrm{r}^{2}=0.721\right.$; intercept's $\left.P<0.001\right)$. As a side analysis we looked at the effect of low ( $<50$ th percentile) versus high $(\geq 50$ th percentile) vitamin B12 status on the difference between pre-to-postoperative tHcy concentrations while controlling for duration of exposure. We found that those with low B12 ( $<638 \mathrm{pmol} / \mathrm{L})$ showed a significantly higher increase in post-exposure tHcy compared to children with high vitamin B12 levels ( $\geq 638 \mathrm{pmol} / \mathrm{L})(P=0.047)$.

\section{Predicted values of tHcy and vitamin B12 concentrations}

Using the equation $\left[y=b_{0}+b_{1}\left(x_{1}+b_{2}\right) x_{2}\right]$ developed from the estimates shown in Table 3.3.5, we were interested in predicting what the preoperative tHcy concentration needed to be, in order to eliminate the post-surgical rise in tHcy concentrations after nitrous oxide exposure of 120 and 180 minutes duration. The predicted value of initial tHcy required to observe a nonsignificant difference in post-exposure tHcy at 120 minutes of nitrous oxide exposure was 5.2 $\mu \mathrm{mol} / \mathrm{L}$ (95\% CI: 3.6, $9.3 \mu \mathrm{mol} / \mathrm{L}$ ). Likewise, the predicted initial tHcy value at 180 minutes of nitrous oxide exposure obtained was $3.9 \mu \mathrm{mol} / \mathrm{L}$ (95\% CI: 2.8, $7.1 \mu \mathrm{mol} / \mathrm{L}$ ) (See Appendix C).

Using the equation $\left[y=b_{0}+b_{1}\left(x_{1}\right)\right]$ developed from the estimates corresponding to the univariate regression analysis between preoperative tHcy concentrations and vitamin B12 levels shown in Table 3.3.6, we were interested in predicting what the vitamin B12 level needed to be in order to present with the preoperative tHcy concentration associated with a non--significant difference in post-exposure tHcy at 120 and 180 minutes of nitrous oxide exposure. We found, a vitamin B12 level of 542.2 pmol/L (95\% CI: 332.2, $1478.8 \mathrm{pmol} / \mathrm{L}$ ) would predict $5.2 \mu \mathrm{mol} / \mathrm{L}$ tHcy. Likewise, a vitamin B12 level 972.4 pmol/L (95\% CI: 568, 2528 pmol/L) would predict $3.9 \mu \mathrm{mol} / \mathrm{L}$ tHcy concentration (See Appendix C). 
Table 3.3.6 Univariate model data: association between preoperative tHcy concentrations and vitamin B12 level

\begin{tabular}{llll}
\hline Parameter & Estimate (b) & Standardized coefficient $(\beta)$ & $P$ value \\
\hline Intercept & $\mathrm{b}_{0} 7.008$ & - & $<0.0001$ \\
Vitamin B12 level & $\mathrm{b}_{1}-0.003$ & -0.387 & 0.0048 \\
\hline
\end{tabular}

Model $\mathrm{r}^{2}=0.277$

Dependent variable: Pre-exposure total homocysteine concentrations

Abbreviations: tHcy total homocysteine

Standardized coefficient: interpreted as the amount of change in preoperative tHcy concentrations as a result of a change (SD units) in each the predictor variable

$\mathrm{b}_{0}$ : value of change in postoperative tHcy concentrations when predictors are set at zero

$\mathrm{b}_{1}$ : the change in postoperative tHcy concentrations as each predictor variable changes 


\subsection{DISCUSSION}

This is the first report analyzing the effects of exposure to nitrous oxide under surgical conditions in pediatric patients. Our results confirm that nitrous oxide anesthesia leads to significantly increased postoperative total homocysteine concentration (1-9). In our sample of pediatric patients exposed to nitrous oxide ( $>2$ hours) inspired at a 50-70\% concentration, postoperative tHcy concentrations were increased by $25 \%$. This is consistent with recent reports of a 20 to $25 \%$ increase in the tHcy concentration after exposure to nitrous oxide in adults ( 3 hours at $\sim 70 \%$ inspired concentration) (2, 3). Earlier studies observed increases in tHcy concentration over $54 \%$ in patients exposed to larger doses of nitrous oxide ( $\sim 5$ hours) $(7,8)$. However, comparisons may not be possible since the authors make no reference to the micronutrient status (7) and MTHFR C677T genotype of sample $(7,8)$.

We observed that the duration of nitrous oxide exposure was the main predictor of the increase in postoperative tHcy concentrations in our sample of pediatric patients $(\mathrm{n}=32$; univariate analysis $\mathrm{r}^{2}=0.69 ; P=<0.0001$ ). This dose-dependent effect was first reported in adults in 1991 by Ermens and collaborators $(\mathrm{n}=40 ; \mathrm{r}=0.73 ; P=<0.0001)(8)$, and confirmed in a number of other studies (1-9). The most dramatic rise in postanesthesia tHcy documented in the literature (from 13.6 to $134.5 \mu \mathrm{mol} / \mathrm{L}$ ), corresponds to a patient exposed to $>24$ hours nitrous oxide (8). In the present study children ( $n=9$ ) exposed to $>3.5$ hours of nitrous oxide presented with postoperative tHcy concentrations $~ 80 \%$ higher than initial concentrations (initial median tHcy $4.1[4.0,6.1]$ vs. post-exposure $7.5[4.7,19.3] \mu \mathrm{mol} / \mathrm{L})$. This is consistent with a recent report by Nagele et.al., where an $80 \%$ increase in median tHcy concentration from baseline to postanesthesia tHcy concentration was observed among 16 adults exposed to nitrous oxide for $>4$ hours $(8.1[7.3,10.0]$ vs. $14[13.1,22.8] \mu \mathrm{mol} / \mathrm{L}$, respectively) (2). 
In our sample of pediatric patients, initial homocysteine status $(5.1[4.1,6.4] \mu \mathrm{mol} / \mathrm{L})$ was a predictor of the increase in post-exposure tHcy concentration (univariate regression $\mathrm{r}^{2}=$ $0.305, P=0.001)$. This suggests that factors that determine homocysteine status, namely nutritional, genetic and other factors may mediate how subjects are affected by exposure to nitrous oxide. This finding is consistent with a study by Nagele et.al. ( $\mathrm{n}=140)$; baseline homocysteine concentrations $(8.1[6.9,9.8] \mu \mathrm{mol} / \mathrm{L})$ were associated with the response to nitrous oxide $(P<0.001)(1)$. Results presented in two recent reports of the ENIGMA Trial $(\mathrm{n}=215)$ were adjusted for baseline tHcy concentration (9.2 [3.0] $\mu \mathrm{mol} / \mathrm{L})$, although an association between initial homocysteine concentration and post-exposure tHcy outcome was not reported $(3,4)$. Cobalamin and folate status have been identified as determinants of homocysteine concentrations in children at a population level (140). Vitamin deficiency and/or enzymatic inefficiency can potentially impair the individual's ability to metabolize a sudden elevation of homocysteine concentration such as induced by exposure to nitrous oxide during surgery.

Two previous studies conducted in countries where the food supply is not fortified with folic acid, showed an inverse correlation between pre-exposure folate levels and tHcy concentrations $(3,8)$. In contrast, children in our study had high folate levels and these were not associated with preoperative homocysteine concentrations and the increase in post-exposure tHcy was independent of initial folate status. It is possible that the reason for previous evidence showing an inverse relationship may have been the overall low folate status of subjects in the samples. For instance, Ermens et. al. (Netherlands 1990) reported that 23 out of 42 patients presented with baseline folate levels below $7.4 \mathrm{nmol} / \mathrm{L}$, with the maximum folate level at 21 $\mathrm{nmol} / \mathrm{L}$. Preoperative folate levels were inversely associated with the baseline tHcy concentrations ( $\left.\mathrm{n}=52 ; \mathrm{r}^{2}=-0.30 ; P<0.025\right)$ and with the absolute increase in tHcy concentrations 
postoperatively ( $\left.\mathrm{n}=40 ; \mathrm{r}^{2}=-0.34 ; P<0.025\right)(8)$. Baseline folate levels $(23.5 \pm 5.1 \mathrm{nmol} / \mathrm{L})$, were inversely correlated with initial tHcy concentrations in ENIGMA Trial participants (n=226; r= 0.27; $P<0.001$ ), (Australia-Hong Kong 2008) (3). Conversely, in our sample of children, the mean preoperative folate level was $84.6 \pm 44.2 \mathrm{nmol} / \mathrm{L}$, with the minimum and maximum plasma folate levels at 31 and $250 \mathrm{nmol} / \mathrm{L}$, respectively.

The high folate levels in our pediatric sample likely reflect the consumption of folic acid fortified foods. At high blood levels ( $>30 \mathrm{nmol} / \mathrm{L}$ ) folate is a weak determinant of homocysteine concentration in adults (75). The prevalence of high serum folate ( $>53.3 \mathrm{nmol} / \mathrm{L})$ in the USA which also fortifies its food supply with folic acid is 20\% in children aged $4-11$ years (235). Fortified foods in Canada contain $>50 \%$ than the recommended intake of folic acid for an adult

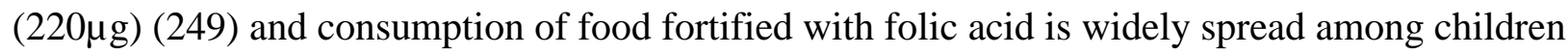
in Canada (250). Although most participants of the present study were infants who did not consume folic acid fortified foods, theoretically it is likely that these infants acquired a substantial folate reserve in utero through nutrient transfer from mother to fetus (251). Furthermore, infant formulas are commonly high in folic acid $(67,252)$. High folate levels may mask initial signs of vitamin B12 deficiency (62).

We found an inverse association between pre-operative vitamin B12 levels and initial homocysteine concentrations (univariate $r^{2}=0.277, P=0.004$ ). Ultimately children with a lower vitamin B12 levels ( $<638 \mathrm{pmol} / \mathrm{L}$ ) showed a greater increase in postoperative tHcy concentrations than those with higher vitamin B12 ( $\geq 638 \mathrm{pmol} / \mathrm{L})$ preoperatively $(P=0.047)$. Furthermore, subjects with a MMA status indicative of vitamin B12 deficiency ( $\geq 0.21 \mu \mathrm{mol} / \mathrm{L}$ ), showed a significantly higher initial tHcy concentration than those with a lower MMA concentration. These findings are consistent with the metabolic function of vitamin B12 as a 
coenzyme required in the methyl transfer reactions that convert homocysteine to methionine (see Figure 2.1) (23). The inverse relationship between circulating cobalamin and homocysteine postfolic acid fortification of the food supply, but not with folate, is well acknowledged and has been reported in population surveys $(75,76,140)$. We demonstrated that the preoperative homocysteine status predicted the increase in post-exposure tHcy concentrations. This suggests an effect of vitamin B12 on the homocysteine outcome after nitrous oxide exposure.

We were interested in predicting the vitamin B12 level needed in order to present with a preoperative tHcy concentration associated with a non-significant rise in tHcy concentrations after nitrous oxide exposure. Based on our results, we calculated that a vitamin B12 concentration of $972.4 \mathrm{pmol} / \mathrm{L}$ would predict a preoperative tHcy concentration $(3.9 \mu \mathrm{mol} / \mathrm{L})$, associated with no increase or difference in homocysteine concentrations after exposure to nitrous oxide for 3 hours. Vitamin B12 levels in our pediatric group were relatively high (577.3 $\pm 203.8 \mathrm{pmol} / \mathrm{L}$ ), which explains that predicted vitamin B12 values calculated from these data were high. Results from a study conducted in Canada by Badner et.al. (2001), may suggest that high vitamin levels are required to prevent or reduce the effect of nitrous oxide exposure on tHcy concentrations (5). Patients undergoing surgery with nitrous oxide were supplemented with folic

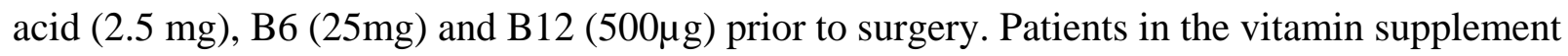
group showed no increase in postoperative tHcy concentrations after exposure to nitrous oxide, whereas those treated with placebo experienced a significant increase (5). Given that mandatory folic acid fortification of the food supply was present at the time of the Badner study it is likely that all patients consumed folic acid in fortified foods in addition to the study supplement or the placebo. This observation suggests that there is an independent effect of vitamin B12 on 
preventing an increase in post nitrous oxide anesthesia tHcy concentrations; consistent with the results reported in the present study.

There was no association of the MTHFR C677T genotype and post-exposure tHcy concentrations. Initial tHcy concentrations did not significantly differ between wild type individuals and those who were homozygous or heterozygous for the MTHFR $T$ allele. This finding is in contrast with data recently published by Nagele and collaborators (2008) who reported significant differences in baseline and postoperative tHcy concentrations between homozygous, heterozygous and non-carrier adults for the MTHFR $T$ allele treated with nitrous oxide. The post-exposure tHcy concentrations nearly tripled in homozygous patients and only subjects in the homozygous group reached concentrations $>15 \mu \mathrm{mol} / \mathrm{L}$ (2).

The presence of the $T$ allele for MTHFR C677T results in reduced enzyme activity and in the general population is associated with high homocysteine concentrations $(99,101)$. We hypothesize that MTHFR C677T genotype had no effect on circulating homocysteine concentration due to the high plasma folate levels of children in the present study $(84.6 \pm 44.2$ $\mathrm{nmol} / \mathrm{L})$. Theoretically, a substantial pool of circulating folate forms can sustain the folate cycle functioning adequately regardless of reduced MTHFR activity in homozygous and heterozygous individuals (see Figure 2.1). In fact, it has been shown in adults that at a low folate level (4.6 nmol/L), homozygous individuals present with significantly higher tHcy concentrations than wild type and heterozygous subjects $(P=0.0001)(253)$. Whilst at high folate levels $(11.9$ $\mathrm{nmol} / \mathrm{L})$, the tHcy concentration did not differ significantly among genotypes $(P=>0.2)$ (253).

In the present study, adequate preoperative vitamin B6 levels ( $\geq 20 \mathrm{nmol} / \mathrm{L})$ showed no correlation with tHcy concentrations ( $\mathrm{n}=13 ; \mathrm{r}=-0.17 ; P=0.54)$. A similar finding was reported in 
the Child and Adolescent Trial for Cardiovascular Health (n= 3524), were vitamin B6 levels $(47.4 \pm 48.2 \mathrm{nmol} / \mathrm{L})$ showed no association with tHcy concentrations after controlling for circulating levels of folate and vitamin B12 (136).

We observed a $\sim 80 \%$ mean increase in the pre-to-post-exposure tHcy concentrations of the 4 breastfed infants in our study. These infants presented with mean MMA $(0.6 \pm 0.4 \mu \mathrm{mol} / \mathrm{L})$ and initial tHcy $(8.7 \pm 1.1 \mu \mathrm{mol} / \mathrm{L})$ concentrations indicative of vitamin B12 deficiency. The low vitamin B12 status in relation to high tHcy and MMA concentrations in breastfed infants reported here is in accordance with data from larger studies published by others $(67-69,236)$. For instance, Hay et.al. reported elevated tHcy concentrations (7.5 [95\% CI 7.0, 7.8] $\mu \mathrm{mol} / \mathrm{L})$ concurrent with high MMA concentrations $(0.53[0.4,0.6] \mu \mathrm{mol} / \mathrm{L})$ in a sample of 127 human milk fed infants (67). Further, vitamin B12 levels of infants fed human milk correlate positively with maternal levels of this micronutrient (69), and recent evidence shows a high prevalence (7.4\%) of maternal cobalamin deficiency (B12 <125 pmol/L) in Canada (66).

Whether the vitamin B12 and homocysteine hematological profile observed in breastfed babies is appropriate in healthy infancy remains to be elucidated. Given that nitrous oxide inactivates vitamin B12, breastfed babies may be at increased risk of developing postoperative hyperhomocysteinemia due to lower vitamin B12 status.

The clinical significance of acute elevated tHcy concentrations induced by nitrous oxide in adults is still under assessment (156), and is unknown in pediatric patients. Published studies in adults treated with nitrous oxide, found that postoperative tHcy concentrations $\geq 13.5 \mu \mathrm{mol} / \mathrm{L}$ were a risk factor for myocardial infarction and stroke (3), levels of $14.1 \pm 5.7 \mu \mathrm{mol} / \mathrm{L}$ were associated with reduced endothelial function (4), and $>17 \mu \mathrm{mol} / \mathrm{L}$ increased the risk of 
myocardial ischemia twofold (6). Five children in our study presented with postoperative tHcy concentrations above $13.5 \mu \mathrm{mol} / \mathrm{L}$.

We acknowledge a number of potential limitations in our study. To reduce the need of venipuncture and of obtaining a blood sample from small children, we did not include a control group. Rather each child served as his/her own control. Lack of a control group may introduce a bias when analyzing the pre-to-postoperative change in tHcy concentrations as we would not detect per se postoperative fluctuations in tHcy concentrations. However it was shown in the ENIGMA Trial that homocysteine does not increase after surgery with other anesthetics ( $\mathrm{n}=179$, baseline $9.7 \pm 5.3$ vs. post-surgical $8.5 \pm 4.0 \mu \mathrm{mol} / \mathrm{L} ; P=<0.0005)$ (3). This has been consistently reported in the adult studies (1-9). Thus, the interpretation of our results may not be limited by lack of control group.

We had small sample size to fully explore diet group interactions with micronutrients. For instance there were only 4 babies fed human milk. However, our finding of vitamin B12 deficiency in breastfed infants is consistent with numerous reports (67-69). The lack of effect of folate and vitamin B6 status in our study may relate to an insufficient sample size. Regardless of sample size requirements, vitamin B6 levels (136) and high circulating levels of folate (75) have shown an only modest effect on tHcy concentrations in the literature.

In conclusion, nitrous oxide exposure during surgery leads to a significant increase in the postoperative tHcy concentrations of children. Duration of exposure to nitrous oxide is the main factor determining this increase. In our sample of children, initial homocysteine status predicted the level of increase in post-exposure tHcy concentration. Vitamin B12 status was the main determinant of preoperative homocysteine concentration. In contrast, circulating folate levels and 
consequently the related MTHFR C677T genotype post fortification of the food supply had no effect. Five children presented with postoperative tHcy concentrations above the level associated with major complications in the postoperative period in adults (3). Lower vitamin B12 status was found in all breastfed infants participating in the study. 


\section{CHAPTER 4 CONCLUSIONS AND FUTURE DIRECTIONS}

Nitrous oxide exposure during surgery leads to a significant increase in the postoperative tHcy concentrations of children. Duration of exposure to nitrous oxide is the main factor determining this increase. In our sample of children, initial homocysteine status predicted the level of increase in post-exposure tHcy concentration. Vitamin B12 status was the main determinant of preoperative homocysteine concentration. In contrast, circulating folate levels and consequently the related MTHFR C677T genotype had no effect. Vitamin B6 levels were not associated with the preoperative tHcy concentration or with the change in postanesthesia tHcy concentrations.

Our study is unique in this area of research since not only did we determine the effect of nitrous oxide on a pediatric population, but we also comprehensively explored the factors influencing this relationship. The present study provides quantitative data that may be used to assess whether children exposed to nitrous oxide are at risk of developing the adverse side effects observed in adults with high postoperative tHcy concentrations $(>13.5 \mu \mathrm{mol} / \mathrm{L})(3,4,6)$.

We showed that post-exposure tHcy concentrations are likely to reach a level of concern ( $>13.5 \mu \mathrm{mol} / \mathrm{L}$ ) in children exposed to $>3.5$ hours of nitrous oxide and in those with high initial tHcy concentrations and/or low vitamin B12 status. In clinical practice implications of these findings may include screening preoperatively for high tHcy and MMA concentrations. A meaningful cutoff for children may be $\geq 8$ and $\geq 0.21 \mu \mathrm{mol} / \mathrm{L}$ for tHcy and MMA concentrations respectively, since these values were associated with elevated postanesthesia tHcy concentrations in the present study and are associated with negative clinical outcomes chronically $(105,230)$. However if routine screening is not in place avoidance of nitrous oxide 
for maintenance of anesthesia may be advisable in long surgeries ( $>3.5$ hours), and if low vitamin B12 status is suspected. Low vitamin B12 status should be suspected in children not consuming a vitamin B12 supplement that are: (1) vegetarian (65), (2) have low intakes of foods from animal origin $(70,71)$ or (3) in exclusively breastfed infants (67-69). Postoperative signs and symptoms of neurologic impairment and anemia originated from vitamin B12 inactivation by nitrous oxide may present after $>3$ weeks of surgery $(173,177,178)$ and neurological damage may be irreversible in infants (177). This presents a compelling reason to avoid nitrous oxide when low vitamin B12 status is suspected.

Alternatively, preventing a postoperative rise in tHcy concentrations may be achieved by reduction of preoperative tHcy concentrations with use of a vitamin supplement. Assuming that the overall vitamin status found in our study population reflects that of children in North America (235), folic acid supplementation may not be necessary in preventing the rise in homocysteine induced by exposure to nitrous oxide. Conversely, vitamin B12 supplementation may prove beneficial. However the dose, duration of use and start of supplementation prior to nitrous oxide anesthesia warrants future research.

Research investigating the clinical significance of preoperative low vitamin B12 status should allow for a follow-up longer than 3 weeks and consider genotyping for the FUT2 rs 492602. A recent report showed a strong linkage between low vitamin B12 levels and carriers of the common rs492602 mutation for the FUT2 gene implicated in vitamin B12 absorption (254).

The negative clinical outcomes reported in the adult studies (endothelial dysfunction, myocardial ischemia and stroke) were observed within the first 24 hours postoperatively, however there was no report of major cardiovascular complications in our sample of pediatric 
patients up to the time of hospital discharge. Given that ischemic events may not be noticeable unless continual monitoring is in place (6), the occurrence in pediatric patients of homocysteineassociated complications requires future investigation.

The lack of information on whether baseline vitamin status influences post-exposure tHcy concentrations prevented us from estimating a priori a sample size requirement for vitamin effect. We conducted post-hoc analyses in order to determine the sample size requirement to confidently detect a difference in pre-to-postoperative tHcy based on folate and vitamin B6 status (low: $\leq 50$ th vs. high: $>$ 50th percentiles). The mean difference in pre-to-postoperative tHcy concentrations between children with lower folate $(<76.7 \mathrm{nmol} / \mathrm{L})$ and vitamin B6 $(<92 \mathrm{nmol} / \mathrm{L})$ status was $0.4 \pm 0.5 \mu \mathrm{mol} / \mathrm{L}$. The sample size requirement to assertively determine this difference, that is, the effect of preoperative folate and vitamin B6 status was 306 and 11038 children respectively. Thus our study was under powered to measure these vitamins effect. However a $0.4 \mu \mathrm{mol} / \mathrm{L}$ increase in postoperative tHcy concentrations may likely not be clinically significant. As discussed above, vitamin B6 levels (136) and high circulating levels of folate (75) would not predict tHcy concentrations. Therefore interpretation of our results may hold valid.

We conducted several statistical analyses and were not able to find a difference in the tHcy concentrations pre-surgically or at postanesthesia between carriers and CC homozygous individuals for the MTHFR C677T polymorphisms. Initial total homocysteine concentrations were not significantly different between genotypes but appeared higher in the CC homozygous compared to carriers of the $T$ allele ( $5.9 \pm 2.2$ vs. $5.2 \pm 1.6$; respectively $P=0.332)$, contrary to the metabolic hypothesis thus clearly no effect on homocysteine concentrations could be attributable to MTHFR C677T genotype. 


\section{REFERENCES}

1. Nagele P, Zeugswetter B, Eberle C, Hupfl M, Mittlbock M, Fodinger M. A common gene variant in methionine synthase reductase is not associated with peak homocysteine concentrations after nitrous oxide anesthesia. Pharmacogenet Genomics 2009;19:325-9.

2. Nagele P, Zeugswetter B, Wiener C, et al. Influence of methylenetetrahydrofolate reductase gene polymorphisms on homocysteine concentrations after nitrous oxide anesthesia. Anesthesiology 2008;109:36-43.

3. Myles PS, Chan MT, Leslie K, Peyton P, Paech M, Forbes A. Effect of nitrous oxide on plasma homocysteine and folate in patients undergoing major surgery. $\mathrm{Br} \mathrm{J}$ Anaesth 2008;100:780-6.

4. Myles PS, Chan MT, Kaye DM, et al. Effect of nitrous oxide anesthesia on plasma homocysteine and endothelial function. Anesthesiology 2008;109:657-63.

5. Badner NH, Freeman D, Spence JD. Preoperative oral B vitamins prevent nitrous oxideinduced postoperative plasma homocysteine increases. Anesth Analg 2001;93:1507-10, table of contents.

6. Badner NH, Beattie WS, Freeman D, Spence JD. Nitrous oxide-induced increased homocysteine concentrations are associated with increased postoperative myocardial ischemia in patients undergoing carotid endarterectomy. Anesth Analg 2000;91:1073-9.

7. Badner NH, Drader K, Freeman D, Spence JD. The use of intraoperative nitrous oxide leads to postoperative increases in plasma homocysteine. Anesth Analg 1998;87:711-3.

8. Ermens AA, Refsum H, Rupreht J, et al. Monitoring cobalamin inactivation during nitrous oxide anesthesia by determination of homocysteine and folate in plasma and urine. Clin Pharmacol Ther 1991;49:385-93.

9. Foschi D, Rizzi A, Zighetti ML, et al. Effects of surgical stress and nitrous oxide anaesthesia on peri-operative plasma levels of total homocysteine. A randomised, controlled study in general surgery. Anaesthesia 2001;56:676-9.

10. Finkelstein JD. Pathways and regulation of homocysteine metabolism in mammals. Semin Thromb Hemost 2000;26:219-25.

11. Brosnan JT, Brosnan ME. The sulfur-containing amino acids: an overview. J Nutr 2006;136:1636S-1640S. 
12. Guttormsen AB, Refsum H, Ueland PM. The interaction between nitrous oxide and cobalamin. Biochemical effects and clinical consequences. Acta Anaesthesiol Scand 1994;38:753-6.

13. Sanders RD, Weimann J, Maze M. Biologic effects of nitrous oxide: a mechanistic and toxicologic review. Anesthesiology 2008;109:707-22.

14. Myles PS, Leslie K, Silbert B, Paech MJ, Peyton P. A review of the risks and benefits of nitrous oxide in current anaesthetic practice. Anaesth Intensive Care 2004;32:165-72.

15. Schneede J, Refsum H, Ueland PM. Biological and environmental determinants of plasma homocysteine. Semin Thromb Hemost 2000;26:263-79.

16. Verhoef P, de Groot LC. Dietary determinants of plasma homocysteine concentrations. Semin Vasc Med 2005;5:110-23.

17. Verhoef P, Steenge GR, Boelsma E, van Vliet T, Olthof MR, Katan MB. Dietary serine and cystine attenuate the homocysteine-raising effect of dietary methionine: a randomized crossover trial in humans. Am J Clin Nutr 2004;80:674-9.

18. Verhoef P, van Vliet T, Olthof MR, Katan MB. A high-protein diet increases postprandial but not fasting plasma total homocysteine concentrations: a dietary controlled, crossover trial in healthy volunteers. Am J Clin Nutr 2005;82:553-8.

19. Rafii M, Elango R, Courtney-Martin G, House JD, Fisher L, Pencharz PB. Highthroughput and simultaneous measurement of homocysteine and cysteine in human plasma and urine by liquid chromatography-electrospray tandem mass spectrometry. Anal Biochem 2007;371:71-81.

20. Molloy AM, Scott JM. Microbiological assay for serum, plasma, and red cell folate using cryopreserved, microtiter plate method. Methods Enzymol 1997;281:43-53.

21. Yazdanpanah M, Chan PC, Evrovski J, Romaschin A, Cole DE. An improved assay for plasma methylmalonic acid using chemical ionization gas chromatography mass spectrometry. Clin Biochem 2003;36:617-20.

22. Eny KM, Wolever TM, Fontaine-Bisson B, El-Sohemy A. Genetic variant in the glucose transporter type 2 is associated with higher intakes of sugars in two distinct populations. Physiol Genomics 2008;33:355-60.

23. Groff S, Gropper SAS. Folic Acid. In: Gropper SAS, Groff S, eds. Advanced nutrition and human metabolism. Third ed. Belmont, CA.: Thomson/Wadsworth, 2004:289 - 298. 
24. Mudd SH, Brosnan JT, Brosnan ME, et al. Methyl balance and transmethylation fluxes in humans. Am J Clin Nutr 2007;85:19-25.

25. Finkelstein JD. Metabolic regulatory properties of S-adenosylmethionine and Sadenosylhomocysteine. Clin Chem Lab Med 2007;45:1694-9.

26. Olteanu H, Banerjee R. Human methionine synthase reductase, a soluble P-450 reductase-like dual flavoprotein, is sufficient for NADPH-dependent methionine synthase activation. J Biol Chem 2001;276:35558-63.

27. Banerjee R. The Yin-Yang of cobalamin biochemistry. Chem Biol 1997;4:175-86.

28. Finkelstein JD, Martin JJ. Methionine metabolism in mammals. Distribution of homocysteine between competing pathways. J Biol Chem 1984;259:9508-13.

29. Zeisel SH, Mar MH, Howe JC, Holden JM. Concentrations of choline-containing compounds and betaine in common foods. J Nutr 2003;133:1302-7.

30. Zeisel SH, Blusztajn JK. Choline and human nutrition. Annu Rev Nutr 1994;14:269-96.

31. Sunden SL, Renduchintala MS, Park EI, Miklasz SD, Garrow TA. Betaine-homocysteine methyltransferase expression in porcine and human tissues and chromosomal localization of the human gene. Arch Biochem Biophys 1997;345:171-4.

32. Delgado-Reyes CV, Wallig MA, Garrow TA. Immunohistochemical detection of betainehomocysteine S-methyltransferase in human, pig, and rat liver and kidney. Arch Biochem Biophys 2001;393:184-6.

33. McKeever MP, Weir DG, Molloy A, Scott JM. Betaine-homocysteine methyltransferase: organ distribution in man, pig and rat and subcellular distribution in the rat. Clin Sci (Lond) 1991;81:551-6.

34. Jhee KH, Kruger WD. The role of cystathionine beta-synthase in homocysteine metabolism. Antioxid Redox Signal 2005;7:813-22.

35. Chen P, Poddar R, Tipa EV, et al. Homocysteine metabolism in cardiovascular cells and tissues: implications for hyperhomocysteinemia and cardiovascular disease. Adv Enzyme Regul 1999;39:93-109.

36. Jencks DA, Mathews RG. Allosteric inhibition of methylenetetrahydrofolate reductase by adenosylmethionine. Effects of adenosylmethionine and NADPH on the equilibrium between active and inactive forms of the enzyme and on the kinetics of approach to equilibrium. J Biol Chem 1987;262:2485-93. 
37. Finkelstein JD, Kyle WE, Harris BJ. Methionine metabolism in mammals: regulatory effects of S-adenosylhomocysteine. Arch Biochem Biophys 1974;165:774-9.

38. Ohuchi S, Morita T, Mori M, Sugiyama K. Hepatic cystathionine beta-synthase activity does not increase in response to methionine supplementation in rats fed a low casein diet: association with plasma homocysteine concentrations. J Nutr Sci Vitaminol (Tokyo) 2009;55:178-85.

39. Prudova A, Bauman Z, Braun A, Vitvitsky V, Lu SC, Banerjee R. S-adenosylmethionine stabilizes cystathionine beta-synthase and modulates redox capacity. Proc Natl Acad Sci U S A 2006;103:6489-94.

40. Ou X, Yang H, Ramani K, et al. Inhibition of human betaine-homocysteine methyltransferase expression by S-adenosylmethionine and methylthioadenosine. Biochem J 2007;401:87-96.

41. Ogawa H, Gomi T, Takusagawa F, Fujioka M. Structure, function and physiological role of glycine N-methyltransferase. Int J Biochem Cell Biol 1998;30:13-26.

42. Mudd SH, Ebert MH, Scriver CR. Labile methyl group balances in the human: the role of sarcosine. Metabolism 1980;29:707-20.

43. Ueland PM. Homocysteine species as components of plasma redox thiol status. Clin Chem 1995;41:340-2.

44. Ubbink JB. The role of vitamins in the pathogenesis and treatment of hyperhomocyst(e)inaemia. J Inherit Metab Dis 1997;20:316-25.

45. Selhub J, Miller JW. The pathogenesis of homocysteinemia: interruption of the coordinate regulation by S-adenosylmethionine of the remethylation and transsulfuration of homocysteine. Am J Clin Nutr 1992;55:131-8.

46. Selhub J. The many facets of hyperhomocysteinemia: studies from the Framingham cohorts. J Nutr 2006;136:1726S-1730S.

47. Stea TH, Uglem S, Wandel M, Mansoor MA, Frolich W. Association between folate intake from different food sources in Norway and homocysteine status in a dietary intervention among young male adults. Br J Nutr 2009:1-8.

48. Silaste ML, Rantala M, Alfthan G, Aro A, Kesaniemi YA. Plasma homocysteine concentration is decreased by dietary intervention. Br J Nutr 2003;89:295-301. 
49. Broekmans WM, Klopping-Ketelaars IA, Schuurman CR, et al. Fruits and vegetables increase plasma carotenoids and vitamins and decrease homocysteine in humans. J Nutr 2000;130:1578-83.

50. Mann NJ, Li D, Sinclair AJ, et al. The effect of diet on plasma homocysteine concentrations in healthy male subjects. Eur J Clin Nutr 1999;53:895-9.

51. Brouwer IA, van Dusseldorp M, West CE, et al. Dietary folate from vegetables and citrus fruit decreases plasma homocysteine concentrations in humans in a dietary controlled trial. J Nutr 1999;129:1135-9.

52. Jacob RA, Wu MM, Henning SM, Swendseid ME. Homocysteine increases as folate decreases in plasma of healthy men during short-term dietary folate and methyl group restriction. J Nutr 1994;124:1072-80.

53. Lutsey PL, Steffen LM, Feldman HA, et al. Serum homocysteine is related to food intake in adolescents: the Child and Adolescent Trial for Cardiovascular Health. Am J Clin Nutr 2006;83:1380-6.

54. Riddell LJ, Chisholm A, Williams S, Mann JI. Dietary strategies for lowering homocysteine concentrations. Am J Clin Nutr 2000;71:1448-54.

55. Malinow MR, Duell PB, Hess DL, et al. Reduction of plasma homocyst(e)ine levels by breakfast cereal fortified with folic acid in patients with coronary heart disease. $\mathrm{N}$ Engl $\mathrm{J}$ Med 1998;338:1009-15.

56. Tucker KL, Selhub J, Wilson PW, Rosenberg IH. Dietary intake pattern relates to plasma folate and homocysteine concentrations in the Framingham Heart Study. J Nutr 1996;126:3025-31.

57. Lonn E, Yusuf S, Arnold MJ, et al. Homocysteine lowering with folic acid and B vitamins in vascular disease. N Engl J Med 2006;354:1567-77.

58. Bleie O, Refsum H, Ueland PM, et al. Changes in basal and postmethionine load concentrations of total homocysteine and cystathionine after B vitamin intervention. Am J Clin Nutr 2004;80:641-8.

59. Brattstrom L. Vitamins as homocysteine-lowering agents. J Nutr 1996;126:1276S-80S.

60. Clarke R, Lewington S, Sherliker P, Armitage J. Effects of B-vitamins on plasma homocysteine concentrations and on risk of cardiovascular disease and dementia. Curr Opin Clin Nutr Metab Care 2007;10:32-9. 
61. Lowering blood homocysteine with folic acid based supplements: meta-analysis of randomised trials. Homocysteine Lowering Trialists' Collaboration. BMJ 1998;316:8948.

62. Gibson S. Rosalind. Principles of Nutritional Assessment. Second ed. New York: OXFORD University Press, 2005.

63. Food and Nutrition Board, Medicine NIo. Dietary Reference Intakes for thiamin, riboflavin, niacin, vitamin B6, folate, vitamin B12, pantothenic acid, biotin and choline. Washington D.C.: The National Academies Press, 2000.

64. Ray JG, Cole DE, Boss SC. An Ontario-wide study of vitamin B12, serum folate, and red cell folate levels in relation to plasma homocysteine: is a preventable public health issue on the rise? Clin Biochem 2000;33:337-43.

65. Huang YC, Chang SJ, Chiu YT, Chang HH, Cheng $\mathrm{CH}$. The status of plasma homocysteine and related B-vitamins in healthy young vegetarians and nonvegetarians. Eur J Nutr 2003;42:84-90.

66. Ray JG, Goodman J, O'Mahoney PR, Mamdani MM, Jiang D. High rate of maternal vitamin B12 deficiency nearly a decade after Canadian folic acid flour fortification. QJM 2008;101:475-7.

67. Hay G, Johnston C, Whitelaw A, Trygg K, Refsum H. Folate and cobalamin status in relation to breastfeeding and weaning in healthy infants. Am J Clin Nutr 2008;88:105-14.

68. Specker BL, Brazerol W, Ho ML, Norman EJ. Urinary methylmalonic acid excretion in infants fed formula or human milk. Am J Clin Nutr 1990;51:209-11.

69. Jones KM, Ramirez-Zea M, Zuleta C, Allen LH. Prevalent vitamin B-12 deficiency in twelve-month-old Guatemalan infants is predicted by maternal B-12 deficiency and infant diet. J Nutr 2007;137:1307-13.

70. Refsum H, Yajnik CS, Gadkari M, et al. Hyperhomocysteinemia and elevated methylmalonic acid indicate a high prevalence of cobalamin deficiency in Asian Indians. Am J Clin Nutr 2001;74:233-41.

71. Rogers LM, Boy E, Miller JW, Green R, Sabel JC, Allen LH. High prevalence of cobalamin deficiency in Guatemalan schoolchildren: associations with low plasma holotranscobalamin II and elevated serum methylmalonic acid and plasma homocysteine concentrations. Am J Clin Nutr 2003;77:433-40. 
72. Louwman MW, van Dusseldorp M, van de Vijver FJ, et al. Signs of impaired cognitive function in adolescents with marginal cobalamin status. Am J Clin Nutr 2000;72:762-9.

73. Higginbottom MC, Sweetman L, Nyhan WL. A syndrome of methylmalonic aciduria, homocystinuria, megaloblastic anemia and neurologic abnormalities in a vitamin B12deficient breast-fed infant of a strict vegetarian. N Engl J Med 1978;299:317-23.

74. Clarke R, Smith AD, Jobst KA, Refsum H, Sutton L, Ueland PM. Folate, vitamin B12, and serum total homocysteine levels in confirmed Alzheimer disease. Arch Neurol 1998;55:1449-55.

75. Ganji V, Kafai MR. Demographic, lifestyle, and health characteristics and serum B vitamin status are determinants of plasma total homocysteine concentration in the postfolic acid fortification period, 1999-2004. J Nutr 2009;139:345-52.

76. Green R, Miller JW. Vitamin B12 deficiency is the dominant nutritional cause of hyperhomocysteinemia in a folic acid-fortified population. Clin Chem Lab Med 2005;43:1048-51.

77. Bleie O, Semb AG, Grundt H, et al. Homocysteine-lowering therapy does not affect inflammatory markers of atherosclerosis in patients with stable coronary artery disease. $\mathrm{J}$ Intern Med 2007;262:244-53.

78. Dose-dependent effects of folic acid on blood concentrations of homocysteine: a metaanalysis of the randomized trials. Am J Clin Nutr 2005;82:806-12.

79. Lee BJ, Huang MC, Chung LJ, et al. Folic acid and vitamin B12 are more effective than vitamin B6 in lowering fasting plasma homocysteine concentration in patients with coronary artery disease. Eur J Clin Nutr 2004;58:481-7.

80. Yap S, Boers GH, Wilcken B, et al. Vascular outcome in patients with homocystinuria due to cystathionine beta-synthase deficiency treated chronically: a multicenter observational study. Arterioscler Thromb Vasc Biol 2001;21:2080-5.

81. Stolzenberg-Solomon RZ, Miller ER, 3rd, Maguire MG, Selhub J, Appel LJ. Association of dietary protein intake and coffee consumption with serum homocysteine concentrations in an older population. Am J Clin Nutr 1999;69:467-75.

82. Ohuchi S, Matsumoto Y, Morita T, Sugiyama K. High casein diet decreases plasma homocysteine concentration in rats. J Nutr Sci Vitaminol (Tokyo) 2009;55:22-30.

83. Okawa H, Morita T, Sugiyama K. Increased plasma homocysteine concentration in rats from a low casein diet. Biosci Biotechnol Biochem 2006;70:3050-3. 
84. Stead LM, Brosnan ME, Brosnan JT. Characterization of homocysteine metabolism in the rat liver. Biochem J 2000;350 Pt 3:685-92.

85. Shimakawa T, Nieto FJ, Malinow MR, Chambless LE, Schreiner PJ, Szklo M. Vitamin intake: a possible determinant of plasma homocyst(e)ine among middle-aged adults. Ann Epidemiol 1997;7:285-93.

86. Ward M, McNulty H, Pentieva K, et al. Fluctuations in dietary methionine intake do not alter plasma homocysteine concentration in healthy men. J Nutr 2000;130:2653-7.

87. Jacques PF, Bostom AG, Wilson PW, Rich S, Rosenberg IH, Selhub J. Determinants of plasma total homocysteine concentration in the Framingham Offspring cohort. Am J Clin Nutr 2001;73:613-21.

88. Mennen LI, de Courcy GP, Guilland JC, et al. Homocysteine, cardiovascular disease risk factors, and habitual diet in the French Supplementation with Antioxidant Vitamins and Minerals Study. Am J Clin Nutr 2002;76:1279-89.

89. Haulrik N, Toubro S, Dyerberg J, Stender S, Skov AR, Astrup A. Effect of protein and methionine intakes on plasma homocysteine concentrations: a 6-mo randomized controlled trial in overweight subjects. Am J Clin Nutr 2002;76:1202-6.

90. Noakes M, Keogh JB, Foster PR, Clifton PM. Effect of an energy-restricted, highprotein, low-fat diet relative to a conventional high-carbohydrate, low-fat diet on weight loss, body composition, nutritional status, and markers of cardiovascular health in obese women. Am J Clin Nutr 2005;81:1298-306.

91. Guttormsen AB, Solheim E, Refsum H. Variation in plasma cystathionine and its relation to changes in plasma concentrations of homocysteine and methionine in healthy subjects during a 24-h observation period. Am J Clin Nutr 2004;79:76-9.

92. Nimni ME, Han B, Cordoba F. Are we getting enough sulfur in our diet? Nutr Metab (Lond) 2007;4:24.

93. Brenton DP, Cusworth DC, Gaull GE. Homocystinuria: Metabolic Studies on 3 Patients. J Pediatr 1965;67:58-68.

94. Okawa H, Morita T, Sugiyama K. Cysteine supplementation decreases plasma homocysteine concentration in rats fed on a low-casein diet in rats. Biosci Biotechnol Biochem 2007;71:91-7. 
95. Fukada S, Shimada Y, Morita T, Sugiyama K. Suppression of methionine-induced hyperhomocysteinemia by glycine and serine in rats. Biosci Biotechnol Biochem 2006;70:2403-9.

96. Ohuchi S, Matsumoto Y, Morita T, Sugiyama K. High-casein diet suppresses guanidinoacetic acid-induced hyperhomocysteinemia and potentiates the hypohomocysteinemic effect of serine in rats. Biosci Biotechnol Biochem 2008;72:325864.

97. Kawakami Y, Ohuchi S, Morita T, Sugiyama K. Hypohomocysteinemic effect of cysteine is associated with increased plasma cysteine concentration in rats fed diets low in protein and methionine levels. J Nutr Sci Vitaminol (Tokyo) 2009;55:66-74.

98. Di Buono M, Wykes LJ, Cole DE, Ball RO, Pencharz PB. Regulation of sulfur amino acid metabolism in men in response to changes in sulfur amino acid intakes. J Nutr 2003;133:733-9.

99. Goyette P, Pai A, Milos R, et al. Gene structure of human and mouse methylenetetrahydrofolate reductase (MTHFR). Mamm Genome 1998;9:652-6.

100. Goyette P, Christensen B, Rosenblatt DS, Rozen R. Severe and mild mutations in cis for the methylenetetrahydrofolate reductase (MTHFR) gene, and description of five novel mutations in MTHFR. Am J Hum Genet 1996;59:1268-75.

101. Frosst P, Blom HJ, Milos R, et al. A candidate genetic risk factor for vascular disease: a common mutation in methylenetetrahydrofolate reductase. Nat Genet 1995;10:111-3.

102. Christensen B, Frosst P, Lussier-Cacan S, et al. Correlation of a common mutation in the methylenetetrahydrofolate reductase gene with plasma homocysteine in patients with premature coronary artery disease. Arterioscler Thromb Vasc Biol 1997;17:569-73.

103. van der Put NM, Steegers-Theunissen RP, Frosst P, et al. Mutated methylenetetrahydrofolate reductase as a risk factor for spina bifida. Lancet 1995;346:1070-1.

104. Kang SS, Wong PW, Bock HG, Horwitz A, Grix A. Intermediate hyperhomocysteinemia resulting from compound heterozygosity of methylenetetrahydrofolate reductase mutations. Am J Hum Genet 1991;48:546-51.

105. Refsum H, Smith AD, Ueland PM, et al. Facts and recommendations about total homocysteine determinations: an expert opinion. Clin Chem 2004;50:3-32. 
106. Sirachainan N, Sasanakul W, Visudtibhan A, et al. The effect of polymorphisms of MTHFR C677T, A1298C, MS A2756G and CBS 844ins68bp on plasma total homocysteine level and the risk of ischemic stroke in Thai children. Thromb Res 2008;122:33-7.

107. Lievers KJ, Kluijtmans LA, Blom HJ. Genetics of hyperhomocysteinaemia in cardiovascular disease. Ann Clin Biochem 2003;40:46-59.

108. Silaste ML, Rantala M, Sampi M, Alfthan G, Aro A, Kesaniemi YA. Polymorphisms of key enzymes in homocysteine metabolism affect diet responsiveness of plasma homocysteine in healthy women. J Nutr 2001;131:2643-7.

109. Friso S, Choi SW, Girelli D, et al. A common mutation in the 5,10methylenetetrahydrofolate reductase gene affects genomic DNA methylation through an interaction with folate status. Proc Natl Acad Sci U S A 2002;99:5606-11.

110. Ueland PM, Hustad S, Schneede J, Refsum H, Vollset SE. Biological and clinical implications of the MTHFR C677T polymorphism. Trends Pharmacol Sci 2001;22:195201.

111. Koch HG, Nabel P, Junker R, et al. The 677T genotype of the common MTHFR thermolabile variant and fasting homocysteine in childhood venous thrombosis. Eur J Pediatr 1999;158 Suppl 3:S113-6.

112. Bailey LB. Folate, methyl-related nutrients, alcohol, and the MTHFR 677C-->T polymorphism affect cancer risk: intake recommendations. J Nutr 2003;133:3748S3753S.

113. Kosch A, Koch HG, Heinecke A, Kurnik K, Heller C, Nowak-Gottl U. Increased fasting total homocysteine plasma levels as a risk factor for thromboembolism in children. Thromb Haemost 2004;91:308-14.

114. Wilcken B, Bamforth F, Li Z, et al. Geographical and ethnic variation of the 677C $>$ T allele of 5,10 methylenetetrahydrofolate reductase (MTHFR): findings from over 7000 newborns from 16 areas world wide. J Med Genet 2003;40:619-25.

115. Delvin EE, Rozen R, Merouani A, Genest J, Jr., Lambert M. Influence of methylenetetrahydrofolate reductase genotype, age, vitamin B-12, and folate status on plasma homocysteine in children. Am J Clin Nutr 2000;72:1469-73.

116. Lievers KJ, Boers GH, Verhoef P, et al. A second common variant in the methylenetetrahydrofolate reductase (MTHFR) gene and its relationship to MTHFR 
enzyme activity, homocysteine, and cardiovascular disease risk. J Mol Med 2001;79:5228.

117. Weisberg I, Tran P, Christensen B, Sibani S, Rozen R. A second genetic polymorphism in methylenetetrahydrofolate reductase (MTHFR) associated with decreased enzyme activity. Mol Genet Metab 1998;64:169-72.

118. Moat SJ, Bao L, Fowler B, Bonham JR, Walter JH, Kraus JP. The molecular basis of cystathionine beta-synthase (CBS) deficiency in UK and US patients with homocystinuria. Hum Mutat 2004;23:206.

119. Orendac M, Zeman J, Stabler SP, et al. Homocystinuria due to cystathionine betasynthase deficiency: novel biochemical findings and treatment efficacy. J Inherit Metab Dis 2003;26:761-73.

120. Mudd SH, Levy HL. Disorders of transsulfuration. In: Scriver CR, Beaudet AL, Sly WS, Valle D, eds. The metabolic and molecular bases of inherited disease. 7th ed. New York: McGraw-Hill, 1995:1279-1327.

121. Yates Z, Lucock M. Methionine synthase polymorphism A2756G is associated with susceptibility for thromboembolic events and altered B vitamin/thiol metabolism. Haematologica 2002;87:751-6; discussion 756.

122. Garibotto G, Valli A, Anderstam B, et al. The kidney is the major site of Sadenosylhomocysteine disposal in humans. Kidney Int 2009.

123. Selhub J. Homocysteine metabolism. Annu Rev Nutr 1999;19:217-46.

124. Refsum H, Guttormsen AB, Fiskerstrand T, Ueland PM. Hyperhomocysteinemia in terms of steady-state kinetics. Eur J Pediatr 1998;157 Suppl 2:S45-9.

125. Christensen B, Refsum H, Vintermyr O, Ueland PM. Homocysteine export from cells cultured in the presence of physiological or superfluous levels of methionine: methionine loading of non-transformed, transformed, proliferating, and quiescent cells in culture. $\mathrm{J}$ Cell Physiol 1991;146:52-62.

126. Remkova A, Remko M. Homocysteine and endothelial markers are increased in patients with chronic liver diseases. Eur J Intern Med 2009;20:482-6.

127. Bosy-Westphal A, Petersen S, Hinrichsen H, Czech N, M JM. Increased plasma homocysteine in liver cirrhosis. Hepatol Res 2001;20:28-38. 
128. Mato JM, Corrales F, Martin-Duce A, Ortiz P, Pajares MA, Cabrero C. Mechanisms and consequences of the impaired trans-sulphuration pathway in liver disease: Part I. Biochemical implications. Drugs 1990;40 Suppl 3:58-64.

129. Matte C, Stefanello FM, Mackedanz V, et al. Homocysteine induces oxidative stress, inflammatory infiltration, fibrosis and reduces glycogen/glycoprotein content in liver of rats. Int J Dev Neurosci 2009;27:337-44.

130. Garibotto G, Sofia A, Valli A, et al. Causes of hyperhomocysteinemia in patients with chronic kidney diseases. Semin Nephrol 2006;26:3-7.

131. van Guldener C, Stehouwer CD. Homocysteine and methionine metabolism in renal failure. Semin Vasc Med 2005;5:201-8.

132. Friedman AN, Bostom AG, Selhub J, Levey AS, Rosenberg IH. The kidney and homocysteine metabolism. J Am Soc Nephrol 2001;12:2181-9.

133. Ducloux D, Motte G, Challier B, Gibey R, Chalopin JM. Serum total homocysteine and cardiovascular disease occurrence in chronic, stable renal transplant recipients: a prospective study. J Am Soc Nephrol 2000;11:134-7.

134. van Guldener C, Stam F, Stehouwer CD. Homocysteine metabolism in renal failure. Kidney Int Suppl 2001;78:S234-7.

135. Kerr MA, Livingstone B, Bates CJ, et al. Folate, related B vitamins, and homocysteine in childhood and adolescence: potential implications for disease risk in later life. Pediatrics 2009;123:627-35.

136. Osganian SK, Stampfer MJ, Spiegelman D, et al. Distribution of and factors associated with serum homocysteine levels in children: Child and Adolescent Trial for Cardiovascular Health. JAMA 1999;281:1189-96.

137. Minniti G, Cerone R, Piana A, Armani U, Lorini R. Plasma and serum total homocysteine concentrations in paediatric patients, evaluated by high-performance liquid chromatography with fluorescence. Clin Chem Lab Med 2000;38:675-6.

138. Ganji V, Kafai MR. Population references for plasma total homocysteine concentrations for U.S. children and adolescents in the post-folic acid fortification era. J Nutr 2005;135:2253-6.

139. Must A, Jacques PF, Rogers G, Rosenberg IH, Selhub J. Serum total homocysteine concentrations in children and adolescents: results from the third National Health and Nutrition Examination Survey (NHANES III). J Nutr 2003;133:2643-9. 
140. Monsen AL, Refsum H, Markestad T, Ueland PM. Cobalamin status and its biochemical markers methylmalonic acid and homocysteine in different age groups from 4 days to 19 years. Clin Chem 2003;49:2067-75.

141. Vilaseca MA, Moyano D, Ferrer I, Artuch R. Total homocysteine in pediatric patients. Clin Chem 1997;43:690-2.

142. Rauh M, Verwied S, Knerr I, Dorr HG, Sonnichsen A, Koletzko B. Homocysteine concentrations in a German cohort of 500 individuals: reference ranges and determinants of plasma levels in healthy children and their parents. Amino Acids 2001;20:409-18.

143. Bates CJ, Mansoor MA, Gregory J, Pentiev K, Prentice A. Correlates of plasma homocysteine, cysteine and cysteinyl-glycine in respondents in the British National Diet and Nutrition Survey of young people aged 4-18 years, and a comparison with the survey of people aged 65 years and over. Br J Nutr 2002;87:71-9.

144. Morris MS, Jacques PF, Selhub J, Rosenberg IH. Total homocysteine and estrogen status indicators in the Third National Health and Nutrition Examination Survey. Am J Epidemiol 2000;152:140-8.

145. Hak AE, Bak AA, Lindemans J, et al. The effect of hormone replacement therapy on serum homocysteine levels in perimenopausal women: a randomized controlled trial. Atherosclerosis 2001;158:437-43.

146. Hodgson JM, Puddey IB, van Bockxmeer FM, Burke V. Acute effects of tea on fasting and non-fasting plasma total homocysteine concentrations in human subjects. Br J Nutr 2007;97:842-6.

147. Nomikos Tzortzis DP, Fragopoulou Elisabeth. Boiled wild artichoke reduces postprandial glycemic and insulinemic response in normal subjects but has no effect on metabolic syndrome patients. Nutrition Research 2007;27:741-749.

148. Fokkema MR, Gilissen MF, Van Doormaal JJ, Volmer M, Kema IP, Muskiet FA. Fasting vs nonfasting plasma homocysteine concentrations for diagnosis of hyperhomocysteinemia. Clin Chem 2003;49:818-21.

149. Guttormsen AB, Schneede J, Fiskerstrand T, Ueland PM, Refsum HM. Plasma concentrations of homocysteine and other aminothiol compounds are related to food intake in healthy human subjects. J Nutr 1994;124:1934-41.

150. Candito M, Bedoucha P, Gibelin P, et al. Fasting, postprandial, and post-methionine-load homocysteinaemia and methylenetetrahydrofolate reductase polymorphism in vascular disease. J Inherit Metab Dis 1999;22:588-92. 
151. Thirup P, Ekelund S. Day-to-day, postprandial, and orthostatic variation of total plasma homocysteine. Clin Chem 1999;45:1280-3.

152. Ubbink JB, Vermaak WJ, van der Merwe A, Becker PJ. The effect of blood sample aging and food consumption on plasma total homocysteine levels. Clin Chim Acta 1992;207:119-28.

153. Nurk E, Tell GS, Nygard O, Refsum H, Ueland PM, Vollset SE. Plasma total homocysteine is influenced by prandial status in humans: the Hordaland Hhomocysteine Sstudy. J Nutr 2001;131:1214-6.

154. Weimann J. Toxicity of nitrous oxide. Best Pract Res Clin Anaesthesiol 2003;17:47-61.

155. Guyton AC, Hall JE. Pain Suppression ("Analgesia") System in the Brain and Spinal Cord. In: Gruliow R, ed. Textbook of Medical Physiology 11th ed. Philadelphia: ELSEVIER SAUNDERS, 2006:602.

156. Myles PS, Leslie K, Peyton P, et al. Nitrous oxide and perioperative cardiac morbidity (ENIGMA-II) Trial: rationale and design. Am Heart J 2009;157:488-494 e1.

157. Greif R, Laciny S, Rapf B, Hickle RS, Sessler DI. Supplemental oxygen reduces the incidence of postoperative nausea and vomiting. Anesthesiology 1999;91:1246-52.

158. Leslie K, Myles PS, Chan MT, et al. Risk factors for severe postoperative nausea and vomiting in a randomized trial of nitrous oxide-based vs nitrous oxide-free anaesthesia. Br J Anaesth 2008.

159. Kaisti KK, Langsjo JW, Aalto S, et al. Effects of sevoflurane, propofol, and adjunct nitrous oxide on regional cerebral blood flow, oxygen consumption, and blood volume in humans. Anesthesiology 2003;99:603-13.

160. Koblin DD, Waskell L, Watson JE, Stokstad EL, Eger EI, 2nd. Nitrous oxide inactivates methionine synthetase in human liver. Anesth Analg 1982;61:75-8.

161. Royston BD, Nunn JF, Weinbren HK, Royston D, Cormack RS. Rate of inactivation of human and rodent hepatic methionine synthase by nitrous oxide. Anesthesiology 1988;68:213-6.

162. Sheraton TE, Gildersleve CD, Hall JE. The use of nitrous oxide in paediatric anaesthetic practice in the United Kingdom: a questionnaire survey. Anaesthesia 2007;62:62-6. 
163. Banks RGS, Henderson RJ, Pratt JM. Reactions of gases in solution. Part III. Some reactions of nitrous oxide with transition-metal complexes. Journal of the Chemical Society 1968;A:2886-2889.

164. Chanarin I. Cobalamins and nitrous oxide: a review. J Clin Pathol 1980;33:909-16.

165. Drummond JT, Matthews RG. Nitrous oxide degradation by cobalamin-dependent methionine synthase: characterization of the reactants and products in the inactivation reaction. Biochemistry 1994;33:3732-41.

166. Landon MJ, Toothill VJ. Effect of nitrous oxide on placental methionine synthase activity. Br J Anaesth 1986;58:524-7.

167. Nunn J. Clinical aspects of the interaction between nitrous oxide and vitamin B12. British Journal of Anaesthesia 1987;59:3-13.

168. Waclawik AJ, Luzzio CC, Juhasz-Pocsine K, Hamilton V. Myeloneuropathy from nitrous oxide abuse: unusually high methylmalonic acid and homocysteine levels. WMJ 2003;102:43-5.

169. Amos RJ, Amess JA, Hinds CJ, Mollin DL. Incidence and pathogenesis of acute megaloblastic bone-marrow change in patients receiving intensive care. Lancet 1982;2:835-8.

170. Skacel PO, Chanarin I, Hewlett A, Nunn JF. Failure to correct nitrous oxide toxicity with folinic acid. Anesthesiology 1982;57:557-8.

171. Lassen HC, Henriksen E, Neukirch F, Kristensen HS. Treatment of tetanus; severe bonemarrow depression after prolonged nitrous-oxide anaesthesia. Lancet 1956;270:527-30.

172. El Otmani H, El Moutawakil B, Moutaouakil F, Gam I, Rafai MA, Slassi I. [Postoperative dementia: toxicity of nitrous oxide]. Encephale 2007;33:95-7.

173. Lacassie HJ, Nazar C, Yonish B, Sandoval P, Muir HA, Mellado P. Reversible nitrous oxide myelopathy and a polymorphism in the gene encoding 5,10methylenetetrahydrofolate reductase. Br J Anaesth 2006;96:222-5.

174. Marie RM, Le Biez E, Busson P, et al. Nitrous oxide anesthesia-associated myelopathy. Arch Neurol 2000;57:380-2.

175. Flippo TS, Holder WD, Jr. Neurologic degeneration associated with nitrous oxide anesthesia in patients with vitamin B12 deficiency. Arch Surg 1993;128:1391-5. 
176. Alarcia R, Ara JR, Serrano M, Garcia M, Latorre AM, Capablo JL. [Severe polyneuropathy after using nitrous oxide as an anesthetic. A preventable disease?]. Rev Neurol 1999;29:36-8.

177. McNeely JK, Buczulinski B, Rosner DR. Severe neurological impairment in an infant after nitrous oxide anesthesia. Anesthesiology 2000;93:1549-50.

178. Selzer RR, Rosenblatt DS, Laxova R, Hogan K. Adverse effect of nitrous oxide in a child with 5,10-methylenetetrahydrofolate reductase deficiency. N Engl J Med 2003;349:4550.

179. Frank S, Deery E, Brindley AA, et al. Elucidation of substrate specificity in the cobalamin (vitamin B12) biosynthetic methyltransferases. Structure and function of the C20 methyltransferase (CbiL) from Methanothermobacter thermautotrophicus. J Biol Chem 2007;282:23957-69.

180. Deacon R, Lumb M, Perry J, et al. Selective inactivation of vitamin B12 in rats by nitrous oxide. Lancet 1978;2:1023-4.

181. Everman BW, Koblin DD. Aging, chronic administration of ethanol, and acute exposure to nitrous oxide: effects on vitamin B12 and folate status in rats. Mech Ageing Dev 1992;62:229-43.

182. Young PB, Kennedy S, Molloy AM, Scott JM, Weir DG, Kennedy DG. Effect of N2O treatment/vitamin B12 deficiency in pigs on tissue concentrations of odd-numbered, branched-chain fatty acids. Int J Vitam Nutr Res 1995;65:255-60.

183. Scott JM, Weir DG. The methyl folate trap. A physiological response in man to prevent methyl group deficiency in kwashiorkor (methionine deficiency) and an explanation for folic-acid induced exacerbation of subacute combined degeneration in pernicious anaemia. Lancet 1981;2:337-40.

184. Christensen B, Refsum H, Garras A, Ueland PM. Homocysteine remethylation during nitrous oxide exposure of cells cultured in media containing various concentrations of folates. J Pharmacol Exp Ther 1992;261:1096-105.

185. Myles PS, Leslie K, Chan MT, et al. Avoidance of nitrous oxide for patients undergoing major surgery: a randomized controlled trial. Anesthesiology 2007;107:221-31.

186. Myles PS, Chan MT, Forbes A, Leslie K, Paech M, Peyton P. Preoperative folate and homocysteine status in patients undergoing major surgery. Clin Nutr 2006;25:736-45. 
187. Amos RJ, Amess JA, Nancekievill DG, Rees GM. Prevention of nitrous oxide-induced megaloblastic changes in bone marrow using folinic acid. Br J Anaesth 1984;56:103-7.

188. Doshi S, McDowell I, Goodfellow J, et al. Relationship between S-adenosylmethionine, S-adenosylhomocysteine, asymmetric dimethylarginine, and endothelial function in healthy human subjects during experimental hyper- and hypohomocysteinemia. Metabolism 2005;54:351-60.

189. Kanani PM, Sinkey CA, Browning RL, Allaman M, Knapp HR, Haynes WG. Role of oxidant stress in endothelial dysfunction produced by experimental hyperhomocyst(e)inemia in humans. Circulation 1999;100:1161-8.

190. Chambers JC, McGregor A, Jean-Marie J, Obeid OA, Kooner JS. Demonstration of rapid onset vascular endothelial dysfunction after hyperhomocysteinemia: an effect reversible with vitamin C therapy. Circulation 1999;99:1156-60.

191. Bellamy MF, McDowell IF, Ramsey MW, et al. Hyperhomocysteinemia after an oral methionine load acutely impairs endothelial function in healthy adults. Circulation 1998;98:1848-52.

192. Hogeveen M, Blom HJ, Van Amerongen M, Boogmans B, Van Beynum IM, Van De Bor M. Hyperhomocysteinemia as risk factor for ischemic and hemorrhagic stroke in newborn infants. J Pediatr 2002;141:429-31.

193. Homocysteine and risk of ischemic heart disease and stroke: a meta-analysis. JAMA 2002;288:2015-22.

194. Bleys J, Miller ER, 3rd, Pastor-Barriuso R, Appel LJ, Guallar E. Vitamin-mineral supplementation and the progression of atherosclerosis: a meta-analysis of randomized controlled trials. Am J Clin Nutr 2006;84:880-7; quiz 954-5.

195. Bazzano LA, Reynolds K, Holder KN, He J. Effect of folic acid supplementation on risk of cardiovascular diseases: a meta-analysis of randomized controlled trials. JAMA 2006;296:2720-6.

196. Wang X, Qin X, Demirtas H, et al. Efficacy of folic acid supplementation in stroke prevention: a meta-analysis. Lancet 2007;369:1876-82.

197. Kelly PJ, Rosand J, Kistler JP, et al. Homocysteine, MTHFR 677C-->T polymorphism, and risk of ischemic stroke: results of a meta-analysis. Neurology 2002;59:529-36.

198. Casas JP, Bautista LE, Smeeth L, Sharma P, Hingorani AD. Homocysteine and stroke: evidence on a causal link from mendelian randomisation. Lancet 2005;365:224-32. 
199. Cronin S, Furie KL, Kelly PJ. Dose-related association of MTHFR 677T allele with risk of ischemic stroke: evidence from a cumulative meta-analysis. Stroke 2005;36:1581-7.

200. Ebbing M, Bleie O, Ueland PM, et al. Mortality and cardiovascular events in patients treated with homocysteine-lowering B vitamins after coronary angiography: a randomized controlled trial. JAMA 2008;300:795-804.

201. Danesh J, Lewington S. Plasma homocysteine and coronary heart disease: systematic review of published epidemiological studies. J Cardiovasc Risk 1998;5:229-32.

202. Yang Q, Botto LD, Erickson JD, et al. Improvement in stroke mortality in Canada and the United States, 1990 to 2002. Circulation 2006;113:1335-43.

203. Liu X, Luo F, Li J, Wu W, Li L, Chen H. Homocysteine induces connective tissue growth factor expression in vascular smooth muscle cells. J Thromb Haemost 2008;6:184-92.

204. Papatheodorou L, Weiss N. Vascular oxidant stress and inflammation in hyperhomocysteinemia. Antioxid Redox Signal 2007;9:1941-58.

205. Handy DE, Zhang Y, Loscalzo J. Homocysteine down-regulates cellular glutathione peroxidase (GPx1) by decreasing translation. J Biol Chem 2005;280:15518-25.

206. Dayal S, Brown KL, Weydert CJ, et al. Deficiency of glutathione peroxidase-1 sensitizes hyperhomocysteinemic mice to endothelial dysfunction. Arterioscler Thromb Vasc Biol 2002;22:1996-2002.

207. Mueller CF, Laude K, McNally JS, Harrison DG. ATVB in focus: redox mechanisms in blood vessels. Arterioscler Thromb Vasc Biol 2005;25:274-8.

208. Jin L, Caldwell RB, Li-Masters T, Caldwell RW. Homocysteine induces endothelial dysfunction via inhibition of arginine transport. J Physiol Pharmacol 2007;58:191-206.

209. Franco MC, Higa EM, D'Almeida V, et al. Homocysteine and nitric oxide are related to blood pressure and vascular function in small-for-gestational-age children. Hypertension 2007;50:396-402.

210. Romerio SC, Linder L, Nyfeler J, et al. Acute hyperhomocysteinemia decreases NO bioavailability in healthy adults. Atherosclerosis 2004;176:337-44.

211. Barbato JC, Catanescu O, Murray K, DiBello PM, Jacobsen DW. Targeting of metallothionein by L-homocysteine: a novel mechanism for disruption of zinc and redox homeostasis. Arterioscler Thromb Vasc Biol 2007;27:49-54. 
212. Ozkan Y, Yardim-Akaydin S, Imren E, Torun M, Simsek B. Increased plasma homocysteine and allantoin levels in coronary artery disease: possible link between homocysteine and uric acid oxidation. Acta Cardiol 2006;61:432-9.

213. Yamamoto M, Hara H, Adachi T. Effects of homocysteine on the binding of extracellular-superoxide dismutase to the endothelial cell surface. FEBS Lett 2000;486:159-62.

214. Gutterman DD, Miura H, Liu Y. Redox modulation of vascular tone: focus of potassium channel mechanisms of dilation. Arterioscler Thromb Vasc Biol 2005;25:671-8.

215. Perez-de-Arce K, Foncea R, Leighton F. Reactive oxygen species mediates homocysteine-induced mitochondrial biogenesis in human endothelial cells: modulation by antioxidants. Biochem Biophys Res Commun 2005;338:1103-9.

216. Jakubowski H. Protein N-homocysteinylation: implications for atherosclerosis. Biomed Pharmacother 2001;55:443-7.

217. Stuhlinger MC, Stanger O. Asymmetric dimethyl-L-arginine (ADMA): a possible link between homocyst(e)ine and endothelial dysfunction. Curr Drug Metab 2005;6:3-14.

218. Hogeveen M, van Beynum I, van Rooij A, Kluijtmans L, den Heijer M, Blom H. Methylmalonic acid values in healthy Dutch children. Eur J Nutr 2008;47:26-31.

219. Papandreou D, Mavromichalis I, Makedou A, Rousso I, Arvanitidou M. Reference range of total serum homocysteine level and dietary indexes in healthy Greek schoolchildren aged 6-15 years. Br J Nutr 2006;96:719-24.

220. van Beynum IM, den Heijer M, Thomas CM, Afman L, Oppenraay-van Emmerzaal D, Blom HJ. Total homocysteine and its predictors in Dutch children. Am J Clin Nutr 2005;81:1110-6.

221. Sirachainan N, Tapanapruksakul P, Visudtibhan A, et al. Homocysteine, MTHFR C677 $\mathrm{T}$, vitamin B12, and folate levels in Thai children with ischemic stroke: a case-control study. J Pediatr Hematol Oncol 2006;28:803-8.

222. Cardo E, Vilaseca MA, Campistol J, Artuch R, Colome C, Pineda M. Evaluation of hyperhomocysteinaemia in children with stroke. Eur J Paediatr Neurol 1999;3:113-7.

223. van Beynum IM, Smeitink JA, den Heijer M, te Poele Pothoff MT, Blom HJ. Hyperhomocysteinemia: a risk factor for ischemic stroke in children. Circulation 1999;99:2070-2. 
224. Refsum H, Grindflek AW, Ueland PM, et al. Screening for serum total homocysteine in newborn children. Clin Chem 2004;50:1769-84.

225. Minet JC, Bisse E, Aebischer CP, Beil A, Wieland H, Lutschg J. Assessment of vitamin B-12, folate, and vitamin B-6 status and relation to sulfur amino acid metabolism in neonates. Am J Clin Nutr 2000;72:751-7.

226. Herbert V. Making sense of laboratory tests of folate status: folate requirements to sustain normality. Am J Hematol 1987;26:199-207.

227. Holleland G, Schneede J, Ueland PM, Lund PK, Refsum H, Sandberg S. Cobalamin deficiency in general practice. Assessment of the diagnostic utility and cost-benefit analysis of methylmalonic acid determination in relation to current diagnostic strategies. Clin Chem 1999;45:189-98.

228. Carmel R. Current concepts in cobalamin deficiency. Annu Rev Med 2000;51:357-75.

229. Green R. Indicators for assessing folate and vitamin B12 status and for monitoring the efficacy of intervention strategies. Food Nutr Bull 2008;29:S52-63; discussion S64-6.

230. Allen LH. How common is vitamin B-12 deficiency? Am J Clin Nutr 2009;89:693S-6S.

231. Scott JM. Folate and vitamin B12. Proc Nutr Soc 1999;58:441-8.

232. Herbert V. Staging vitamin B-12 (cobalamin) status in vegetarians. Am J Clin Nutr 1994;59:1213S-1222S.

233. Tully DB, Allgood VE, Cidlowski JA. Modulation of steroid receptor-mediated gene expression by vitamin B6. FASEB J 1994;8:343-9.

234. Hamfelt A. Age Variation of Vitamin B6 Metabolism in Man. Clin Chim Acta 1964;10:48-54.

235. Pfeiffer CM, Johnson CL, Jain RB, et al. Trends in blood folate and vitamin B-12 concentrations in the United States, 1988 2004. Am J Clin Nutr 2007;86:718-27.

236. Karademir F, Suleymanoglu S, Ersen A, et al. Vitamin B12, folate, homocysteine and urinary methylmalonic acid levels in infants. J Int Med Res 2007;35:384-8.

237. WHO/FAO. Vitamin B12. Vitamin and mineral requirements in human nutrition. 2nd ed. Geneva, Switzerland, 2004:279-88. 
238. ESHA Research. The Food Processor SQL Edition. version 10.2 ed. Salem OR USA, 2003:analysis software for Windows.

239. Selhub J, Morris MS, Jacques PF, Rosenberg IH. Folate-vitamin B-12 interaction in relation to cognitive impairment, anemia, and biochemical indicators of vitamin B-12 deficiency. Am J Clin Nutr 2009;89:702S-6S.

240. Pfeiffer CM, Caudill SP, Gunter EW, Osterloh J, Sampson EJ. Biochemical indicators of $B$ vitamin status in the US population after folic acid fortification: results from the National Health and Nutrition Examination Survey 1999-2000. Am J Clin Nutr 2005;82:442-50.

241. de Benoist B. Conclusions of a WHO Technical Consultation on folate and vitamin B12 deficiencies. Food Nutr Bull 2008;29:S238-44.

242. Selhub J, Jacques PF, Dallal G, Choumenkovitch S, Rogers G. The use of blood concentrations of vitamins and their respective functional indicators to define folate and vitamin B12 status. Food Nutr Bull 2008;29:S67-73.

243. Courtney-Martin G, Chapman KP, Moore AM, Kim JH, Ball RO, Pencharz PB. Total sulfur amino acid requirement and metabolism in parenterally fed postsurgical human neonates. Am J Clin Nutr 2008;88:115-24.

244. Rasmussen K, Moller J. Total homocysteine measurement in clinical practice. Ann Clin Biochem 2000;37 ( Pt 5):627-48.

245. Houghton LA, Sherwood KL, Pawlosky R, Ito S, O'Connor DL. [6S]-5Methyltetrahydrofolate is at least as effective as folic acid in preventing a decline in blood folate concentrations during lactation. Am J Clin Nutr 2006;83:842-50.

246. Rybak ME, Pfeiffer CM. Clinical analysis of vitamin B(6): determination of pyridoxal 5'phosphate and 4-pyridoxic acid in human serum by reversed-phase high-performance liquid chromatography with chlorite postcolumn derivatization. Anal Biochem 2004;333:336-44.

247. Miller SA, Dykes DD, Polesky HF. A simple salting out procedure for extracting DNA from human nucleated cells. Nucleic Acids Res 1988;16:1215.

248. United Nations Children's Fund, United Nations University, World Health Organization. Iron Deficiency Anemia Assessment, Prevention and Control: A guide for programme managers. In: WHO/NHD/01.3, ed. Geneva Switzerland: World Health Organization, 2001:1-114. 
249. Shakur YA, Rogenstein C, Hartman-Craven B, Tarasuk V, O'Connor DL. How much folate is in Canadian fortified products 10 years after mandated fortification? Can J Public Health 2009;100:281-4.

250. Hennessy-Priest K, Mustard J, Keller H, et al. Folic acid food fortification prevents inadequate folate intake among preschoolers from Ontario. Public Health Nutr 2009;12:1548-55.

251. Yasuda S, Hasui S, Yamamoto C, et al. Placental folate transport during pregnancy. Biosci Biotechnol Biochem 2008;72:2277-84.

252. Han YH, Yon M, Han HS, Kim KY, Tamura T, Hyun TH. Folate contents in human milk and casein-based and soya-based formulas, and folate status in Korean infants. Br J Nutr 2009;101:1769-74.

253. de Bree A, Verschuren WM, Bjorke-Monsen AL, et al. Effect of the methylenetetrahydrofolate reductase $677 \mathrm{C}-->\mathrm{T}$ mutation on the relations among folate intake and plasma folate and homocysteine concentrations in a general population sample. Am J Clin Nutr 2003;77:687-93.

254. Hazra A, Kraft P, Selhub J, et al. Common variants of FUT2 are associated with plasma vitamin B12 levels. Nat Genet 2008;40:1160-2. 
APPENDIX A CONSENT FORMS 


\section{SickKids}

THE HOSPITAL FOR

SICK CHILDREN

Research Ethics Board

\section{Research Consent for parents/guardians}

\section{Title of Research Project:}

Effect of nitrous oxide exposure during surgery on the homocysteine concentrations of children.

\section{Investigator(s):}

Principal Investigators:

Study Coordinator:

Supervisor:
(416) 813-7844

(416) 813-7445 ext 6417

(416) 813-7654 ext 1490

(416) 813-7654 ext 5777

Dubraiicka Pichardo MSc C.

Dr. Deborah L. O’Connor

Your child is being invited to participate in this research study; however he/she is under no obligation to participate.

One of the researchers will explain the purpose of the study. He or she will explain how the study will be carried out and what you (your child) will be asked to do. They will also explain the possible risks and possible benefits of being in the study. You should ask the researcher any questions you have about any of these things before you decide whether you wish to let your child take part in the study. This process is called informed consent.

This form also explains the research study. Please read the form and talk to one of the researchers about any questions you may have. Then if you decide that your child will be in the study, please sign and date this form in front of the person who explained it to you. You will be given a copy of this form to keep and a copy of this consent form will be inserted in your child's health record.

\section{Background information:}

Nitrous oxide, (also known as laughing gas), is often used as an anesthetic to put patients to sleep for surgery. What we know is that when nitrous oxide is used in adults, it can cause the levels of homocysteine in the blood to rise. Homocysteine is a naturally occurring amino acid that is made by your body when sulfur-containing amino acids are made. When there are high levels of homocysteine in the blood, it can affect the function of the blood vessels and may be 
related to complications after surgery. We know that nitrous oxide causes an increase in homocysteine levels by reducing the activity of vitamin B12 and folate (also called folic acid). We know that giving adults vitamin B12 and folate before surgery prevents homocysteine levels from being increased by nitrous oxide. However we do not know if homocysteine levels in children are increased when nitrous oxide anesthesia is used.

\section{The purpose of this study:}

The purpose of this study is to determine the effect that nitrous oxide anesthetic has on the blood levels of homocysteine in children and how this is influenced by the levels of vitamins B12, B6 and folate levels in the body. We will be measuring and comparing the levels of homocysteine and these vitamins in the blood, both before and after surgery.

\section{Description of the Research:}

This study will involve 28 children under 11 years of age, who are having surgery lasting two hours or more, with nitrous oxide anesthesia at a 50 to $70 \%$ concentration. If your child meets the requirements to be in the study and you (the parent or guardian) provide informed consent, a blood sample will be collected according to your child's age, for the purpose of measuring homocysteine and indicators of blood vitamins as described in the table below.

\section{TOTAL amount of blood required for the study \& tests to be conducted:}

\begin{tabular}{|l|l|l|l|}
\hline Age group & $\begin{array}{l}\text { Amount of blood } \\
\text { needed for the } \\
\text { study }\end{array}$ & Comparable amount & $\begin{array}{l}\text { Tests to be conducted } \\
\text { with this blood sample }\end{array}$ \\
\hline $0-2$ years old & $1.94 \mathrm{~mL}$ & $\begin{array}{l}\text { Less than half a } \\
\text { teaspoon }\end{array}$ & $\begin{array}{l}\text { Homocysteine, cysteine, } \\
\text { methionine, plasma } \\
\text { folate, vitamin B12 \& } \\
\text { MTHFR677C } \rightarrow \mathrm{T} \\
\text { genotyping. }\end{array}$ \\
\hline $2-4$ years old & $4.55 \mathrm{~mL}$ & One teaspoon & $\begin{array}{l}\text { All of the above as well as: } \\
\text { Methylmalonic acid, } \\
\text { Red blood cells folate } \\
\text { \& Haematocrit }\end{array}$ \\
\hline $4-10$ years old & $10.55 \mathrm{~mL}$ & Two teaspoons & $\begin{array}{l}\text { All of the above as well as: } \\
\text { Vitamin B6 }\end{array}$ \\
\hline
\end{tabular}

The blood samples will be collected on two separate occasions. The first sample will be taken after the child is asleep in the operating room. The second sample will be collected between 1224 hours after the first sample, in fasting conditions (before the child has had anything to eat) from the catheter that will be in your child's arm. If your child is sent home before the second sample is collected, the Study Coordinator and a Registered Nurse will visit at your home to collect the sample. Although an additional poke is required to obtain this blood sample, a topical 
anesthetic cream (i.e. EMLA or Maxilene) will be applied to the child's skin before poking, to reduce any discomfort.

This same blood sample will also be used for DNA testing to determine whether your child has a common genetic mutation. This mutation can influence the levels of folate in your child's blood and can influence the total homocysteine concentration (see the Research Consent for Genetic Testing form which will also require your signature). In addition, we will interview you (the parent/guardian) to find out the subject's sex and fasting conditions (when your child last ate). Also, if your child takes vitamin supplements, we will ask you about the dose, frequency and brand of vitamins

supplements consumed 1-2 weeks before the scheduled surgery. The total time required for the interview will be approximately 15 minutes. We will review your child's anesthesia records to obtain the time he or she received the nitrous oxide and which other medications were given to your child during surgery. If your doctor decides to use an anesthetic other than nitrous oxide, your child will no longer be in the study. In this case, your child will not have the extra amount of blood taken during or after surgery.

\section{What are the Potential Harms to the patient from participating in this study?}

The only potential harm to your child from participating in this study is that an additional quantity of blood will be needed for the blood tests in this study. This amount is in addition to the amount that is normally needed for the medical care of your child. To reduce discomfort to the child, we will try to collect the test sample at the same time that clinical blood work is being done, or by taking the sample from an installed indwelling catheter. However, if an additional blood sample is needed, for example if your child is sent home after surgery and before the second sample is collected, the Study Coordinator and a Registered Nurse will visit at your home to collect the sample. Although an additional poke is required to obtain this blood sample, a topical anesthetic cream (i.e. EMLA or Maxilene) will be applied to the child's skin before poking, to reduce the discomfort. Just as in any blood test, there may be a small amount of bleeding when blood is taken from a vein and there may be slight discomfort and bruising or redness that will usually disappear in a few days.

\section{What are the Potential Benefits to the patient?}

There are no direct benefits for the patients participating in this study. The parents or guardians of the child may receive the results of the vitamin and homocysteine tests as well as the genetic test, once they become available. The knowledge generated through this study may help improve clinical practice and nutritional treatment of children who have surgery in SickKids and other pediatric facilities. 


\section{Confidentiality:}

Your privacy and confidentiality will be respected and no information about who your child is and/or who you are will be given to anyone or be published without your permission, unless the law requires us to do this. The law requires us to give information to the authorities in the cases of child abuse, infectious diseases, or suicidal ideas, or if the court orders us to give them the study papers.

If you agree to participate in this study, a copy of this Research Consent Form will be included in the patient health record and you will receive a copy for your files. By signing this Research Consent Form, you are agreeing to allow SickKids Clinical Research Monitors, to review your child's health record to check on the study.

The data produced from this study will be stored in a secure, locked location. Only members of the research team (and those individuals described above) will have access to the data. This could include external research team members. Following completion of the research study, the data will be kept as long as required by legislation and then destroyed as required by SickKids policy. Published study results will not reveal your identity.

\section{Reimbursement:}

There is no financial reimbursement for participating in this study. To show our thanks for your child's participation, we will give your child a small age-appropriate gift, such as a toy or movie passes and a certificate of participation.

\section{Participation:}

If you choose to let your child take part in this study you can take your child out of the study at any time. The care your child gets at Sick Kids will not be affected in any way by whether your child takes part in this study. Upon request you will be given access to the results of the study once they become available. New information that we get while we are doing this study may affect your decision to take part in this study. If this happens, we will tell you about this new information and we will ask you again if you still want to be in the study. During this study we may create new tests, new medicines, or other things that may be worth some money. Although we may make money from these findings, we cannot give your child any of this money now or in the future because your child took part in this study. Your child may be required to assent his or her participation on this study. If your child become ill or are harmed because of study participation, we will treat your child for free. Your signing this consent form does not interfere with your legal rights in any way. The study staff, any people who gave money for the study, or the hospital are still responsible, legally and professionally, for what they do. 


\section{Sponsorship:}

This study is sponsored by Dr. Deborah O'Connor and SickKids and funded by the Heinz/Mead Jonson/Weston Endowment fund.

\section{Conflict of Interest:}

"I, and the other research team members, have no conflict of interest to declare". This means that we will not benefit financially from the outcomes of this study.

\section{Consent:}

"By signing this form, I agree that:

1) You have explained this study to me. You have answered all my questions.

2) You have explained the possible harms and benefits (if any) of this study.

3) I know what I could do instead of having my child take part in this study. I understand that I have the right to refuse to let my child take part in the study. I also have the right to take my child out of the study at any time. My decision about my child taking part in the study will not affect my child's health care at Sick Kids.

4) I am free now, and in the future, to ask questions about the study.

5) I have been told that my child's medical records will be kept private except as described to me.

6) I understand that no information about my child will be given to anyone or be published without first asking my permission."

7) I have read and understood pages 1 to 5 of this consent form. I agree, or consent, that my child may take part in this study.

Printed Name of Parent/Legal Guardian

Printed Name of person who explained consent

Printed Witness' name (if the parent/legal guardian does not read English)
Parent/Legal Guardian’s signature \& date

Signature \& date

Witness’ signature \& date

If you have any questions about this study, please call Dubraiicka Pichardo at x5777 or pager 416-232-5940

If you have questions about your child's rights as a subject in a study or injuries during a study, please call the Research Ethics Manager at 416-813-5718. 


\section{SickKids}

THE HOSPITAL FOR

SICK CHILDREN

Research Ethics Board

\section{Genetic Consent for parents/guardians}

Title of Research Project:

Effect of nitrous oxide exposure during surgery on the homocysteine concentrations of children.

Investigator(s):

Principal Investigators: $\quad$ Dr. Deborah L. O’Connor, PhD, RD （416) 813-7844

Dr. Igor Luginbuehl MD (416) $813-7445$ ext 6417

Dr. Paul Wales MD (416) $813-7654$ ext 1490

Study Coordinator:

Dubraiicka Pichardo MSc C. (416) 813-7654 ext 5777

Supervisor: $\quad$ Dr. Deborah L. O’Connor

This genetic test will determine if your child has a specific genetic mutation in the MTHFR enzyme

We will be using your child's blood sample to find out if she or he has a specific genetic mutation in an enzyme called methylene tetrahydrofolate reductase, called MTHFR for short. A genetic mutation is a small change in the DNA sequence which may influence how an enzyme works. This genetic test will be looking for a specific mutation in the sequence of the MTHFR enzyme; this mutation is referred to as MTHFR C677T. This mutation is common in the general population and has been shown to be present in approximately $20 \%$ of those of Italian descent, in about $10-15 \%$ of those who are of Caucasian and Asian descent, and between 2-3\% of those of African descent.

\section{If you have the MTHFR C677CT genetic mutation, you process folate less efficiently}

The MTHFR enzyme normally processes folate, one of the B vitamins, in the blood. People with the MTHFR C677T mutation can still process folate (also called folic acid), but less efficiently. Half of those who have this mutation have a mild form and half of the people who have this mutation have a form that may affect how folate is processed in the body. The effects of having the MTHFR C677T mutation are only a concern when the person has low amounts of folate in the blood; most people who have the mutation go through life and never have a health problem as a result of the mutation. 


\section{We are doing this study to find out how having the mutation affects both homocysteine and folate levels in children.}

The levels of folate and MTHFR enzyme activity can influence the levels of homocysteine in the blood; if a person has a MTHFR C677T mutation, they may accumulate high levels of homocysteine in the blood, if their blood folate is low. We want to determine if your child has the MTHFR C677T mutation, and if so, if she or he has the mild or more severe form of the mutation. We will then use this information to help us understand how her or his blood homocysteine and folate levels are related.

\section{How this genetic test will affect your child?}

The genetic test will use the same blood sample that was taken before surgery, so no additional blood needs to be taken from your child. The only genetic test that you are consenting to, and the only test that will be done at this time, is the test for the MTHFR enzyme mutation. Once the test is completed, the rest of the blood sample will be destroyed.

I confirm that the have done [professional's name] has explained the genetic tests that I am about to with respect to and that any questions that I have asked have been

[name of genetic condition]

answered to my satisfaction. The discomforts, consequences and possible risks associated with these tests have been explained to me. I understand that it is my choice whether or not to have this testing. Results of this test will be explained to me and I understand that this information may be shared, if necessary, with professionals involved in my child's medical care, including our family physician. I have been assured that records relating to me or my child and the care that he/she received will be kept confidential, and that no information will be released or printed that will reveal my or my child's identity without my permission or unless required by law.

I understand that when my child has the maturity to understand these tests she/he may request the information and it will be made available to him/her. 
I understand that the interpretation of the genetic information will depend in part on the family information that I have given. Differences between family information and the results of genetic tests occur when the parents of a child are different from those reported.

I understand that although genetic testing is usually accurate, as with all testing some inaccuracies may occur. Also genetic testing is ongoing and new research may mean that the interpretation of the test results may change over time. On occasion, in the process of testing for one genetic condition, another genetic alteration may be identified. Such findings would be reported to your health care provider to discuss with you.

I understand that it is my responsibility to notify the Clinical Genetics department of any change of address, and to check with the department for updated genetics information and counseling that I feel my child may need.

\section{Closed Consent:}

Closed consent means that any tissue or DNA obtained from my child will be analyzed and then destroyed. Specifically, I give my consent for a blood sample to be taken for testing related only to the verification of the MTHFR C677T genotype; this testing will be undertaken in an accredited clinical service laboratory and/or a research laboratory and that the sample and any DNA extracted from it will be destroyed once the results of the testing are available. I also understand that if I want any further genetic testing to be done in the future, I will need to have another sample taken from my child.

\section{Parent/Guardian Signature:}

Witness signature:

\section{Date:}

Date: 


\section{SickKids}

THE HOSPITAL FOR

SICK CHILDREN

Research Ethics Board

\section{ASSENT FORM}

\section{Title of Research Project:}

Effect of nitrous oxide exposure during surgery on the homocysteine concentrations of children.

\section{Investigator(s):}

Principal Investigators:

Dr. Deborah L. O’Connor, PhD, RD

(416) 813-7844

Dr. Igor Luginbuehl MD

(416) 813-7445 ext 6417

Dr. Paul Wales MD

(416) 813-7654 ext 1490

Study Coordinator:

Dubraiicka Pichardo MSc C.

(416) 813-7654 ext 5777

Supervisor:

Dr. Deborah L. O’Connor

\section{Why are we doing this study?}

Just before your surgery, you will be asked to breathe a gas called Nitrous Oxide. Breathing the Nitrous Oxide will put you to sleep for your surgery so you will feel no discomfort or pain. We know that when adults breathe this gas, a substance called homocysteine can build up in their blood. We know that the homocysteine in the blood is sometimes related to problems after surgery, because of the way that it affects blood vessels. What we do not know, is how the body reacts in children and we don't know if the vitamins in your body may be involved with the homocysteine. We are doing this study because we want to find out how homocysteine affects children and if the vitamins in your body are involved. The results of this study will help us to understand if we need to prevent homocysteine from building up in children when they are having surgery, and will give us ideas of how we might do that.

\section{What will happen during the study?}

If you take part in the study, your treatment and surgery will happen exactly as planned, except that we will take a small amount of extra blood from you, equal to two teaspoons or less. Usually when you are having surgery, the nurse will take a sample of blood from you when you are asleep in the operating room and also first thing the next morning. If you take part in the study, we will take a bit more blood at that time. If you go home before we have time to take the blood, a nurse will visit you at you home to obtain your blood sample. To take a blood sample from you, the nurse will need to poke you, but will first put a cream on your skin to make it numb so it will hurt less. Your blood will be tested to measure 
homocysteine, four vitamins B, and to find out if you have a gene that affects the way the vitamin folate (also called folic acid) works.

\section{Are there good things and bad things about the study?}

The good things:

Although being part of this study will not help you in any way, your parents may receive the results from your blood tests and they may let you know the results if it is appropriate or important. Being part of this study may help other children who are having surgery in the future. To show our thanks for being part of the study, you will be given a small gift from us.

The bad things:

When the nurse takes the blood from you, you may feel discomfort and may bleed a bit. A cream will be used to numb your skin where the nurse takes the blood, so it won't hurt as much. You may get a bruise or redness in that location which will usually disappear in a few days.

\section{Who will know about what I did in the study?}

Information about the results of your lab tests are private information and only the research team from Sick Kids will see these results. If we see that the results of your tests are important for your treatment and health, we will let your doctor know.

\section{Can I decide if I want to be in the study?}

Yes, you can decide if you want to be in the study or not. No one will be angry or upset if you do not want to be in the study. We are talking to your parent/legal guardians about the study, and you can talk to them about it too.

\section{Assent:}

The following section must be included at the end of the assent form:

"I was present when read this form and said that he or she agreed, or assented, to take part in this study”.

Printed Name of person who obtained assent Signature \& Date 


\section{APPENDIX B PREDICTED VALUES}


Plot of predicted values: initial tHcy concentrations and vitamin B12 levels

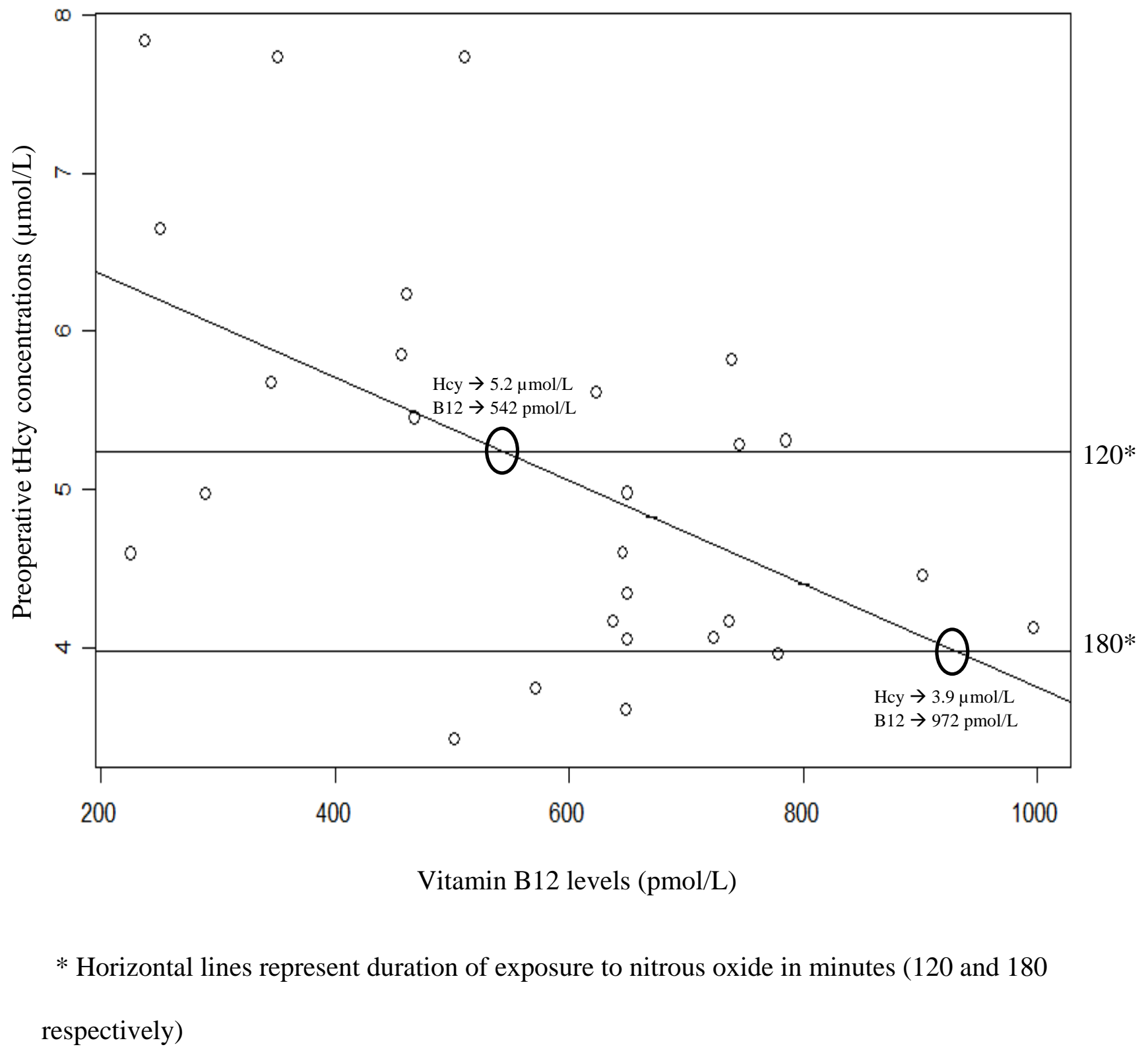

